UNIVERSIDADE DE SÃO PAULO

FACULDADE DE ECONOMIA, ADMINISTRAÇÃO E CONTABILIDADE DEPARTAMENTO DE ADMINISTRAÇÃO PROGRAMA DE PÓS-GRADUAÇÃo EM ADMINISTRAÇÃo

CONTRIBUIÇÕES DO SISTEMA DE REMUNERAÇÃO DOS EXECUTIVOS PARA O DESEMPENHO FINANCEIRO: UM ESTUDO COM EMPRESAS INDUSTRIAIS BRASILEIRAS

Elizabeth Krauter

Orientador: Prof. Dr. Almir Ferreira de Sousa 
Profa Dra. Suely Vilela

Reitora da Universidade de São Paulo

Prof. Dr. Carlos Roberto Azzoni

Diretor da Faculdade de Economia, Administração e Contabilidade

Prof. Dr. Isak Kruglianskas

Chefe do Departamento de Administração

Prof. Dr. Lindolfo Galvão de Albuquerque

Coordenador do Programa de Pós-Graduação em Administração 


\section{ELIZABETH KRAUTER}

CONTRIBUIÇÕES DO SISTEMA DE REMUNERAÇÃO DOS EXECUTIVOS PARA O DESEMPENHO FINANCEIRO: UM ESTUDO COM EMPRESAS INDUSTRIAIS BRASILEIRAS

Tese apresentada ao Departamento de Administração da Faculdade de Economia, Administração e Contabilidade da Universidade de São Paulo como requisito para a obtenção do título de Doutor em Administração.

Orientador: Prof. Dr. Almir Ferreira de Sousa

\section{SÃO PAULO}




\section{FICHA CATALOGRÁFICA}

Elaborada pela Seção de Processamento Técnico do SBD/FEA/USP

\section{Krauter, Elizabeth}

Contribuições do sistema de remuneração dos executivos para o desempenho financeiro : um estudo com empresas industriais brasileiras / Elizabeth Krauter. - São Paulo, 2009.

$180 \mathrm{p}$.

Tese (Doutorado) - Universidade de São Paulo, 2009

Bibliografia.

1. Salários 2. Executivos 3. Finanças das empresas I. Universidade de São Paulo. Faculdade de Economia, Administração e Contabilidade. II. Título.

CDD - 658.32 
Às minhas filhas,

Paula e Bruna 
Agradeço a Deus por mais esta conquista.

Agradeço às minhas filhas, Paula e Bruna, pelo amor, o carinho, a compreensão, a paciência e o apoio constantes.

Agradeço ao professor e orientador Dr. Almir Ferreira de Sousa pelo apoio e incentivo na condução do trabalho, além das oportunidades oferecidas para meu desenvolvimento profissional.

Agradeço aos professores da banca de qualificação Dr. Eduardo Kazuo Kayo e Dr. José Roberto Ferreira Savoia, pelas importantes contribuições para o desenvolvimento do estudo.

Agradeço aos professores do Programa de Pós-Graduação em Administração da FEAUSP pelos ensinamentos transmitidos.

Agradeço aos professores da banca do Consórcio Doutoral EnANPAD 2008, Dr. Luiz Eduardo Teixeira Brandão e Dr. Walter Lee Ness Jr, pelas valiosas sugestões para o desenvolvimento desta tese.

Agradeço à equipe do Programa de Estudos em Gestão de Pessoas (Progep) da FIA, por ter disponibilizado os dados para a realização do trabalho.

Agradeço à equipe da Fundação Instituto de Pesquisas Contábeis, Atuariais e Financeiras (FIPECAFI), em especial, ao Prof. Dr. Ariovaldo dos Santos, por ter disponibilizado importantes informações para a realização da pesquisa.

Agradeço ao CNPq pelo apoio financeiro durante o curso de doutorado.

Agradeço aos professores Dr. Diógenes de Souza Bido e Dr. Antonio Airton Carneiro de Freitas pela ajuda nos testes estatísticos.

Agradeço aos professores Dr. R. N. Anantharaman (Indian Institute of Technology), Dr. A. K. Paul (Christ College Institute of Management), Dr. Rui Vieira (Universidade Nova de Lisboa), Dra. Cynthia E. Devers (Wisconsin School of Business) e Dra. Corine Boon (Erasmus University Rotterdam), pela troca de artigos e informações sobre pesquisas. Agradeço pelo apoio administrativo recebido de: Carolina Bürckle, Joyce Pereira Ramos, Lina Nakata, Cesar Yokomizo, Valéria Lourenção e Maria Aparecida Sales. 


\section{RESUMO}

O objetivo desta tese é investigar a relação entre a remuneração dos executivos e o desempenho financeiro das empresas, no contexto do mercado brasileiro. A premissa é que o sistema de remuneração pode ajudar a direcionar os esforços dos executivos para os objetivos estratégicos do negócio, contribuindo para que a companhia alcance níveis superiores de desempenho financeiro. A amostra não-probabilística é formada por 44 empresas industriais. Elas foram selecionadas dentre as eleitas como "As 150 Melhores Empresas para Você Trabalhar" no Brasil, em 2007. Os dados da pesquisa são secundários e foram extraídos de dois bancos de dados: a) Programa de Estudos em Gestão de Pessoas (Progep), vinculado à Fundação Instituto de Administração (FIA); b) Fundação Instituto de Pesquisas Contábeis, Atuariais e Financeiras (FIPECAFI). Para operacionalizar a variável independente remuneração, são utilizados, além do salário mensal e do salário variável, três índices criados especialmente para este trabalho: benefícios, carreira e desenvolvimento. Esses índices medem o acesso a benefícios; a mecanismos de estímulo e suporte à carreira; a mecanismos de estímulo à educação e ao desenvolvimento profissional. Trata-se de itens oferecidos pelas empresas a seus diretores, vice-presidentes e presidentes, os quais são denominados, neste trabalho, de "executivos". Esses dados de remuneração referem-se ao exercício de 2006. Para operacionalizar a variável desempenho financeiro, são utilizados três indicadores contábeis crescimento das vendas, retorno sobre patrimônio líquido e margem líquida sobre as vendas dos exercícios sociais de 2006 e de 2007. O porte das companhias é utilizado como variável de controle e é medido pelo logaritmo natural do número de funcionários. A hipótese da pesquisa de que existe uma relação positiva e significante entre a remuneração dos executivos e o desempenho financeiro das empresas, no contexto do mercado brasileiro, é verificada por meio de um conjunto de testes estatísticos: de igualdade de médias, análise de correlação e análise de regressão. Os resultados do teste de Mann-Whitney não apresentam evidências de que existe relação entre as variáveis. A análise de correlação de Pearson mostra associações fracas e negativas entre as seguintes variáveis: a) índice de carreira e crescimento das vendas de 2006; b) índice de carreira e retorno sobre patrimônio líquido de 2006; c) índice de desenvolvimento e retorno sobre patrimônio líquido de 2006. Já a análise de correlação de Spearman aponta: a) associação fraca e positiva entre índice de benefícios e margem líquida sobre as vendas de 2006; b) associação fraca e negativa entre índice de desenvolvimento e retorno sobre patrimônio líquido de 2006. Os resultados da análise de regressão linear múltipla não permitem comprovar a existência de relação positiva e significante entre a remuneração dos executivos e o desempenho financeiro das empresas. As contribuições deste trabalho estão em produzir conceitos mais amplos para operacionalizar as variáveis, estudar a relação no contexto do mercado brasileiro e abrir perspectivas para a realização de novos trabalhos acadêmicos. 


\begin{abstract}
This thesis is intended to investigate the relation between remuneration of executives and the financial performance of the companies in the context of the Brazilian marketplace. The underlying assumption is that the remuneration system may help to direct the efforts of executives towards the business' strategic purposes. Hence, it will contribute for the company to attain higher levels of financial performance. The non-probabilistic sample is comprised of 44 industrial organizations. They have been selected out from the "150 Best Companies to Work For" in Brazil in 2007. The research data are secondary and have been taken from two databases: a) Programa de Estudos em Gestão de Pessoas (Progep) linked to Fundação Instituto de Administração (FIA); b) Fundação Instituto de Pesquisas Contábeis, Atuariais e Financeiras (FIPECAFI). In order to operationalize the independent remuneration variable, in addition to using the monthly salary and the variable salary, three indexes that have been especially created for this paper were used: benefits, career and development. These indexes measure the access to benefits, the fostering mechanisms and the support to career, and also the mechanisms fostering the education and the professional development. These are items the companies offer their officers, vice presidents and CEOs, which are referred to in this paper as "executives". These remuneration data refer to the fiscal year of 2006. In order to operationalize the financial performance variable, three accounting indicators are usedgrowth of sales, return on equity and net margin - for the fiscal years of 2006 and 2007. The companies' size is used as a control variable and is measured by the natural logarithm of the number of employees. The research hypothesis that there is a positive and significant relation between the remuneration of executives and the financial performance of companies in the context of the Brazilian marketplace is verified by means of a set of statistical tests of: the Mann-Whitney test, correlation analysis and regression analysis. The results of the MannWhitney test do not present any evidences that there actually is a relation between variables. The Pearson correlation analysis shows weak and negative associations between the following variables: a) index of career and growth of sales in 2006; b) index of career and return on equity in 2006; c) index of development and return on equity in 2006. While Spearman correlation analysis points out: a) weak and positive association between the index of benefits and the net margin in 2006; b) weak and negative association between the development index and return on equity in 2006. The results of the multiple regression analysis do not allow to evidence the existence of a positive and significant relation between the remuneration of executives and the financial performance of companies. The contributions of this thesis are in producing broader concepts in order to operationalize the variables, study the relation in the context of the Brazilian marketplace and open up perspectives for the development of new academic studies.
\end{abstract}




\section{SUMÁRIO}

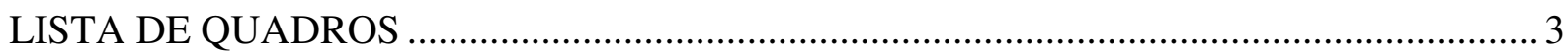

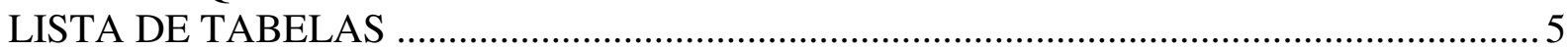

1 INTRODUÇÃO

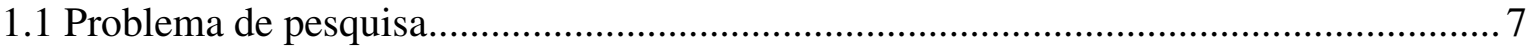

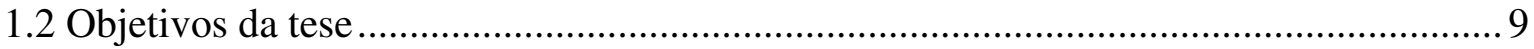

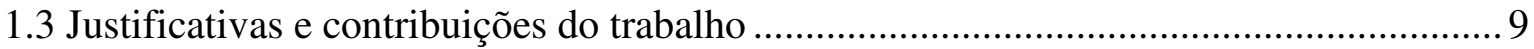

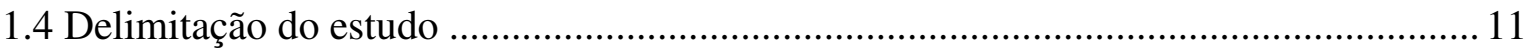

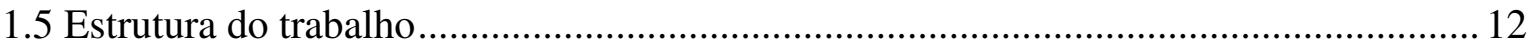

\section{FUNDAMENTAÇÃO TEÓRICA}

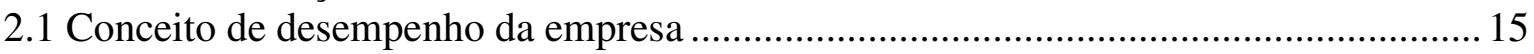

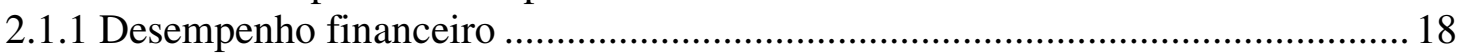

2.1.2 Medidas de desempenho financeiro utilizadas em pesquisas anteriores ............. 19

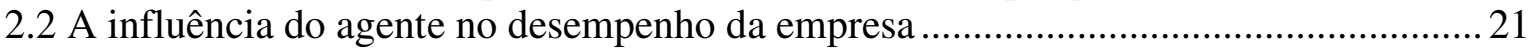

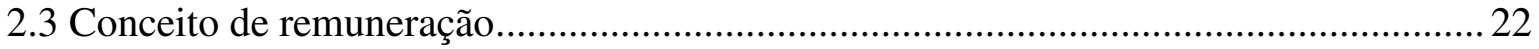

2.4 Contribuição da administração de Recursos Humanos para o desempenho da

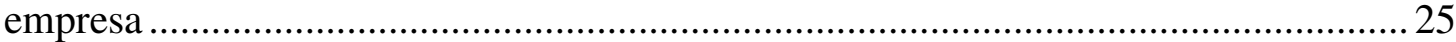

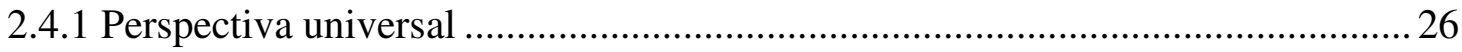

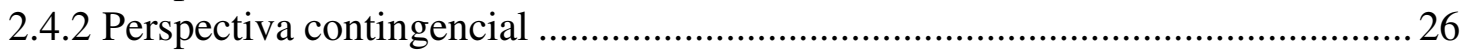

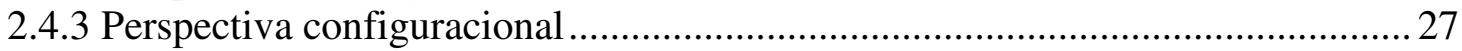

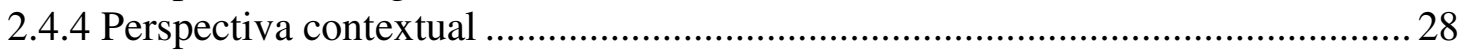

2.5 Principais resultados e características de pesquisas anteriores .................................... 29

3 METODOLOGIA DA PESQUISA

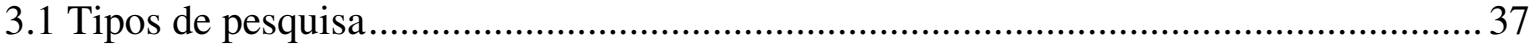

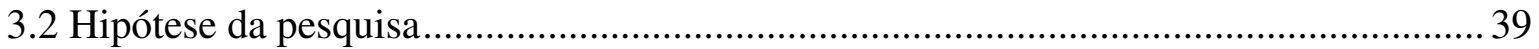

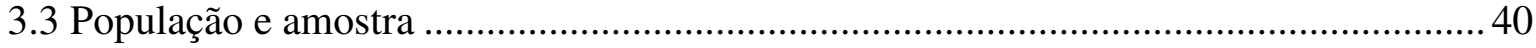

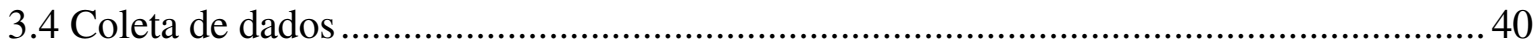

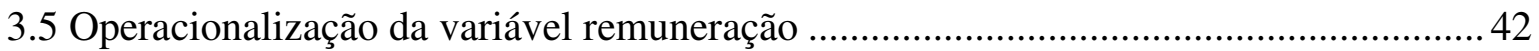

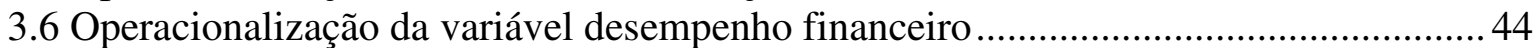

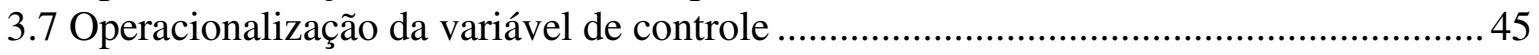

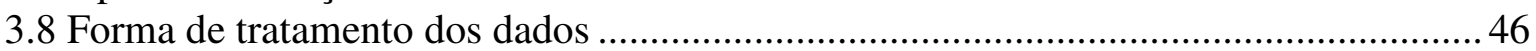

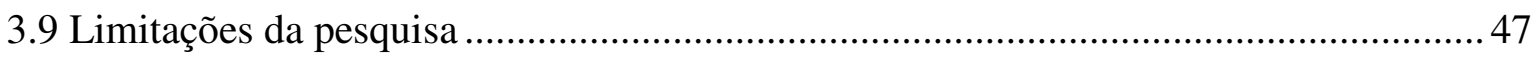

\section{TRATAMENTO DOS DADOS}

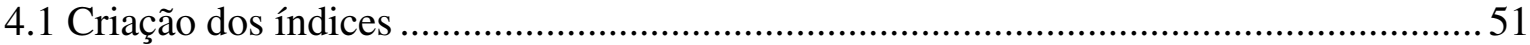

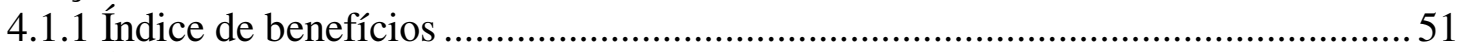

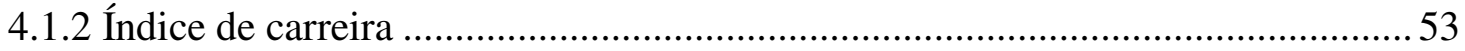

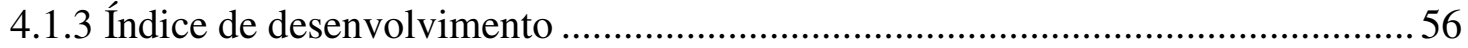

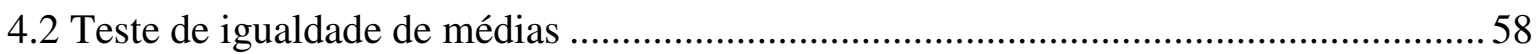

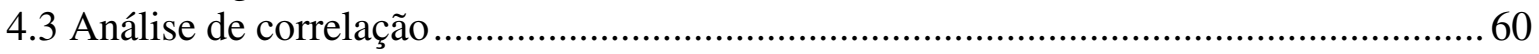

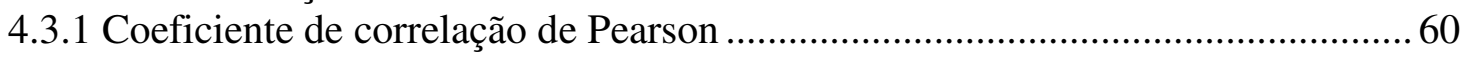

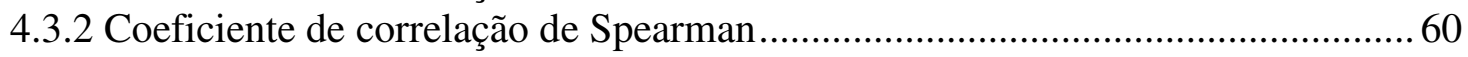

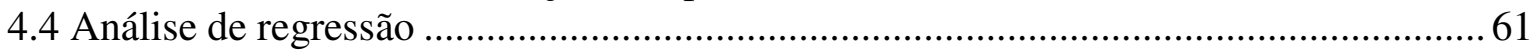

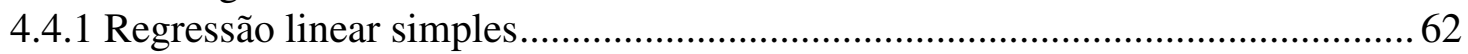

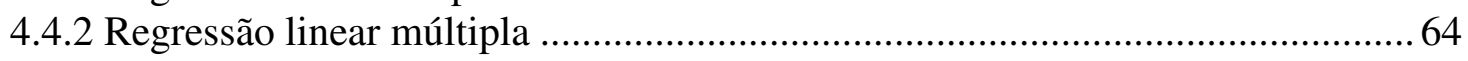

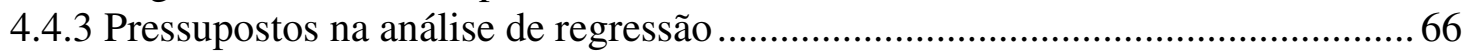


4.4.4 Modelos de regressão linear utilizados na pesquisa

\section{ANÁLISE DOS RESULTADOS DA PESQUISA}

5.1 Análise descritiva

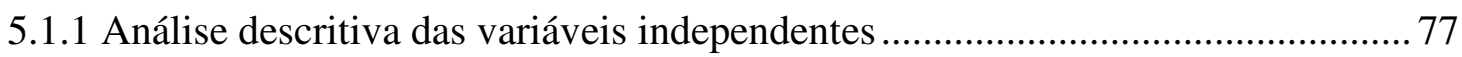

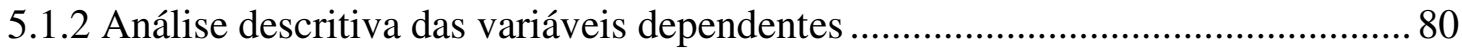

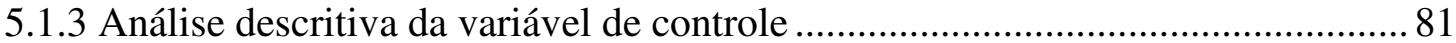

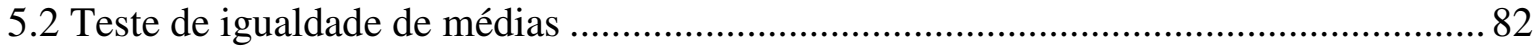

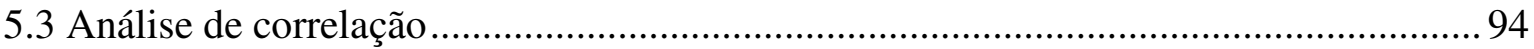

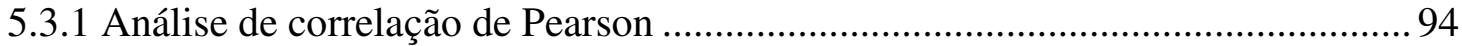

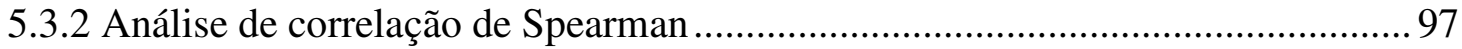

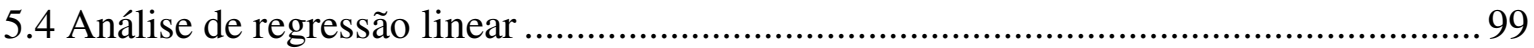

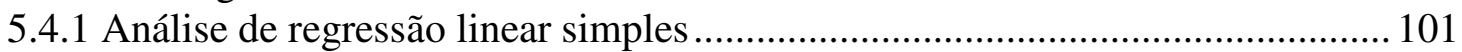

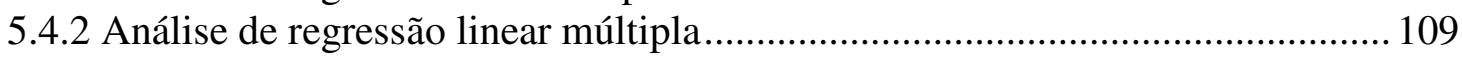

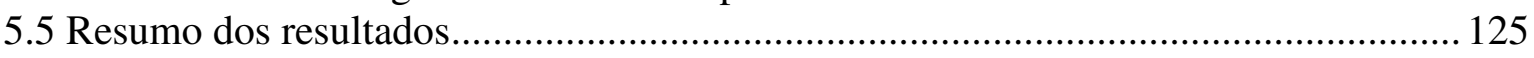

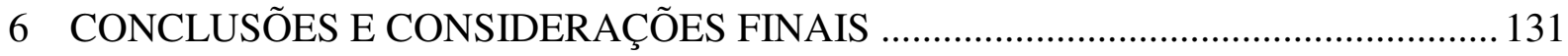

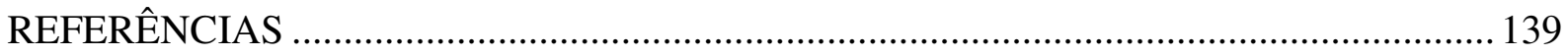

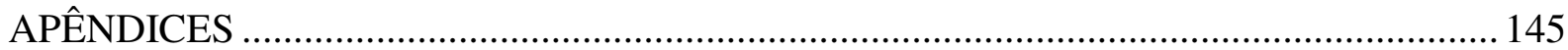




\section{LISTA DE QUADROS}

Quadro 1 - Resumo das principais contribuições de cada perspectiva .................................. 28

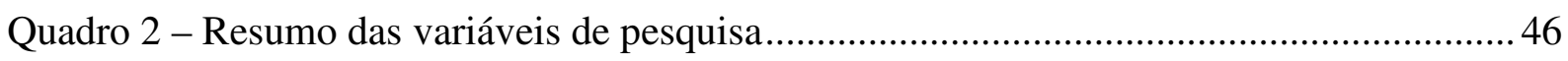

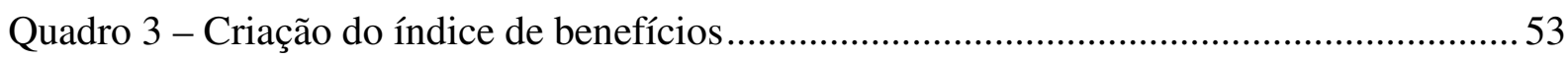

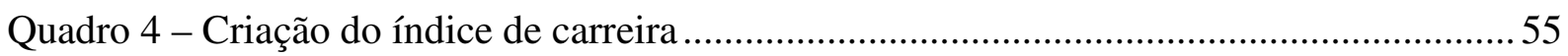

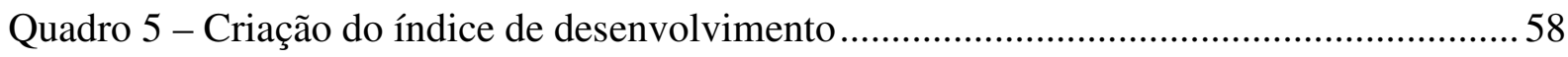

Quadro 6 - Critério do Progep para classificar as empresas quanto ao porte ..........................69

Quadro 7- Sigla das variáveis utilizadas nos testes .............................................................. 81

Quadro 8 - Interpretação do coeficiente de correlação ........................................................ 94

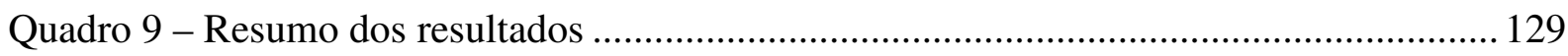




\section{LISTA DE TABELAS}

Tabela 1 - Setor de atuação das empresas da amostra ........................................................ 70

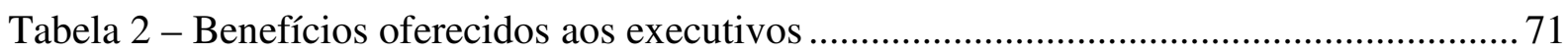

Tabela 3 - Processo de planejamento e acompanhamento do desenvolvimento

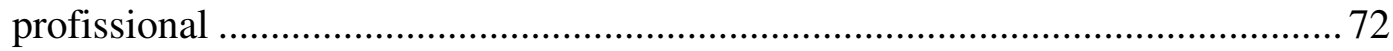

Tabela 4 - Estímulo e suporte para o planejamento de carreira ............................................... 73

Tabela 5 - Política de recolocação de executivos demitidos.................................................. 74

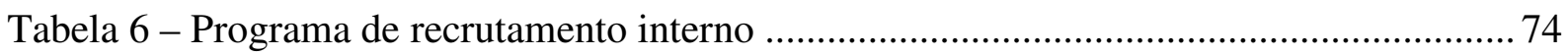

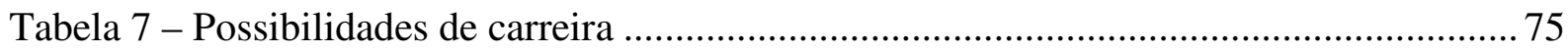

Tabela 8 - Programa de preparação para aposentadoria ................................................... 75

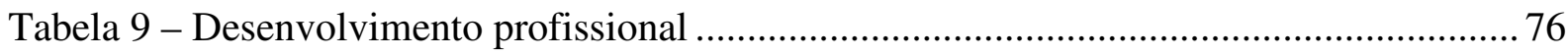

Tabela 10 - Valor dos índices para cada empresa da amostra .............................................. 78

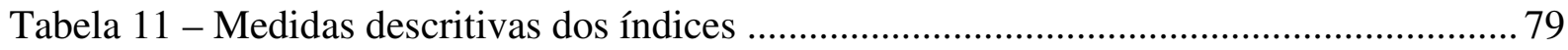

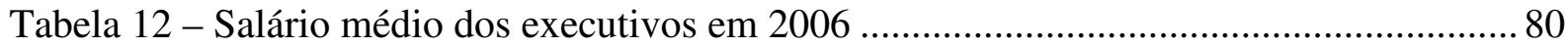

Tabela 13 - Medidas descritivas dos indicadores financeiros.............................................. 80

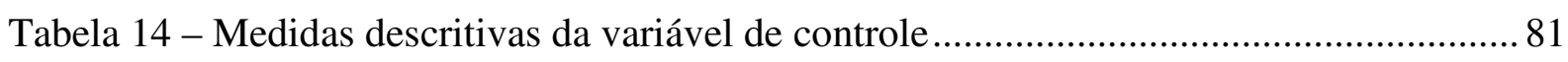

Tabela 15 - Teste K-S com correção de Lilliefors .............................................................. 82

Tabela 16 - Teste de Mann-Whitney - grupo salmen baixo versus grupo salmen alto ........... 84

Tabela 17 - Estatísticas do teste de Mann-Whitney - grupo salmen baixo versus

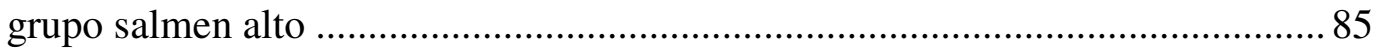

Tabela 18 - Teste de Mann-Whitney - grupo salvar baixo versus grupo salvar alto................ 86

Tabela 19 - Estatísticas do teste de Mann-Whitney - grupo salvar baixo versus

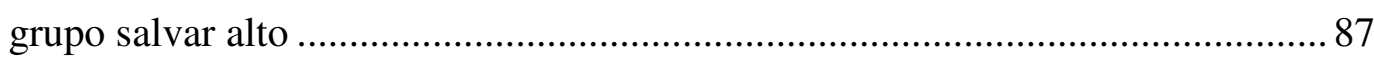

Tabela 20 - Teste de Mann-Whitney - grupo ibenef baixo versus grupo ibenef alto.............. 88

Tabela 21 - Estatísticas do teste de Mann-Whitney - grupo ibenef baixo versus

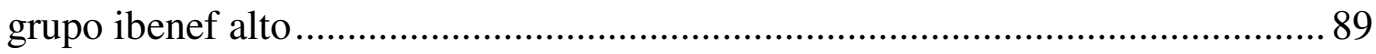

Tabela 22 - Teste de Mann-Whitney - grupo icarr baixo versus grupo icarr alto ....................90

Tabela 23 - Estatísticas do teste de Mann-Whitney - grupo icarr baixo versus

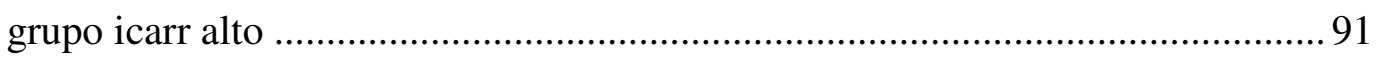

Tabela 24 - Teste de Mann-Whitney - grupo idesen baixo versus grupo idesen alto ............ 92

Tabela 25 - Estatísticas do teste de Mann-Whitney - grupo idesen baixo versus

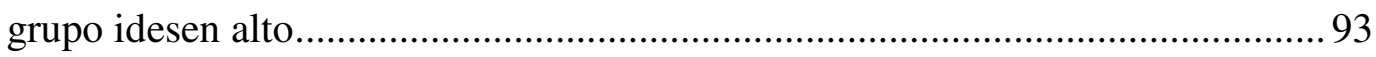

Tabela 26 - Matriz de correlações de Pearson ......................................................................... 95 
Tabela 27 - Matriz de correlações de Spearman 98

Tabela 28 - Resumo do modelo de regressão - cven06 e icarr. 102

Tabela 29 - ANOVA do modelo de regressão - cven06 e icarr 102

Tabela 30 - Coeficientes do modelo de regressão - cven06 e icarr....................................... 103

Tabela 31 - Resumo do modelo de regressão - roe06 e icarr .............................................. 104

Tabela 32 - ANOVA do modelo de regressão - roe06 e icarr................................................ 105

Tabela 33 - Coeficientes do modelo de regressão - roe06 e icarr ......................................... 105

Tabela 34 - Resumo do modelo de regressão - roe06 e idesen ............................................ 107

Tabela 35 - ANOVA do modelo de regressão - roe06 e idesen ........................................... 107

Tabela 36 - Coeficientes do modelo de regressão - roe06 e idesen ...................................... 108

Tabela 37 - Resumo do modelo de regressão múltipla - cven06 ........................................ 110

Tabela 38 - ANOVA do modelo de regressão múltipla - cven06 ........................................ 110

Tabela 39 - Coeficientes do modelo de regressão múltipla - cven06.................................... 111

Tabela 40 - Resumo do modelo de regressão múltipla - roe06 …........................................ 113

Tabela 41 - ANOVA do modelo de regressão múltipla - roe06............................................ 113

Tabela 42 - Coeficientes do modelo de regressão múltipla - roe06 .................................... 114

Tabela 43 - Resumo do modelo de regressão múltipla - mven06 ........................................ 115

Tabela 44 - ANOVA do modelo de regressão múltipla - mven06........................................ 116

Tabela 45 - Coeficientes do modelo de regressão múltipla - mven06 .................................. 116

Tabela 46 - Resumo do modelo de regressão múltipla - cven07 …..................................... 118

Tabela 47 - ANOVA do modelo de regressão múltipla - cven07 ....................................... 118

Tabela 48 - Coeficientes do modelo de regressão múltipla - cven07................................... 119

Tabela 49 - Resumo do modelo de regressão múltipla - roe07 …....................................... 121

Tabela 50 - ANOVA do modelo de regressão múltipla - roe07.......................................... 121

Tabela 51 - Coeficientes do modelo de regressão múltipla - roe07 ……............................. 122

Tabela 52 - Resumo do modelo de regressão múltipla - mven07 ....................................... 123

Tabela 53 - ANOVA do modelo de regressão múltipla - mven07 ....................................... 124

Tabela 54 - Coeficientes do modelo de regressão múltipla - mven07 ……........................... 124 


\section{INTRODUÇÃO}

\subsection{Problema de pesquisa}

A globalização, o aumento da concorrência, a redução do ciclo de vida dos produtos e serviços, além do aparecimento de novas tecnologias, tornaram o ambiente empresarial mais complexo e instável. Este cenário dinâmico - marcado pela velocidade das mudanças, pela inovação de produtos e processos, pela demanda por mais qualidade e pela busca da satisfação dos clientes como diferencial competitivo - aumentou a importância dos ativos intangíveis, principalmente das pessoas, que passaram a ser vistas como fonte de vantagem competitiva sustentável.

Nos últimos anos, vários pesquisadores buscaram entender a natureza da relação entre administração de Recursos Humanos ${ }^{1}$ (RH) e desempenho da empresa. Alguns focaram em uma ou em várias práticas de $\mathrm{RH}$ e verificaram seu efeito em medidas de desempenho financeiro e/ou operacional (por exemplo: GERHART; MILKOVICH, 1990; HAREL; TZAFRIR, 1999). Outros examinaram o efeito de sistemas de práticas de RH - denominadas de "Sistemas de Trabalho de Alto Desempenho" - no desempenho financeiro e/ou operacional das empresas (por exemplo: HUSELID, 1995; VARMA et al, 1999). Delery e Doty (1996) e Alcázar et al (2005) identificaram quatro perspectivas para descrever a relação entre a administração de RH e o desempenho da empresa: perspectiva universal, perspectiva contingencial, perspectiva configuracional e perspectiva contextual (detalhadas no Capítulo 2).

De todas as práticas de RH, a remuneração é considerada de vital importância tanto para a empresa, por ser um item relevante na composição de seus custos, como para as pessoas, pois simboliza o valor relativo de seu trabalho (DUTRA, 2002b; SCHUSTER; ZINGHEIM, 1992).

Segundo Gómez-Mejia e Welbourne (1988), o sistema de remuneração, se estruturado de maneira apropriada, pode ajudar a empresa a direcionar os esforços individuais para os

\footnotetext{
1 Apesar de, atualmente, adotar-se a expressão "gestão de pessoas", optou-se por manter "administração de Recursos Humanos" devido ao fato de esse vocábulo ter sido encontrado com mais frequência nos materiais consultados para o desenvolvimento da tese.
} 
objetivos estratégicos do negócio, contribuindo para que a companhia alcance níveis superiores de desempenho financeiro.

A remuneração dos executivos é um assunto complexo e controverso, que tem atraído a atenção da mídia (CONYON, 2006) e de pesquisadores de várias áreas, como: Finanças, Contabilidade, Recursos Humanos e Estratégia (CARLON et al, 2006). Recentemente, o caso dos "bônus milionários" foi notícia nos principais meios de comunicação de todo o mundo. Executivos - na maioria, americanos - receberam somas vultosas em dinheiro, como remuneração variável, apesar de terem contribuído para a quebra das companhias que administravam. A questão que deu origem ao debate foi a aparente falta de relação entre a remuneração desses executivos e o desempenho de suas organizações.

A abordagem mais utilizada nas pesquisas sobre remuneração de executivos é a teoria do principal-agente (CONYON, 2006) ou teoria de agência. Segundo esta, o principal (acionista) contrata um agente (executivo) para executar alguma tarefa em seu favor, envolvendo a delegação de autoridade para tomada de decisão. Se as partes - acionista e executivo - agirem de modo a maximizar sua utilidade pessoal, existem razões para acreditar que o agente nem sempre agirá de acordo com os melhores interesses do acionista (JENSEN; MECKLING, 1976).

Como os acionistas têm um controle imperfeito sobre seus executivos, o sistema de remuneração é considerado, por muitos, o mecanismo mais eficiente para alinhar os interesses e limitar as divergências (AGGARWAL; SAMWICK, 1999; DEVERS et al, 2007; SHIM; LEE, 2003; TOSI et al, 2000).

As pesquisas que estudaram a relação entre a remuneração dos executivos e o desempenho financeiro das empresas utilizaram, em sua maioria, dados de corporações norte-americanas e/ou focaram o contexto norte-americano (BÁLKIN; GÓMEZ-MEJIA, 1987; BARKEMA; GÓMEZ-MEJIA, 1998). Os resultados são divergentes e não-conclusivos (BÁLKIN; GÓMEZ-MEJIA, 1987; BARKEMA; GÓMEZ-MEJIA, 1998). Algumas encontraram relações fracas; outras observaram relações não significantes entre as variáveis (BARKEMA; GÓMEZ-MEJIA, 1998). 
Segundo Huselid (1995), apesar do número considerável de pesquisas realizadas nos últimos anos, existem poucas evidências empíricas sobre a existência de relação entre a remuneração dos executivos e o desempenho financeiro das empresas. Para Barkema e Gómez-Mejia (1998), a realização de estudos em outros contextos, diferentes do norte-americano, pode contribuir para o melhor entendimento deste tema.

A relevância e a importância do tema, aliadas ao interesse de compreender essa relação no contexto do mercado brasileiro, motivaram a realização da tese. Esta procura responder ao seguinte questionamento:

Qual a relação entre a remuneração dos executivos e o desempenho financeiro das empresas, no contexto do mercado brasileiro?

\subsection{Objetivos da tese}

Tendo como base o problema descrito anteriormente, esta tese tem como objetivo:

Investigar a relação entre a remuneração dos executivos e o desempenho financeiro das empresas, no contexto do mercado brasileiro.

Adicionalmente, procura sistematizar a literatura existente sobre a relação entre a remuneração dos executivos e o desempenho das empresas, além de conhecer as características do sistema de remuneração dos executivos das organizações brasileiras.

\subsection{Justificativas e contribuições do trabalho}

A relevância do tema na atualidade, as divergências encontradas em resultados de pesquisas anteriores da mesma natureza e a ausência de estudos no contexto do mercado brasileiro justificam a realização deste trabalho. 
Diversos trabalhos utilizaram a remuneração direta (salário fixo + salário variável) para operacionalizar a variável remuneração (como os de: ATTAWAY, 2000; MARÍN; SÁNCHEZ, 2002-2003). As organizações têm, frequentemente, incorporado remuneração não financeira a seus pacotes de remuneração de executivos, e essa informação foi ignorada nas pesquisas realizadas (CARLON et al, 2006). Este trabalho adota um conceito mais amplo de remuneração. Para operacionalizá-lo, considera a remuneração financeira e a não financeira. A remuneração financeira inclui: o salário mensal médio; o salário variável médio; os benefícios recebidos pelos executivos. A não financeira engloba: os programas formais de planejamento e acompanhamento de carreira, de recolocação de executivos demitidos e de recrutamento interno; a preparação para a aposentadoria; os programas de treinamento e educação disponibilizados a executivos. Essas informações sobre benefícios, carreira, educação e desenvolvimento são agrupadas em três índices construídos especialmente para este trabalho.

O desempenho organizacional é um tema frequente em muitas áreas da Administração. Embora a importância do conceito de desempenho seja amplamente reconhecida, não existe consenso entre os pesquisadores a respeito de como operacionalizá-lo (VENKATRAMAN; RAMANUJAM, 1986). Venkatraman e Ramanujam (1986) desenvolveram um esquema para delimitar o domínio desse conceito. Eles entendem que o desempenho da empresa é um subconjunto do conceito global de efetividade organizacional. Dentro desse esquema (detalhado na seção 2.1), este trabalho enquadra-se no domínio do desempenho financeiro, que se caracteriza pelo uso de indicadores contábeis.

Alguns autores, como Chakravarthy (1986), Keats (1990) e Venkatraman e Ramanujam (1986; 1987), acreditam que o conceito de desempenho é multidimensional e, para medi-lo adequadamente, é preciso utilizar mais de um indicador. Com o intuito de tornar este trabalho mais abrangente do que os já realizados, utilizam-se três indicadores contábeis: crescimento das vendas, retorno sobre patrimônio líquido e margem líquida sobre as vendas, de dois exercícios sociais. A finalidade é medir as diferentes dimensões do conceito desempenho financeiro. Os três indicadores foram selecionados por serem os mais aplicados em pesquisas empíricas (CARTON; HOFER, 2006; LEE et al, 2003).

Apesar de os indicadores contábeis apresentarem algumas limitações, optou-se por seu uso em razão da presença, na amostra, de empresas de capital fechado. Essa opção também possibilita 
comparar os resultados deste estudo com os resultados de pesquisas realizadas em outros contextos.

Este trabalho diferencia-se dos anteriores ao criar três índices - benefícios, carreira e desenvolvimento - e produzir conceitos mais amplos para operacionalizar as variáveis. As principais contribuições estão em:

- ampliar o conhecimento existente sobre a relação entre a remuneração dos executivos e o desempenho financeiro das empresas;

- estudar essa relação no contexto do mercado brasileiro;

- abrir perspectivas para a realização de novos trabalhos acadêmicos;

- fornecer subsídios para as empresas aperfeiçoarem seus sistemas de remuneração.

\subsection{Delimitação do estudo}

O presente estudo foca o setor industrial brasileiro. A amostra não-probabilística é formada por 44 empresas, selecionadas dentre as eleitas como "As 150 Melhores Empresas para Você Trabalhar" no Brasil, em 2007. Os dados da pesquisa são secundários. As informações relativas à variável independente remuneração foram extraídas do banco de dados do Programa de Estudos em Gestão de Pessoas (Progep), vinculado à Fundação Instituto de Administração (FIA).

A FIA, por meio desse programa, é responsável pela realização da pesquisa que elege anualmente as melhores empresas para se trabalhar no Brasil. Os dados de remuneração provenientes do exercício de 2006 - referem-se à recompensa recebida por diretores, vicepresidentes e presidentes, os quais são aqui denominados de "executivos". 
Já os indicadores contábeis para medir a variável dependente desempenho financeiro foram extraídos do banco de dados da Fundação Instituto de Pesquisas Contábeis, Atuariais e Financeiras (FIPECAFI), responsável pela publicação das "500 Melhores e Maiores" empresas do Brasil. As informações pertencem aos exercícios sociais de 2006 e 2007. Esse banco de dados foi escolhido por reunir:

- empresas de capital aberto e de capital fechado;

- informações de um número maior de organizações, se comparado a outras fontes, como Gazeta Mercantil e Valor Econômico.

\subsection{Estrutura do trabalho}

Este trabalho está dividido em seis capítulos. No primeiro, são apresentados: a contextualização e o problema de pesquisa, os objetivos a serem alcançados, suas justificativas e contribuições, bem como a delimitação do estudo.

O Capítulo 2 é reservado à fundamentação teórica. São introduzidos o conceito de desempenho da empresa, a influência do agente nesse desempenho, o conceito de remuneração, a contribuição da administração de Recursos Humanos para o desempenho da empresa, além dos principais resultados e características de algumas pesquisas sobre o tema.

O Capítulo 3 descreve a metodologia do estudo. Introduz a hipótese do trabalho, o método de amostragem e a coleta de dados. Também apresenta a operacionalização das variáveis independentes, dependentes e de controle, a forma como os dados foram tratados e as limitações do estudo.

O critério para a criação dos índices, os testes estatísticos para tratar os dados e os modelos de regressão utilizados na pesquisa são abordados no Capítulo 4.

O Capítulo 5 traz as análises descritivas e os resultados dos testes estatísticos, bem como a análise desses resultados. 
As conclusões, considerações finais e recomendações para futuros trabalhos são desenvolvidas no Capítulo 6. Em seguida, elencam-se as referências exploradas para o desenvolvimento da tese e, finalmente, apresentam-se os apêndices com os dados trabalhados. 


\section{FUNDAMENTAÇÃO TEÓRICA}

\subsection{Conceito de desempenho da empresa}

O desempenho organizacional é um tema freqüente em muitas áreas da Administração. Tratase de um assunto que interessa tanto a acadêmicos quanto a executivos. Embora a importância do conceito de desempenho seja amplamente reconhecida, não existe consenso a respeito da terminologia e da definição básica (VENKATRAMAN; RAMANUJAM, 1986).

Para Venkatraman e Ramanujam (1986), é importante delimitar o domínio do conceito de desempenho. Eles entendem que o desempenho da empresa é um subconjunto do conceito global de efetividade organizacional. A Figura 1 apresenta um esquema desenvolvido pelos autores para descrever esse domínio.

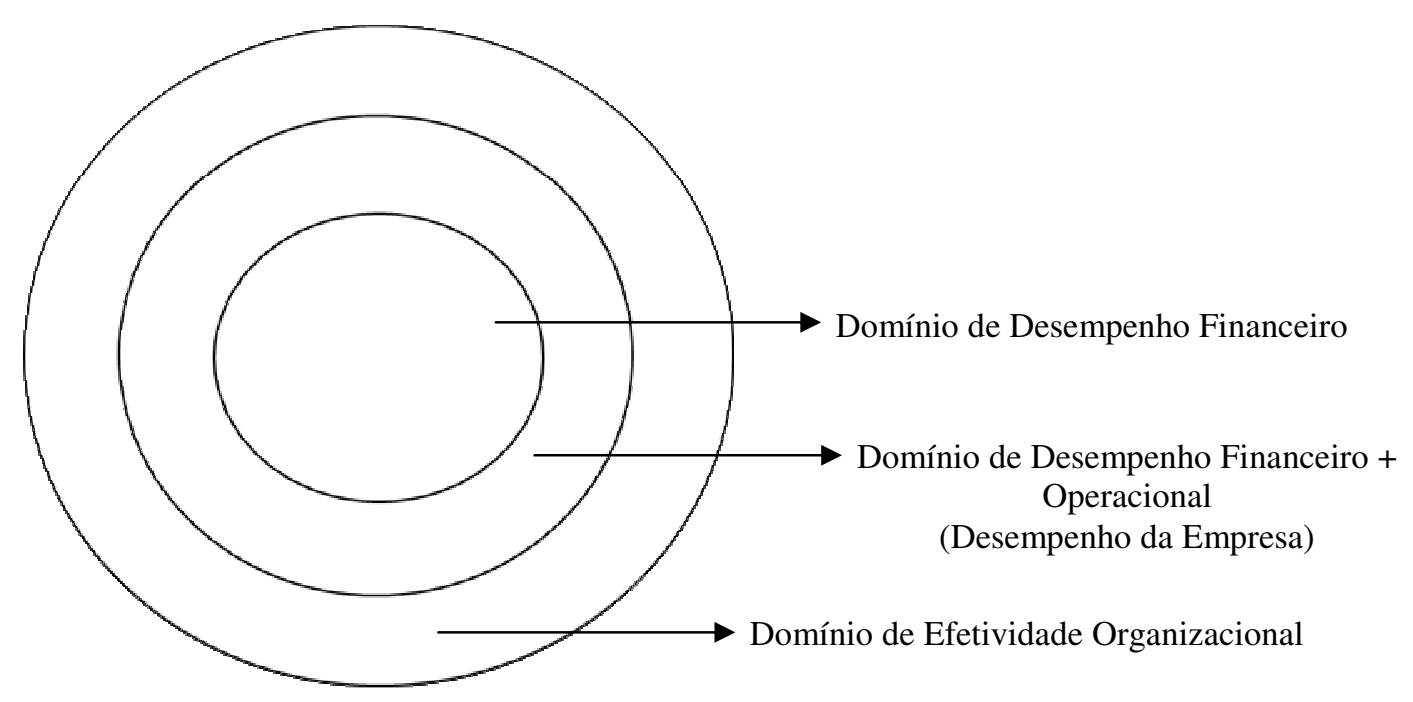

Figura 1 - O domínio do desempenho da empresa

FONTE: VENKATRAMAN; RAMANUJAM, 1986, p. 803. 
Segundo esse esquema, existem três domínios de desempenho da empresa. O domínio mais estreito (Domínio de Desempenho Financeiro) concentra-se no uso de indicadores financeiros. Os indicadores mais utilizados neste domínio são: crescimento das vendas, rentabilidade ROI (Return On Investment - Retorno sobre Investimento), ROS (Return On Sales - Retorno sobre Vendas) e ROE (Return On Equity - Retorno sobre Patrimônio Líquido) - e lucro por ação. Refletindo a visão corrente de que medidas de "mercado" ou "baseadas em valor" são mais apropriadas do que as medidas contábeis, alguns estudos têm utilizado medidas como market-to-book e Q de Tobin. Para Venkatraman e Ramanujam (1986), a utilização dessas medidas não muda a abordagem, que permanece financeira em sua orientação.

Um domínio mais abrangente de desempenho da empresa (Domínio de Desempenho Financeiro + Operacional) inclui indicadores de desempenho operacional (indicadores não financeiros) além de indicadores de desempenho financeiro. No Domínio de Desempenho Financeiro + Operacional são utilizadas medidas como participação de mercado, introdução de novos produtos, qualidade do produto, medidas de eficiência tecnológica, entre outras. $\mathrm{O}$ terceiro domínio, o da efetividade organizacional, engloba os dois anteriores. A maioria dos estudos empíricos tem focado os dois primeiros: Desempenho Financeiro e Desempenho Financeiro + Operacional (VENKATRAMAN; RAMANUJAM, 1986).

Enquanto o desempenho da empresa pode ser medido por indicadores financeiros, indicadores operacionais, ou por ambos, uma questão adicional na operacionalização do conceito é a fonte dos dados, que tanto pode ser primária (os dados são coletados diretamente nas empresas) quanto secundária (os dados estão disponíveis ao público). Usando indicadores financeiros e operacionais e fonte dos dados, Venkatraman e Ramanujam (1986) desenvolveram o esquema apresentado na Figura 2. Este apresenta quatro abordagens internas (numeradas de 1 a 4) e seis abordagens transversais (representadas pelas letras de A a F), totalizando dez abordagens alternativas para operacionalização.

A abordagem 1 usa indicadores financeiros obtidos de fonte secundária. A abordagem 2 usa indicadores financeiros obtidos de fonte primária. Já as abordagens 3 e 4 usam indicadores operacionais coletados de fontes secundária e primária, respectivamente. 


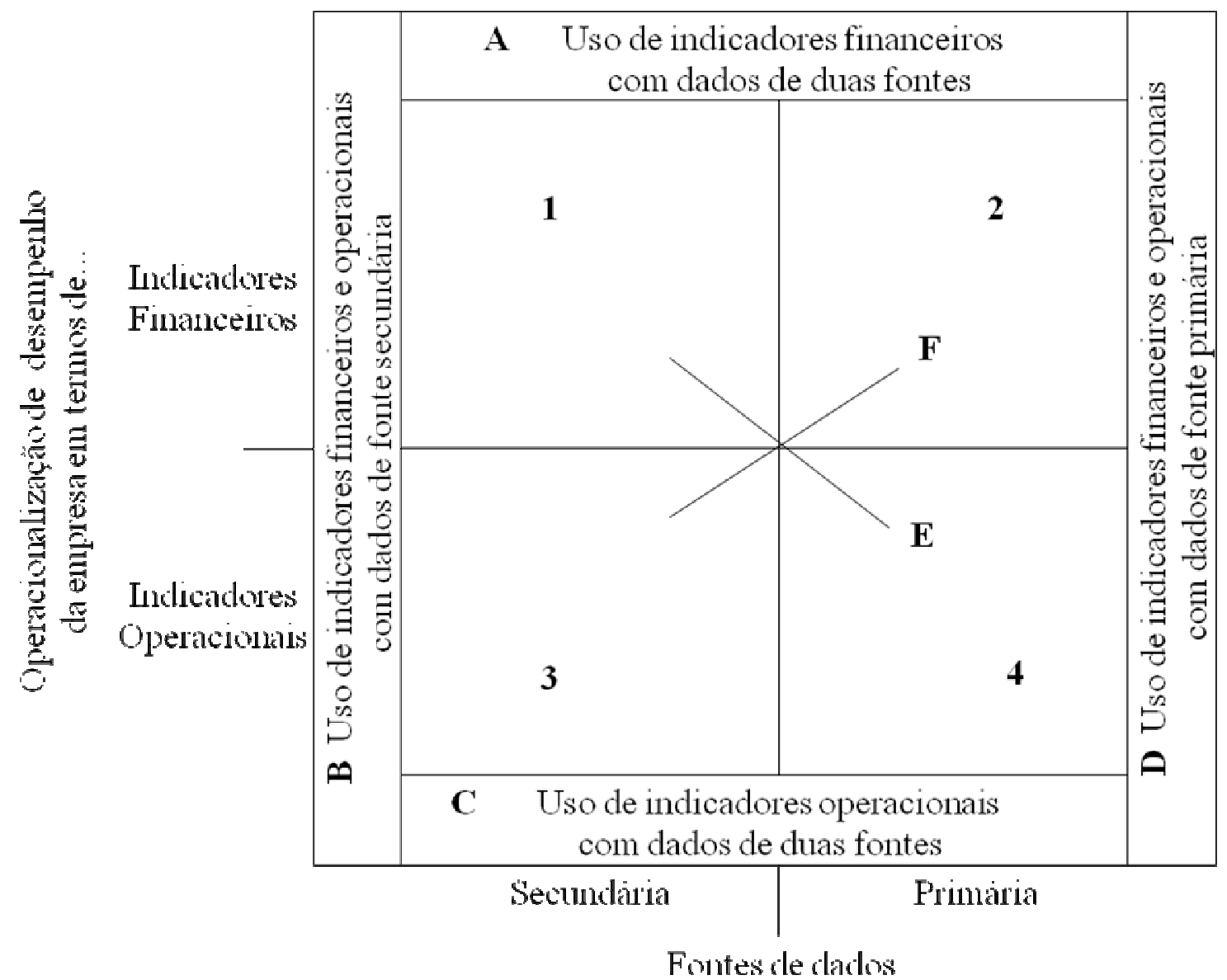

Figura 2 - Esquema para classificar abordagens alternativas e medir o desempenho da empresa FONTE: VENKATRAMAN; RAMANUJAM, 1986, p. 805.

Essas quatro abordagens utilizam uma perspectiva mais estreita para operacionalizar o conceito de desempenho. As outras seis (A a F) representam um desenvolvimento significativo na operacionalização do conceito, segundo Venkatraman e Ramanujam (1986):

- a abordagem A utiliza indicadores financeiros coletados de fontes primária e secundária;

- a abordagem B utiliza indicadores financeiros e operacionais obtidos de fonte secundária;

- a abordagem $\mathrm{C}$ utiliza indicadores operacionais obtidos de fontes primária e secundária;

- a abordagem D usa indicadores financeiros e operacionais oriundos de fonte primária; 
- a abordagem E usa indicadores financeiros obtidos de fonte secundária e indicadores operacionais extraídos de fonte primária;

- a abordagem F usa indicadores operacionais provenientes de fonte secundária $\mathrm{e}$ indicadores financeiros obtidos de fonte primária.

Esse esquema de classificação permite ao pesquisador comparar e contrastar as diferentes abordagens para operacionalizar o conceito de desempenho da empresa.

\subsubsection{Desempenho financeiro}

Alguns autores, como Chakravarthy (1986), Keats (1990) e Venkatraman e Ramanujam (1986; 1987), acreditam que o conceito desempenho tem múltiplas dimensões. Assim, para medi-lo, é preciso utilizar mais de um indicador.

Venkatraman e Ramanujam (1987) demonstraram que o construto desempenho financeiro tem, pelo menos, duas dimensões distintas: crescimento e rentabilidade. Cada uma dessas pode ser operacionalizada por um ou mais indicadores. A rentabilidade, por exemplo, pode ser medida por indicadores como ROA (Return On Assets - Retorno sobre Ativos), ROE, ROI. O crescimento pode ser dimensionado por indicadores como aumento das vendas e do número de funcionários.

Carton e Hofer (2006) propõem a utilização de indicadores contábeis para operacionalizar o construto desempenho financeiro. Eles alegam que:

- os indicadores não financeiros não têm uma definição ou uma medida-padrão;

- $\quad$ as medidas de mercado só podem ser utilizadas por empresas de capital aberto; 
- $\quad$ os indicadores contábeis são os mais utilizados em estudos empíricos.

Os autores reconhecem que os indicadores contábeis apresentam algumas deficiências, mas ressaltam dois pontos fortes:

- os pesquisadores têm acesso a esses indicadores, que são disponibilizados pelas empresas nas demonstrações financeiras;

- $\quad$ existe uniformidade na apresentação dos dados, pois as demonstrações são preparadas seguindo um conjunto de normas, os princípios contábeis geralmente aceitos.

\subsubsection{Medidas de desempenho financeiro utilizadas em pesquisas anteriores}

O conceito de desempenho financeiro é dominante nas pesquisas empíricas. Entretanto, não existe consenso entre os pesquisadores a respeito de quais indicadores devem ser adotados (CARTON; HOFER, 2006). Com o objetivo de verificar que medidas estavam sendo utilizadas para medir o desempenho das empresas, Carton e Hofer (2006) fizeram uma revisão dos estudos empíricos publicados de julho de 1996 a junho de 2001 em cinco publicações americanas: Academy of Management Journal, Strategic Management Journal, Journal of Management, Journal of Business Venturing e Entrepreneurship Theory \& Practice.

Dos 1.045 artigos analisados, 138 utilizavam o desempenho da empresa como variável dependente. Desses 138 artigos, 64 (46\%) adotavam somente uma medida para representar o construto desempenho; 35 (25\%) utilizavam duas medidas; os 39 (29\%) restantes aplicavam de três a oito medidas de desempenho. Oitenta e oito medidas diferentes foram utilizadas como variável dependente nesses 138 artigos.

Utilizando a classificação encontrada na maioria dos livros de Finanças e de Contabilidade, Carton e Hofer (2006) agruparam essas 88 medidas em 9 dimensões: 
- Rentabilidade ou Lucratividade: medidas contábeis e índices. Ex.: ROA, ROE, ROS, ROI;

- Operacional: medidas não financeiras. Ex.: participação de mercado, satisfação de clientes, inovação de produtos, produtividade, qualidade;

- $\quad$ Medidas de mercado: medidas que incorporam o valor de mercado da empresa. Ex.: Q de Tobin, MVA $^{\circledR}$ (Valor de Mercado Adicionado);

- Crescimento: medidas contábeis que incluem mudanças absolutas ou percentuais nos ativos totais, ativos operacionais, vendas, despesas operacionais;

- $\quad$ Eficiência: medidas que representam como a empresa está utilizando seus recursos. Ex.: vendas por metro quadrado, vendas por empregado;

- Liquidez: medidas que mostram a habilidade da empresa em cumprir seus compromissos no prazo. Ex.: liquidez corrente, liquidez seca;

- Tamanho: por exemplo, vendas totais e número de empregados;

- Solvência: medidas que indicam se a empresa sobreviverá. Ex.: modelo de Altman.

Dos 138 artigos analisados por Carton e Hofer (2006), 70\% utilizavam, pelo menos, uma medida de lucratividade. Em segundo lugar, ficaram as medidas de crescimento e, em terceiro, com $17 \%$, as medidas de mercado.

Para Lee et al (2003), as medidas mais utilizadas nas pesquisas empíricas em Administração são: ROA, ROE, ROS e crescimento das vendas. Segundo os autores, tal utilização assegura a comparação dos resultados dos diversos estudos. Sobre as controvérsias a respeito do uso de medidas contábeis no lugar daquelas de mercado, os autores afirmam que existem evidências de que essas quatro medidas contábeis são altamente correlacionadas com o valor de mercado da companhia. 


\subsection{A influência do agente no desempenho da empresa}

A remuneração de executivos é um assunto complexo e controverso, que tem atraído a atenção da mídia (CONYON, 2006) e de pesquisadores de várias áreas, como: Finanças, Contabilidade, Recursos Humanos e Estratégia (CARLON et al, 2006).

A abordagem mais utilizada nas pesquisas sobre a remuneração de executivos é a teoria do principal-agente (CONYON, 2006), conhecida como teoria de agência. Esta baseia-se na premissa de que o principal (o acionista ou o proprietário) delega autoridade a um agente (o executivo) e espera que este maximize seus interesses (ROSSETTI et al, 2008; TOSI et al, 2000).

O principal pode incorrer em algumas perdas - chamadas de "custos de agência", quando o agente persegue objetivos diferentes dos seus (TOSI et al, 2000). Segundo Tosi et al (2000), os acionistas têm, pelo menos, três problemas para reduzir o custo de agência. Primeiro, demonstram dificuldade de supervisionar de perto as atividades dos executivos. Segundo, os executivos revelam-se mais conhecedores do negócio do que os acionistas (assimetria de informação). Terceiro, os executivos podem utilizar recursos da companhia para perseguir objetivos não compatíveis com os melhores interesses dos acionistas.

O desafio é induzir o executivo, maximizador da própria utilidade e avesso ao risco, a agir com a finalidade de aumentar o valor/desempenho da empresa (BLOOM; MILKOVICH, 1998). De acordo com a teoria de agência, o pacote de remuneração é o mecanismo mais eficiente para alinhar os interesses de acionistas e executivos (AGGARWAL; SAMWICK, 1999; DEVERS et al, 2007; SHIM; LEE, 2003; TOSI et al, 2000). O argumento do alinhamento pressupõe que a remuneração influencia o comportamento do executivo. Este, por sua vez, influencia o desempenho da empresa (DEVERS et al, 2007).

O acionista procura estruturar pacotes ótimos de remuneração. Um pacote ótimo de remuneração não significa um pacote perfeito, mas o melhor que o acionista pode estruturar para evitar que o executivo maximize sua própria utilidade (CONYON, 2006). 
De acordo com Conyon (2006), o pacote de remuneração do executivo é composto de quatro componentes básicos: 1. os executivos recebem um salário-base, geralmente, igual ao das empresas concorrentes; 2. os executivos recebem um bônus anual, normalmente, atrelado a medidas de desempenho contábil; 3. os executivos recebem stock options, que representam um direito, mas não uma obrigação de comprar ações no futuro, a um preço de exercício predefinido; 4. os executivos recebem planos de incentivo de longo prazo.

\subsection{Conceito de remuneração}

Há várias terminologias para expressar "remuneração". No Brasil, não existe uma terminologia única. Recentemente, o uso dessa expressão tem crescido num sentido mais amplo, considerando outros fatores além do pacote financeiro (HANASHIRO et al, 2007).

A remuneração é um dos sistemas mais importantes e complexos da administração de Recursos Humanos. Ao mesmo tempo em que estimula a busca por desempenhos cada vez melhores, o sistema de remuneração alinha o comportamento das pessoas com os objetivos da empresa (BÁLKIN; GÓMEZ-MEJIA, 1987). A Figura 3 apresenta o conceito de remuneração que será utilizado neste trabalho.

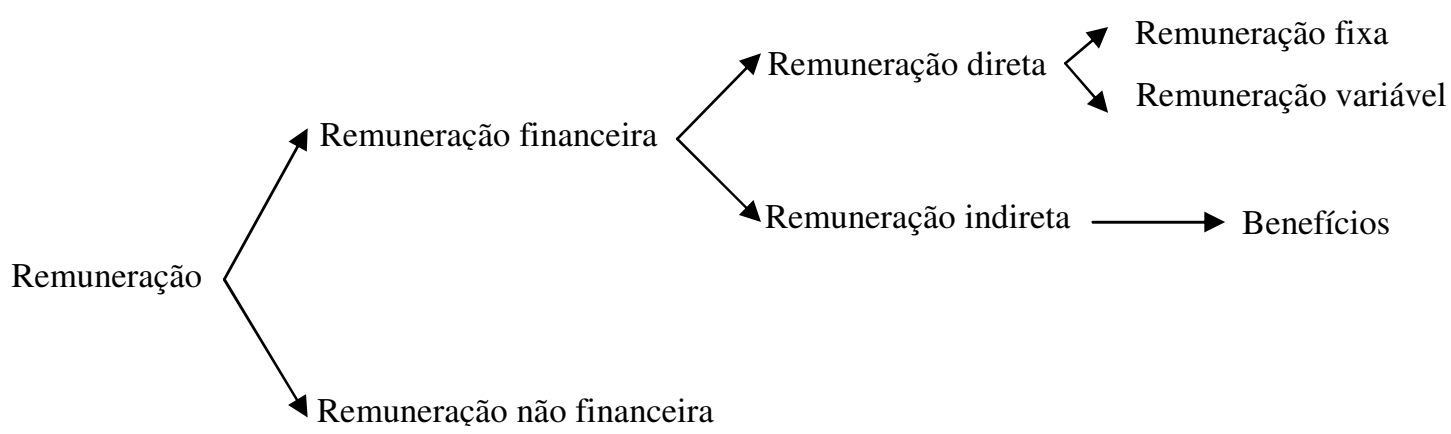

Figura 3 - $O$ conceito de remuneração

FONTE: Elaborado pela autora. 
A remuneração financeira "é a contrapartida econômica e/ou financeira de um trabalho realizado pela pessoa" (DUTRA, 2002b, p. 181). Pode ser dividida em remuneração direta e remuneração indireta. O primeiro tipo refere-se ao montante total em dinheiro recebido pela pessoa, em contrapartida ao trabalho realizado. Inclui a remuneração fixa e a remuneração variável (CHIAVENATO, 2000; DUTRA, 2002b). O segundo tipo será detalhado adiante.

A remuneração fixa é o montante em dinheiro previamente ajustado entre a pessoa e a empresa, pago regularmente pelo trabalho realizado. Normalmente, está atrelada às tarefas e à posição ocupada pela pessoa na companhia (DUTRA, 2002b).

Já a remuneração variável é o montante em dinheiro recebido em razão do alcance de determinadas metas previamente ajustadas entre a pessoa e a empresa. Existem várias alternativas de remuneração variável. Os modelos mais utilizados no Brasil, segundo Xavier et al (1999), são:

- Bônus/gratificação: utilizado principalmente por grandes empresas multinacionais para remunerar os altos escalões. Os valores são pagos periodicamente, em razão do resultado obtido.

- Comissão: é a forma mais antiga e tradicional de remuneração. Utilizada principalmente para remunerar os funcionários da área comercial, consiste em um percentual sobre o volume de vendas.

- Incentivos/campanhas: utilizados principalmente para o alcance de metas preestabelecidas, têm um tempo de duração determinado. O pagamento é feito por meio de bens, serviços ou viagens.

- Participação nos resultados: a remuneração ocorre em função do alcance de metas previamente negociadas entre a organização e seus funcionários.

- Participação nos lucros: consiste na distribuição de uma porcentagem dos lucros, a partir de fórmulas e critérios previamente estabelecidos. 
- Participação acionária: é uma forma de incentivo de longo prazo, geralmente, destinada aos cargos de direção. Caracteriza-se pela distribuição ou venda facilitada de ações, que podem ser negociadas, após um período de carência.

Segundo Dutra (2002b), a maior dificuldade para se criar um sistema de remuneração adequado está na definição de critérios que diferenciem as pessoas conforme sua contribuição para a empresa. Os dois principais conjuntos de critérios para determinação da remuneração são: os que têm como referência o mercado de trabalho, e os que têm como referência os padrões internos de equidade. O primeiro utiliza informações externas à empresa, principalmente de pesquisa salarial, e tem como objetivo tornar o sistema de remuneração mais competitivo. $\mathrm{O}$ segundo utiliza informações internas à empresa e tem como objetivo garantir um ambiente de segurança e justiça.

A remuneração indireta (segundo tipo) é representada pelos benefícios relacionados ao trabalho realizado, concedidos às pessoas envolvidas. Seu objetivo é oferecer segurança e conforto (DUTRA, 2002b). São exemplos de benefícios: assistência médica, assistência odontológica, seguro de vida em grupo, automóvel, entre outros.

As empresas, frequentemente, incorporam recompensa não financeira aos seus pacotes de remuneração (CARLON et al, 2006). Aspectos relacionados à carreira e ao desenvolvimento pessoal e profissional são dois dos fatores não financeiros em questão. Segundo a FIA (2007), o aspecto mais valorizado pelas pessoas é a perspectiva de crescimento profissional. Essa possibilidade é materializada por meio da carreira profissional oferecida. Em seguida, vem o treinamento e a educação, considerados aspectos fundamentais para sustentar o desenvolvimento pessoal e profissional.

London e Stumpf (1982) definem carreira como uma sequência de posições ocupadas e de trabalhos realizados por uma pessoa durante sua vida profissional, englobando duas perspectivas: a do indivíduo e a da empresa. O entendimento e a avaliação da experiência profissional pertencem à perspectiva do indivíduo. Já as políticas, procedimentos e decisões ligadas às esferas organizacional, de remuneração e de movimento de pessoas pertencem à 
perspectiva da empresa. Para Dutra (2002a, p. 110), a carreira deve ser vista "como uma estrada sempre em construção pela pessoa e pela empresa".

Em relação à carreira, as ações das organizações englobam mecanismos de planejamento e acompanhamento de carreira, de recolocação em caso de demissão, de recrutamento interno e de preparação para a aposentadoria.

Quanto ao desenvolvimento pessoal e profissional, as empresas têm adotado um processo de aprendizagem contínuo. O objetivo é desenvolver as competências empresariais e humanas consideradas críticas para o negócio. Esse processo engloba: a utilização de múltiplas formas de aprendizagem, o desenvolvimento de programas que reflitam o compromisso da empresa com a cidadania empresarial, o envolvimento de gerentes e líderes com o processo de educação, a criação de sistemas de avaliação dos resultados dos investimentos em educação, a parceria com instituições de ensino superior, dentre outros (EBOLI, 2002).

\subsection{Contribuição da administração de Recursos Humanos para o desempenho da empresa}

Nos últimos anos, vários pesquisadores têm buscado entender a natureza da relação entre a administração de Recursos Humanos (RH) e o desempenho da empresa. Eles têm buscado, principalmente, evidências de que a administração de RH tem impacto positivo neste contexto.

Delery e Doty (1996) identificaram três perspectivas para descrever essa relação. São elas: perspectiva universal, perspectiva contingencial e perspectiva configuracional. Alcázar et al (2005) propuseram a inclusão de uma quarta perspectiva. Utilizando a terminologia apresentada por Brewster (1995; 1999), eles a chamaram de “perspectiva contextual”. 


\subsubsection{Perspectiva universal}

A perspectiva universal representa a abordagem mais simples de análise da relação entre administração de RH e desempenho empresarial (ALCÁZAR et al, 2005; BOSELIE et al, 2001; DELERY; DOTY, 1996). A relação entre a variável independente (práticas de RH) e a variável dependente (desempenho da empresa) é universal, é a mesma para a população toda (DELERY; DOTY, 1996; YOUNDT et al, 1996). As principais premissas dessa perspectiva são:

- $\quad$ Existe uma relação linear entre práticas ou sistemas de RH e desempenho da empresa (BOSELIE et al, 2001; DELERY; DOTY, 1996; YOUNDT et al, 1996);

- Algumas práticas de RH são melhores do que outras, e a utilização dessas práticas resulta em melhor desempenho da organização. Elas são chamadas de "Práticas de Trabalho de Alto Desempenho" ou de "melhores práticas” (DELERY; DOTY, 1996);

- O desempenho da empresa é medido em termos de indicadores financeiros, como lucro, ou por participação de mercado e nível de vendas (BOSELIE et al, 2001).

A perspectiva universal não considera a sinergia ou a integração de diferentes práticas de RH. Mesmo quando diversas práticas são analisadas em conjunto, como no modelo de "Sistema de Trabalho de Alto Desempenho" (High Performance Work Systems) (BECKER; HUSELID, 1998; HUSELID, 1995; HUSELID et al, 1997), a análise limita-se a um ponto de vista aditivo (ALCÁZAR et al, 2005). Além disso, não existe consenso entre os pesquisadores a respeito do que seria a "melhor" prática (YOUNDT et al, 1996).

\subsubsection{Perspectiva contingencial}

A perspectiva contingencial rejeita a linearidade da perspectiva universal e inclui a interatividade entre as variáveis. A relação entre a variável independente e a variável 
dependente não é estável, e varia devido à presença de outras variáveis, chamadas de "variáveis contingenciais". Assim, a influência das práticas de RH no desempenho da empresa é condicionada por outras variáveis (ALCÁZAR et al, 2005; DELERY; DOTY, 1996).

Segundo Alcázar et al (2005), as variáveis contingenciais podem ser agrupadas em três categorias:

- Variáveis estratégicas: as práticas de RH precisam ser consistentes com a estratégia da empresa para resultar em desempenho superior (DELERY; DOTY, 1996; YOUNDT et $a l$, 1996). Segundo Delery e Doty (1996), a estratégia é a variável contingencial mais utilizada nas pesquisas.

- Variáveis organizacionais: as práticas de RH são condicionadas por fatores como: tamanho da empresa, tecnologia, estrutura.

- Variáveis ambientais: as práticas de RH não podem ser formuladas e ímplementadas sem considerar o contexto: competitivo, tecnológico, macroeconômico e trabalhista.

\subsubsection{Perspectiva configuracional}

A perspectiva configuracional é mais complexa que as duas anteriores. Adota um ponto de vista sistêmico, considera a sinergia e incorpora o princípio da equifinalidade (ALCÁZAR et al, 2005; DELERY; DOTY, 1996). Segundo este princípio, um mesmo objetivo pode ser alcançado utilizando diferentes caminhos e partindo de diferentes condições iniciais (CHIAVENATO, 2000).

Essa visão define o sistema de RH como um conjunto multidimensional de diferentes elementos que podem ser combinados para formar um conjunto infinito de configurações (ALCÁZAR et al, 2005). Essas configurações representam tipos ideais e, portanto, não são fenômenos observáveis empiricamente (DELERY; DOTY, 1996). 
Segundo essa ótica, para que uma empresa alcance desempenho superior, suas práticas de RH precisam apresentar alinhamento tanto horizontal quanto vertical. Alinhamento horizontal é a consistência interna das práticas de RH de uma empresa. Alinhamento vertical é a congruência das práticas de RH com outras características organizacionais, por exemplo, com a estratégia da companhia (ALCÁZAR et al, 2005; DELERY; DOTY, 1996).

\subsubsection{Perspectiva contextual}

A perspectiva contextual surgiu para explicar o contexto organizacional europeu. Essa perspectiva propõe a expansão do conceito de administração de RH para englobar as relações da empresa com o governo e os sindicatos. Ela também visa à ampliação dos atores envolvidos na formulação e implementação da administração de RH, com a inclusão dos stakeholders. Diferentemente das demais perspectivas, esta adota como nível de análise o ambiente social (ALCÁZAR et al, 2005).

Para a perspectiva contextual, a administração de RH contribui para o sucesso e para a sobrevivência de longo prazo da empresa não só por melhorar o desempenho, mas também, por ajudar a integrar e a legitimar a companhia em seu ambiente (ALCÁZAR et al, 2005).

Apesar das diferenças entre as quatro perspectivas, elas são complementares. O Quadro 1 apresenta um resumo das principais contribuições de cada uma delas.

Quadro 1 - Resumo das principais contribuições de cada perspectiva

\begin{tabular}{|l|l|l|l|}
\hline \multicolumn{1}{|c|}{ Universal } & \multicolumn{1}{|c|}{ Contingencial } & \multicolumn{1}{c|}{ Configuracional } & \multicolumn{1}{c|}{ Contextual } \\
\hline $\begin{array}{l}\text { • Demonstração da } \\
\text { importância do capital } \\
\text { humano nas organizações }\end{array}$ & $\begin{array}{l}\bullet \text { Inclusão de outras } \\
\text { variáveis para mediar a } \\
\text { relação entre RH e } \\
\text { desempenho }\end{array}$ & $\begin{array}{l}\bullet \text { Análise interna do } \\
\text { sistema de RH } \\
\bullet \text { Inclusão da sinergia e da } \\
\text { interdependência entre os } \\
\text { diferentes elementos do } \\
\text { sistema de RH } \\
\bullet \text { Diferentes configurações } \\
\text { de RH podem ser } \\
\text { igualmente eficientes }\end{array}$ & $\begin{array}{l}\text { RH em um contexto } \\
\text { macrossocial de RH }\end{array}$ \\
\hline
\end{tabular}

FONTE: Baseado em ALCÁZAR et al, 2005, p. 235. 


\subsection{Principais resultados e características de pesquisas anteriores}

Várias pesquisas apontam a existência de uma relação entre administração de RH e desempenho da empresa. Alguns pesquisadores focaram em uma ou em várias práticas de RH, examinando seu efeito em diversas medidas de desempenho. São exemplos os estudos de: Delaney e Huselid (1996); Gerhart e Milkovich (1990); Harel e Tzafrir (1999); Terpstra e Rozell (1993). Outros estudiosos examinaram o efeito de sistemas de práticas de RH, denominadas de "Sistemas de Trabalho de Alto Desempenho", como os estudos de: Huselid (1995); Varma et al (1999).

Os trabalhos que focaram a relação entre remuneração e desempenho partiram do pressuposto de que o sistema de remuneração é um mecanismo essencial. Por meio dele, os esforços individuais são direcionados para os objetivos estratégicos do negócio. Quando o sistema de remuneração é estruturado de maneira apropriada, esse processo pode contribuir para o aumento do desempenho da companhia (GÓMEZ-MEJIA; WELBOURNE, 1988).

Segue-se uma breve apresentação de estudos empíricos que estudaram a relação entre administração de RH e desempenho da empresa.

- Gerhart e Milkovich (1990) utilizaram a teoria de agência para examinar as consequências de diferentes estratégias de remuneração. Os autores utilizaram os dados de uma pesquisa nacional realizada entre 1981 e 1985, por uma empresa de consultoria especializada em remuneração, com cerca de 14.000 executivos de média e de alta gerências de 200 empresas. Os resultados apontaram uma associação entre remuneração variável e desempenho financeiro.

- Gómez-Mejia (1992) testou o alinhamento entre remuneração e estratégia de diversificação, observando seu efeito. Foram utilizados dados primários e secundários. $\mathrm{O}$ alto executivo da área de $\mathrm{RH}$ responsável pela remuneração foi o respondente. A amostra era formada por organizações com mais de 500 funcionários. Para operacionalizar as variáveis remuneração e estratégia de diversificação, o autor 
desenvolveu escalas baseadas em estudos anteriores de Bálkin e Gómez-Mejia (1987; 1990), Gómez-Mejia e Welbourne (1988), e Kerr (1985). Para medir o desempenho, utilizaram-se quatro indicadores: EPS médio (Earnings Per Share - Lucros por Ação), ROI médio, retorno médio da ação e variação anual do valor médio de mercado da empresa. Como variáveis de controle, consideraram-se: despesa de P\&D (Pesquisa \& Desenvolvimento), tamanho da empresa, ciclo de vida do produto e proporção de custos de mão-de-obra em relação aos custos totais. Os resultados da análise multivariada revelaram que o desempenho da companhia ocorre em função do alinhamento da remuneração com a estratégia.

Terpstra e Rozell (1993) examinaram a relação entre práticas de recrutamento, de seleção, e medidas de desempenho, em uma amostra de 201 empresas. Os dados foram coletados por meio de questionário, e o respondente foi o principal executivo de RH. O desempenho foi medido de maneira subjetiva, com o auxílio de dois indicadores contábeis: crescimento das vendas e lucro. Não foram utilizadas medidas de mercado porque, na amostra, havia empresas de capital fechado. Como variáveis de controle foram utilizados: número de funcionários e setor de atuação. O teste de correlação confirmou a ligação entre práticas de recrutamento e lucro. Os resultados da regressão hierárquica mostraram a existência de relação positiva e significante entre práticas de recrutamento e lucro.

Arthur (1994) examinou o efeito de sistemas de práticas de RH no desempenho de 30 mini-usinas de aço americanas. O autor utilizou os resultados de sua pesquisa de 1992, que identificou dois tipos de sistemas de práticas de RH: o sistema do tipo "controle" e o sistema do tipo "comprometimento". As variáveis de controle utilizadas foram: tamanho da empresa, sindicalização dos empregados e estratégia. O desempenho foi medido pela eficiência, taxa de refugo e turnover. Os resultados mostraram que as organizações com sistema de RH do tipo "comprometimento" apresentavam produtividade maior, taxa de refugo e turnover menores do que aquelas com sistema do tipo "controle".

- Huselid (1995) examinou a ligação entre "Práticas de Trabalho de Alto Desempenho" e o desempenho da companhia. A relação de 13 práticas de $\mathrm{RH}$, chamadas de "alto desempenho", foi elaborada pelo autor com base no estudo de Delaney et al (1989). 
Para medir o desempenho, utilizaram-se as seguintes medidas: uma medida contábil, uma medida baseada no mercado, além de medidas de turnover e de produtividade dos empregados. A despesa operacional foi utilizada como proxy da remuneração dos empregados. Os dados foram coletados por intermédio de questionário respondido pelo executivo sênior de RH, em uma amostra de 968 empresas. Dados secundários também foram utilizados. Os resultados das análises de regressão comprovaram a hipótese de que a adoção de "Práticas de Trabalho de Alto Desempenho" está associada a turnover menor e à produtividade maior dos empregados, além de uma melhora no desempenho financeiro da empresa.

Delaney e Huselid (1996) examinaram a associação entre práticas de RH e medidas de desempenho organizacional. Os dados de 590 empresas foram obtidos por entrevista telefônica e questionário. Foram coletados: a) dados objetivos e subjetivos de práticas de RH; b) dados subjetivos de indicadores de desempenho organizacional. A amostra incluía organizações com fins lucrativos e sem fins lucrativos, que haviam participado de uma pesquisa nacional pela National Organizations Survey. Os resultados das regressões sugeriram que práticas de administração de $\mathrm{RH}$ são positivamente relacionadas com medidas subjetivas de desempenho organizacional.

Montemayor (1996) examinou a relação entre política de remuneração, estratégia empresarial e desempenho da empresa em uma amostra de 261 empresas de vários setores. Os dados foram coletados com o uso de questionário, e os respondentes foram membros da American Compensation Association (ACA). As variáveis foram medidas de forma subjetiva, a partir da percepção do respondente. Os resultados das análises multivariadas demonstraram que as empresas de alto desempenho adotavam políticas de remuneração congruente com sua estratégia empresarial.

Rajagopalan (1997) examinou, no desempenho da companhia, as implicações decorrentes do alinhamento entre orientação estratégica e características dos planos de incentivo, em uma amostra de 50 grandes empresas de eletricidade dos Estados Unidos, no período de 1988 a 1992. Foram utilizados dados secundários e dados primários. O questionário procurava identificar a orientação estratégica, segundo a tipologia de Miles e Snow (1978), e foi respondido pelo CEO ou pelo vice-presidente das empresas. Dados secundários foram utilizados para operacionalizar as medidas de controle, as 
características dos planos de incentivo e o desempenho organizacional. Para medir o desempenho, foram utilizados três indicadores contábeis - retorno anual do capital empregado, ROA, ROE - e uma medida de mercado - ganho no preço da ação. Como variável de controle, foram utilizadas cinco medidas relacionadas ao setor, além do tamanho da companhia, medido pelo logaritmo natural do ativo total. Os resultados das análises de regressão apontaram que os planos de incentivo resultam em desempenho superior somente se estiverem alinhados à estratégia empresarial.

Harel e Tzafrir (1999) investigaram a relação entre seis práticas de RH e o desempenho da empresa. As seis práticas de RH - recrutamento, seleção, remuneração, participação do empregado, mercado interno de trabalho e treinamento - foram escolhidas por serem consideradas estratégicas e universais, em outros estudos, como os de Delaney et al (1989); Delery e Doty (1996); Huselid (1995). A amostra era formada por 76 empresas dos setores público e privado, com mais de 200 empregados, localizadas em Israel. O desempenho foi medido de maneira subjetiva e com duas variáveis. A primeira variável - desempenho organizacional - comparava o desempenho da empresa com seus concorrentes, em aspectos como: qualidade do produto/serviço, desenvolvimento de novos produtos, habilidade de atrair e reter empregados, satisfação de cliente etc. A segunda variável - desempenho do mercado - comparava o desempenho econômico da empresa com seus concorrentes, em aspectos como: preço de produto, aumento das vendas, lucratividade etc. Foram utilizadas como variáveis de controle: setor, tamanho, tempo de existência da empresa, grau de sindicalização e ambiente externo. Os dados foram coletados com questionário, respondido pelo vice presidente de RH. Os resultados das análises de correlação e de regressão apontaram impacto das práticas de RH na performance da empresa.

Attaway (2000) examinou a relação entre o desempenho da empresa e a remuneração do CEO (Chief Executive Officer) em uma amostra de 42 grandes companhias do setor de computadores e eletrônicos, nos Estados Unidos. Os dados secundários foram coletados no período de 1992 a 1996. As variáveis de controle utilizadas foram: idade do CEO, tempo no cargo, porcentagem de ações da empresa em poder do CEO e grau de escolaridade do CEO. O ROE mediu o desempenho da empresa. Os resultados das análises de correlação e de regressão mostraram que existia uma relação fraca, mas positiva, entre o desempenho da empresa e a remuneração do CEO. 
Marín e Sánchez (2002-2003) desenvolveram um modelo baseado na teoria de agência para verificar a existência de relação entre remuneração de executivos, orientação estratégica da companhia e desempenho financeiro. A amostra era formada por 253 grandes empresas manufatureiras espanholas, pertencentes a 6 setores. Como a maioria delas era de capital fechado, os autores utilizaram medidas contábeis. Foram utilizados o ROI e o ROE. Para levantar as características da remuneração, utilizou-se um questionário "auto-preenchível", composto de dez itens. Estes foram agrupados em três blocos, medindo cada uma das três dimensões de remuneração: 1. nível de remuneração em relação ao mercado; 2. tipo de incentivo (curto ou longo prazo); 3. mix de remuneração (fixo e variável). Para medir cada item, foi utilizada uma escala Likert de 7 pontos. O respondente foi o executivo responsável pelo RH.

O questionário apresentava também três questões para levantar a orientação estratégica das companhias. As variáveis de controle englobavam fatores organizacionais tamanho da empresa (medido pelo logaritmo das vendas) e setor de atuação - e fatores individuais - tempo no cargo e experiência profissional.

A análise fatorial - método componente principal e rotação varimax - foi utilizada para as respostas referentes à remuneração. Em seguida, aplicou-se a análise de regressão múltipla hierárquica. Os resultados mostraram que as empresas que remuneram seus executivos - com salários acima do nível de mercado, incentivos de longo prazo e alta porcentagem de componente variável - tiveram um impacto positivo no desempenho financeiro.

Paul e Anantharaman (2002) analisaram a relação entre práticas de RH, estratégia empresarial e desempenho organizacional, em uma amostra de 34 empresas de software, localizadas na Índia. As práticas de RH foram estudadas sob o ponto de vista do empregado. Para medir a estratégia foi utilizado o instrumento desenvolvido por Conant et al (1990), com a finalidade de identificar os tipos estratégicos de Miles e Snow (1978). Quanto ao desempenho, foram estudadas duas dimensões: operacional e financeira. A dimensão operacional foi definida em termos de: retenção do empregado, produtividade do empregado, qualidade do produto, rapidez na entrega, custo operacional e satisfação do cliente. A dimensão financeira foi medida considerando: crescimento das vendas, lucro líquido e ROI, no período de 1997 a 2000. Os dados 
foram coletados por dois tipos de questionário. O primeiro tipo procurava levantar informações sobre práticas de RH e estratégia e foi respondido pelos engenheiros de software. O segundo tipo procurava levantar informações subjetivas sobre $\mathrm{o}$ desempenho da empresa e foi respondido pelos executivos seniores. Os autores separaram as companhias segundo o tipo estratégico e utilizaram teste de correlação e análise de regressão múltipla entre práticas de RH e medidas de desempenho. Embora os resultados das análises estatísticas tenham mostrado que o tipo reator difere dos demais tipos estratégicos quanto às práticas de RH, não foram encontradas diferenças significativas entre os outros três tipos: exploradores, analisadores e defensores. Quanto ao desempenho, a análise mostrou que os exploradores apresentavam vantagem sobre os outros tipos estratégicos em quase todas as variáveis.

Mak e Akhtar (2003) examinaram a relação entre práticas de RH, orientação estratégica da empresa e desempenho financeiro, em uma amostra de 63 companhias de capital aberto de Hong Kong. Os dados foram coletados por questionário respondido pelo responsável do RH. O questionário levantava informações sobre 7 práticas de RH, nas esferas gerencial e não-gerencial. Essas práticas foram identificadas por Delery e Doty (1996) como estratégicas. Custo, qualidade e inovação foram as orientações estratégicas examinadas. O desempenho financeiro foi medido pelo logaritmo do ROE. O resultado da análise de correlação indicou que, das 7 práticas de RH estudadas, somente descrição de cargos e participação nos lucros apresentavam correlação positiva e significante com o desempenho da empresa, tanto no aspecto gerencial como naquele não-gerencial.

Paul e Anantharaman (2003) desenvolveram um modelo para explicar como as práticas de RH influenciam o desempenho da empresa. As práticas de RH - seleção, treinamento, cargo, ambiente de trabalho, avaliação de desempenho, remuneração, desenvolvimento de carreira e incentivos - foram estudadas sob o ponto de vista do empregado. Foram pesquisadas duas dimensões de desempenho: operacional e financeira. O desempenho operacional foi medido por: retenção do empregado, produtividade, qualidade do produto, velocidade de entrega do serviço e custos operacionais. O desempenho financeiro foi medido em termos de: crescimento das vendas, lucro líquido e ROI, no período de 1997 a 2000. O modelo utilizava quatro variáveis intervenientes: competência, trabalho em grupo, comprometimento e orientação ao cliente. A amostra era composta de 34 empresas de software, localizadas 
na Índia. Os dados sobre práticas de RH e sobre as variáveis intervenientes foram levantados por um questionário respondido pelos engenheiros. $\mathrm{E}$ os dados sobre desempenho financeiro foram fornecidos pelo CEO.

Primeiramente, foi utilizada análise fatorial - método componente principal e rotação varimax. Em seguida, teste de correlação bivariada entre as práticas de $\mathrm{RH}$, variáveis intervenientes e medidas de desempenho. Os resultados apontaram que as práticas de RH têm correlação positiva significante com todas as variáveis intervenientes. As práticas de RH - seleção, avaliação de desempenho, remuneração e desenvolvimento de carreira - não têm correlação significante com velocidade de entrega de serviço. A avaliação de desempenho também não apresentou uma correlação significante com o desempenho financeiro. Foi utilizado, então, o teste de regressão múltipla - método stepwise. Os resultados apontaram que nenhuma prática isolada de RH afeta diretamente o desempenho financeiro, mas todas as práticas de $\mathrm{RH}$ influenciaram indiretamente o desempenho financeiro, por intermédio de uma ou mais variáveis intervenientes.

Marín e Sánchez (2005) analisaram a influência da interação entre remuneração de executivos e estratégia, em uma amostra de 82 grandes organizações espanholas do setor químico-farmacêutico. Os dados relativos à remuneração e à estratégia foram coletados por questionário, respondido pelo mais alto executivo de RH. Foram utilizados dados secundários para medir o desempenho das empresas. O ROI e o ROE foram as medidas selecionadas. Elas foram calculadas em dois momentos diferentes: antes da realização da pesquisa, no período de 1997 a 2000; depois da pesquisa, no período de 2001 a 2003.

Para medir a estratégia, os autores desenvolveram uma estrutura que combinava a tipologia de Miles e Snow (1978) com o conceito de risco. Essa combinação resultou em três categorias de orientação estratégica: exploradores (contexto de alto risco para os executivos), defensores (contexto de baixo risco para os executivos) e reatores (contexto com nível desconhecido de risco). Como variáveis de controle foram utilizados: tamanho da empresa (medido pelo logaritmo das vendas) e custo variável de mão-deobra (medido pela porcentagem do custo de mão-de-obra em relação ao custo total de produção). Os resultados das análises estatísticas indicaram que as companhias que alinharam a estrutura do sistema de remuneração dos executivos ao contexto estratégico apresentavam melhor desempenho financeiro. 
Ozkan (2007) examinou a relação entre a remuneração do CEO e o desempenho da empresa, em uma amostra de 390 empresas britânicas não financeiras, presentes no índice FTSE All Share, no período de 1999 a 2005. A remuneração incluiu: saláriobase, bônus, stock options e planos de incentivo de longo prazo. O desempenho foi medido pelo retorno da ação e pelo ROA. Como variáveis de controle foram utilizadas as variáveis de governança: concentração de propriedade e estrutura do conselho. Utilizou-se também o tamanho da empresa, medido pelas vendas e pela oportunidade de crescimento. Este foi dimensionado pelo Q de Tobin. Os resultados dos testes de regressão indicaram que existe uma relação positiva e significante entre remuneração recebida em dinheiro (salário-base + bônus) e desempenho. Revelaram ainda uma relação positiva, mas não significante, entre remuneração total e desempenho. 


\section{METODOLOGIA}

\subsection{Tipos de pesquisa}

Cervo e Bervian (1973, p. 65) definem pesquisa "como uma atividade voltada para a solução de problemas. Seu objetivo consiste em descobrir respostas para perguntas, através do emprego de processos científicos".

Vergara (2006) propõe dois critérios para classificar os tipos de pesquisa: um refere-se aos fins; outro refere-se aos meios. Quanto aos fins, uma pesquisa pode ser:

- Exploratória: é realizada quando há pouco conhecimento acumulado sobre o tema;

- Descritiva: tem como objetivo a descrição das características de determinada população, ou de determinado fenômeno, ou o estabelecimento de relações entre variáveis;

- Explicativa: o objetivo é identificar os fatores que contribuem para a ocorrência de determinado fenômeno;

- Metodológica: está associada ao desenvolvimento de instrumentos, procedimentos para atingir determinado fim;

- Aplicada: tem finalidade prática. O objetivo é resolver problemas concretos;

- Intervencionista: o objetivo é interferir na realidade estudada para modificá-la.

Quanto aos meios, a pesquisa pode ser:

- Pesquisa de campo: investigação empírica;

- Pesquisa de laboratório: "experiência realizada em local circunscrito" (Ibid., p. 48); 
- Documental: faz uso de material não disponível para consultas públicas;

- Bibliográfica: faz uso de material acessível ao público em geral, como: livros, revistas etc;

- Experimental: quando o pesquisador manipula e controla variáveis independentes e observa as variações que ocorrem em variáveis dependentes;

- Ex post facto: refere-se a um fato que já ocorreu;

- Participante: quando o pesquisado participa com o pesquisador;

- Pesquisa ação: quando existe intervenção na realidade social;

- Estudo de caso: envolve uma ou poucas unidades e tem como objetivo aprofundar, detalhar.

Aplicando os critérios propostos por Vergara (2006), esta pesquisa classifica-se como descritiva, bibliográfica e documental. A pesquisa é descritiva porque tem como objetivo estudar a relação entre variáveis. É bibliográfica porque faz uso de material publicado em livros, revistas e bases de dados - ProQuest ${ }^{\circledR}$, EBSCO $^{\circledR}$ e SSRN. É documental porque utiliza dados da pesquisa “As 150 Melhores Empresas para Você Trabalhar", que não estão disponíveis para consulta pública.

Utiliza-se o método quantitativo, que consiste em empregar recursos e técnicas estatísticas para investigar a relação entre as variáveis. A presente pesquisa aplica teste de igualdade de médias, análise de correlação e análise de regressão para investigar a existência de relação entre remuneração de executivos e desempenho financeiro das empresas.

Segundo o esquema desenvolvido por Venkatraman e Ramanujam (1986) para medir o desempenho da empresa - descrito na seção 2.1 "Conceito de desempenho da empresa" desta tese -, o presente estudo enquadra-se na abordagem 1, pois utiliza indicadores financeiros obtidos de fonte secundária. Quanto à classificação proposta por Delery e Doty (1996), para 
descrever a relação entre administração de Recursos Humanos e desempenho da empresa apresentada na seção 2.4 "Contribuição da administração de Recursos Humanos para o desempenho da empresa" -, esta pesquisa enquadra-se na perspectiva universal, pois parte da premissa de que existe uma relação linear entre remuneração e desempenho da empresa e essa relação é universal.

\subsection{Hipótese da pesquisa}

Lakatos e Marconi (1991, p. 125) definem a expressão hipótese como "um enunciado geral de relações entre variáveis (fatos, fenômenos)". A hipótese constitui "uma suposta, provável e provisória resposta a um problema" que está sendo investigado (MARCONI; LAKATOS, 2003, p. 126).

As pesquisas que estudaram a relação entre a remuneração dos executivos e o desempenho financeiro das empresas apresentaram resultados divergentes (BÁLKIN; GÓMEZ-MEJIA, 1987; BARKEMA; GÓMEZ-MEJIA, 1998). Algumas encontraram relações fracas; outras observaram relações não significantes entre as variáveis (BARKEMA; GÓMEZ-MEJIA, 1998). Elas utilizaram, em sua maioria, dados de empresas norte-americanas e/ou focaram o contexto norte-americano (BÁLKIN; GÓMEZ-MEJIA, 1987; BARKEMA; GÓMEZ-MEJIA, 1998).

Vários desses trabalhos aplicaram o salário fixo e o salário variável para medir remuneração, adotando apenas um indicador contábil para medir desempenho financeiro. O desempenho foi medido de forma subjetiva, a partir da percepção do respondente (BECKER; GERHART, 1996).

Este estudo explora conceitos mais amplos: para operacionalizar a variável independente remuneração, utiliza - além do salário mensal e do salário variável - três índices criados especialmente para esta pesquisa: benefícios, carreira e desenvolvimento. Já para operacionalizar a variável dependente desempenho financeiro, utilizam-se três indicadores contábeis - crescimento das vendas, retorno sobre patrimônio líquido e margem líquida sobre as vendas - de dois exercícios sociais. 
Esses fatos, aliados a ausência de estudos no contexto do mercado brasileiro, levam o presente trabalho a testar a seguinte hipótese:

Existe relação positiva e significante entre a remuneração dos executivos e o desempenho financeiro das empresas, no contexto do mercado brasileiro.

\subsection{População e amostra}

O método de amostragem empregado foi o não-probabilístico, em que a inclusão ou a exclusão de elementos na amostra fica a critério do pesquisador. Assim, nem todo elemento da população-alvo tem chance de ser selecionado. Como consequiência, não será possível generalizar os resultados encontrados para a população (FÁVERO et al, 2009).

Dentre as 150 empresas eleitas pelo Programa de Estudos em Gestão de Pessoas (Progep), da FIA, como as melhores para se trabalhar no Brasil, em 2007, foram identificadas 71 companhias industriais. Desse total, foram excluídas 25 organizações. Estas, por não publicarem suas demonstrações contábeis nos anos de 2006 e 2007, não tinham seus dados disponíveis no banco de dados da Fundação Instituto de Pesquisas Contábeis, Atuariais e Financeiras (FIPECAFI). Foram excluídas ainda duas empresas que não disponibilizaram ao Progep os valores de salário mensal médio e salário variável médio de seus executivos, referentes a 2006. Assim, a amostra é formada por 44 empresas industriais, com informações disponíveis nos bancos de dados citados acima.

\subsection{Coleta de dados}

Os dados utilizados na pesquisa são secundários. As informações das variáveis independentes e da variável de controle foram extraídas do banco de dados do Progep, responsável pela pesquisa que elege anualmente "As 150 Melhores Empresas para Você Trabalhar" no Brasil. As companhias com, no mínimo, 100 empregados e que operam no mercado brasileiro e/ou 
internacional há mais de 5 anos podem participar da pesquisa que, em 2006, contou com a participação de 491 empresas.

O Progep utiliza, na pesquisa, dois tipos de questionários:

1. Preenchido pelos empregados, que registram suas percepções sobre as empresas em que trabalham. Esses empregados são selecionados aleatoriamente;

2. Preenchido pelas empresas, que declaram suas práticas de gestão de pessoas. Essas práticas precisam ser comprovadas. Para isso, as organizações apresentam ao Progep um caderno de evidências (chamado de Book) das práticas declaradas no questionário.

Os questionários preenchidos pelos empregados e pelas empresas são tabulados, com préclassificação de 220 companhias. Essa pré-classificação depende de critérios preestabelecidos pelo Progep. As organizações pré-classificadas recebem a visita de um jornalista, que realiza dinâmica de grupo com empregados de cargo operacional, entrevistas com o responsável pela área de RH e observação do ambiente de trabalho.

Para selecionar as 150 melhores empresas para trabalhar, o Progep utiliza o Índice de Felicidade no Trabalho (IFT). Esse índice é calculado com a seguinte fórmula:

$$
\mathrm{IFT}=(\text { IQAT } \times 0,70)+(\text { IQGP } \times 0,25)+(\text { Visita } \times 0,05)
$$

Onde:

IQAT é o Índice de Qualidade do Ambiente de Trabalho. É obtido dos questionários respondidos pelos empregados. O IQAT equivale a $70 \%$ do total de pontos na apuração do IFT.

IQGP é o Índice de Qualidade da Gestão de Pessoas. É obtido dos questionários respondidos pelas empresas e do material adicional, que comprova as informações declaradas. O IQGP equivale a $25 \%$ do total de pontos na apuração do IFT. 
Visita - dados obtidos por meio das visitas dos jornalistas às empresas pré-classificadas. Equivale a 5\% do total de pontos na apuração do IFT.

As 220 empresas pré-classificadas são elencadas em ordem decrescente na pontuação do IFT, e as 150 mais bem colocadas são eleitas as melhores para se trabalhar no Brasil.

Os questionários preenchidos pelas 44 empresas da amostra forneceram algumas das informações utilizadas para o desenvolvimento desta tese: salário mensal médio, salário variável médio, benefícios oferecidos, mecanismos de estímulo e suporte à carreira, mecanismos de estímulo à educação e ao desenvolvimento profissional, incluindo o número de funcionários das companhias.

Os dados da variável dependente foram extraídos do banco de dados da FIPECAFI, responsável pela publicação das "500 Melhores e Maiores” empresas do Brasil. Esse banco contém informações de todas as companhias que publicaram as demonstrações contábeis no Diário Oficial dos Estados, além daquelas limitadas que submeteram suas demonstrações à análise da fundação. Assim, esse banco de dados reúne informações de empresas de capital aberto e de capital fechado.

\subsection{Operacionalização da variável remuneração}

As informações sobre remuneração provêm do exercício de 2006 e referem-se à recompensa recebida por diretores, vice-presidentes e presidentes, aqui denominados de "executivos". Para operacionalizar a variável remuneração, foram coletadas as seguintes informações no banco de dados do Progep:

a) Valor do salário nominal mensal médio do executivo em dezembro de 2006, em reais;

b) Valor médio recebido pelo executivo durante o ano de 2006, em reais, como remuneração variável e/ou bônus; 
c) Acesso dos executivos a 12 benefícios: assistência médica; consultórios médicos nas instalações da empresa; assistência odontológica; subsídio para a compra de medicamentos; atendimento psicológico; seguro de vida em grupo; subsídio para a formação educacional; subsídio para a especialização profissional; subsídio para o estudo de idiomas; suporte à educação dos filhos; subsídio para a aquisição de moradia; financiamentos e empréstimos.

d) Acesso dos executivos a 25 mecanismos de estímulo e suporte à carreira. Esses mecanismos compreendem: planejamento e acompanhamento do desenvolvimento profissional; estímulo e suporte para o planejamento de carreira; recolocação de executivos demitidos; recrutamento interno; informações sobre possibilidades de carreira; preparação para aposentadoria.

e) Acesso dos executivos a 8 mecanismos de estímulo à educação e ao desenvolvimento profissional: programas educacionais que incorporam a identificação das competências críticas empresariais e humanas; múltiplas formas de aprendizagem; programas que reflitam o compromisso da empresa com a cidadania empresarial; gerentes e líderes envolvidos com o processo de aprendizagem; programas disseminadores da cultura organizacional; sistemas eficazes de avaliação dos investimentos em educação e dos resultados obtidos; compartilhamento de conhecimentos e troca de experiências; parcerias com instituições de ensino superior.

A partir dessas informações sobre benefícios, carreira, educação e desenvolvimento profissional, foram criados 3 índices: de benefícios, de carreira e de desenvolvimento. $\mathrm{O}$ índice de benefícios mede o acesso dos executivos a 12 benefícios. $O$ índice de carreira mede o acesso dos executivos a 25 mecanismos de estímulo e suporte à carreira. $\mathrm{O}$ índice de desenvolvimento mede o acesso dos executivos a 8 mecanismos de estímulo à educação e ao desenvolvimento profissional. Os critérios utilizados para a elaboração desses índices são descritos no Capítulo 4.

Portanto, para operacionalizar a variável remuneração, foram utilizadas as seguintes medidas: salário mensal médio, salário variável médio, índice de benefícios, índice de carreira e índice de desenvolvimento. A Figura 4 apresenta o modelo utilizado nesta tese. 


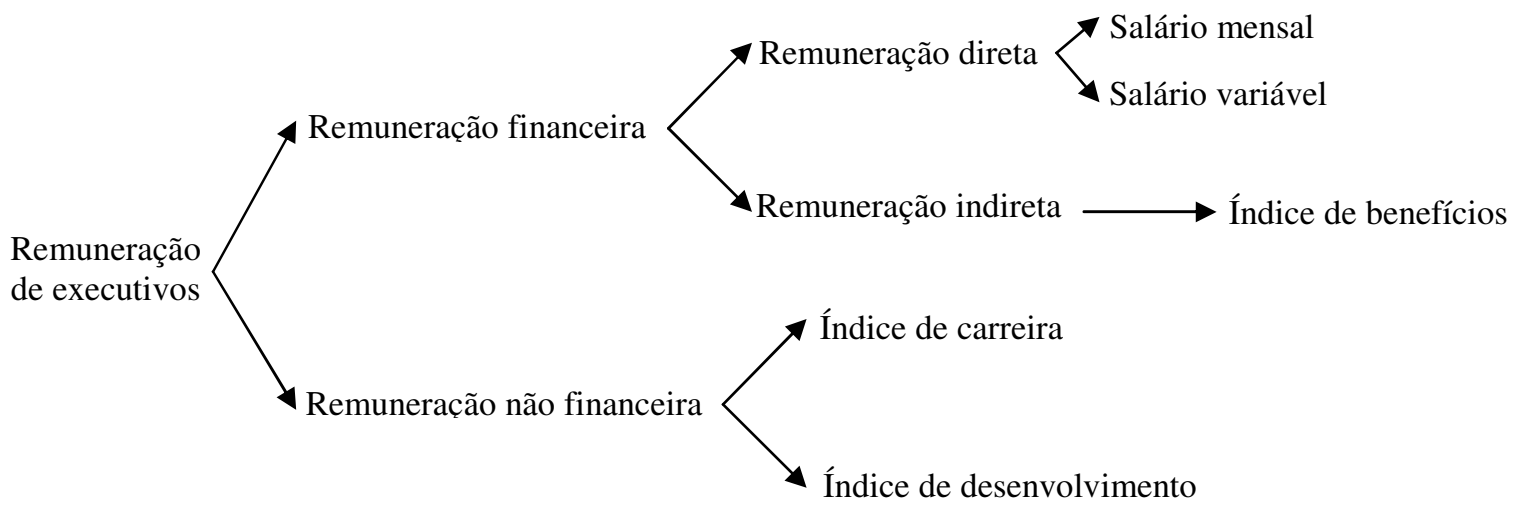

Figura 4 - Componentes da remuneração dos executivos FONTE: Elaborado pela autora.

\subsection{Operacionalização da variável desempenho financeiro}

Os três indicadores contábeis utilizados para operacionalizar a variável desempenho financeiro foram extraídos do banco de dados da FIPECAFI. A escolha desses indicadores levou em consideração os seguintes fatores:

a) Das 44 empresas da amostra, 36 trabalham com capital fechado. Desse modo, não poderiam ser utilizados indicadores de mercado.

b) Conforme mencionado na seção 2.1.1, o desempenho financeiro é um construto multidimensional. Portanto, requer a utilização de mais de um indicador para medir as diferentes dimensões do construto. Foram utilizados os indicadores financeiros: crescimento das vendas, retorno sobre patrimônio líquido e margem líquida sobre as vendas, que, de acordo com o referencial teórico, estão entre os indicadores contábeis mais utilizados em pesquisas empíricas. O crescimento das vendas, por exemplo, foi utilizado nas pesquisas de Paul e Anantharaman (2002; 2003); Terpstra e Rozell (1993). Já o retorno sobre patrimônio líquido (ROE) foi abordado nas pesquisas de Attaway (2000); Marín e Sánchez (2002-2003; 2005); Rajagopalan (1997); entre outros. A margem líquida sobre as vendas é uma das medidas mais utilizadas nas pesquisas empíricas, 
segundo Carton e Hofer (2006) e Lee et al (2003). Os indicadores utilizados neste trabalho dizem respeito aos anos de 2006 e 2007. A seguir, apresenta-se a maneira como a FIPECAFI calcula cada um desses indicadores.

O crescimento das vendas mostra a evolução da receita bruta de vendas em reais, descontada a inflação média, apontada pela variação do IGP-M. O indicador é expresso em porcentagem.

O retorno sobre patrimônio líquido resulta da divisão do lucro líquido, ajustado de acordo à inflação, pelo patrimônio líquido, que é atualizado pelos efeitos da inflação. O resultado é multiplicado por 100, para ser expresso em porcentagem.

A margem líquida sobre as vendas resulta da divisão do lucro líquido, ajustado conforme a inflação, pela receita de vendas, em reais, descontada a inflação. O resultado é expresso em porcentagem.

\subsection{Operacionalização da variável de controle}

A variável de controle é selecionada com base na possível influência que exerce sobre as variáveis dependentes e independentes. Se aquela de controle (que é independente) possuir uma forte correlação com alguma destas variáveis e for omitida do modelo, a relação entre as variáveis de interesse pode não ser evidenciada de maneira correta.

A literatura destaca que o porte da empresa é um fator relevante. Nesta tese, o porte da companhia é representado pelo número de funcionários em 2006 - a pesquisa de Terpstra e Rozell (1993) utilizou o número de empregados como variável de controle. Essa informação foi coletada no banco de dados do Progep. Devido à grande variação do número de colaboradores entre as empresas da amostra, optou-se pela transformação da variável. Assim, a pesquisa utiliza o logaritmo natural do número de funcionários para medir o porte das organizações da amostra. 
O setor de atuação é outra variável de controle muito utilizada nas pesquisas. No caso deste estudo, as empresas da amostra pertencem a 14 setores diferentes, e o número de companhias em cada área é pequeno. Assim, opta-se pela não utilização do setor como variável de controle.

O Quadro 2 apresenta as variáveis utilizadas nesta pesquisa.

Quadro 2 - Resumo das variáveis de pesquisa

\begin{tabular}{|l|l|}
\hline \multicolumn{1}{|c|}{ Nome da variável } & \multicolumn{1}{c|}{ Tipo de variável } \\
\hline Salário Mensal Médio & Variável independente \\
\hline Salário Variável Médio & Variável independente \\
\hline Índice de Benefícios & Variável independente \\
\hline Índice de Carreira & Variável independente \\
\hline Índice de Desenvolvimento & Variável independente \\
\hline Crescimento das Vendas - 2006 & Variável dependente \\
\hline Retorno sobre Patrimônio Líquido - 2006 & Variável dependente \\
\hline Margem Líquida sobre as Vendas - 2006 & Variável dependente \\
\hline Crescimento das Vendas - 2007 & Variável dependente \\
\hline Retorno sobre Patrimônio Líquido - 2007 & Variável dependente \\
\hline Margem Líquida sobre as Vendas - 2007 & Variável dependente \\
\hline Porte & Variável de controle \\
\hline
\end{tabular}

FONTE: Elaborado pela autora.

\subsection{Forma de tratamento dos dados}

Para a tabulação dos dados, é utilizado o programa estatístico Statistical Package for the Social Sciences (SPSS), - versão 16.0 for Windows.

A estatística descritiva é escolhida para organizar, resumir e apresentar os dados estatísticos (STEVENSON, 2001). Para as variáveis qualitativas, são apresentadas as frequências absolutas (n) e as frequências relativas (\%). Para as variáveis quantitativas, são apresentadas as medidas: média, mediana, desvio-padrão, valor mínimo e valor máximo. 
A relação entre a remuneração e o desempenho financeiro é investigada por meio de um conjunto de testes estatísticos:

- Teste de igualdade de médias;

- Análise de correlação;

- Análise de regressão linear simples;

- Análise de regressão linear múltipla.

O Capítulo 4 detalha o tratamento desses dados.

\subsection{Limitações da pesquisa}

a) Seleção da amostra

As empresas selecionadas para a amostra podem ser consideradas benchmarking em gestão de pessoas. Assim, a amostra pode não ser uma representação das companhias industriais em geral. Além disso, o fato de as organizações da amostra apresentarem relação harmoniosa entre capital e trabalho aumenta a possibilidade de comprovação da hipótese de pesquisa. Apesar dessas ressalvas, os resultados são relevantes para a discussão sobre a relação entre a remuneração dos executivos e o desempenho financeiro das empresas.

b) Relações de causalidade entre as variáveis

A presente pesquisa considera a remuneração dos executivos como variável independente e o desempenho financeiro das empresas como variável dependente. A idéia subjacente é que a remuneração induz os executivos a agirem de acordo com os interesses estratégicos da organização, levando esta a um desempenho superior. Apesar de a literatura suportar esta hipótese, existe a possibilidade de a relação ser outra: a empresa remunera melhor seus executivos em razão de apresentar desempenho financeiro superior. 
c) As definições operacionais das variáveis

As pesquisas anteriores que estudaram a relação entre a remuneração dos executivos e o desempenho financeiro das empresas utilizaram salário fixo mais salário variável (ou bônus) para operacionalizar a variável remuneração. Adotaram também um indicador contábil para medir o desempenho financeiro. Este estudo utiliza, além do salário fixo e do salário variável, três índices: benefícios, carreira e desenvolvimento. Estes foram criados a partir de informações coletadas no banco de dados do Progep, para operacionalizar a remuneração dos executivos. Além disso, inclui três indicadores contábeis, de dois exercícios sociais, para medir o desempenho financeiro. Como variável de controle, utiliza o logaritmo natural do número de funcionários.

As variáveis da pesquisa podem ser operacionalizadas de outras formas. Outros componentes do sistema de remuneração, como as stock options recebidas pelos executivos, poderiam ser considerados variável independente. Já variáveis de governança corporativa, como a quantidade de ações em poder dos executivos, poderiam ser utilizadas como variáveis de controle. O acesso a essas informações foi prejudicado pela pouca transparência das empresas.

d) Tamanho da amostra

A maior parte das 71 empresas industriais - selecionadas dentre as melhores para se trabalhar no Brasil, em 2007 - é de capital fechado. A não obrigatoriedade de divulgação das demonstrações financeiras, por parte dessas empresas, dificulta a obtenção dos dados financeiros. Os bancos de dados das publicações Gazeta Mercatil e Valor Econômico também foram consultados. Utilizou-se o banco de dados da FIPECAFI, porque este, quando comparado aos demais, apresenta informações de um número maior de empresas. Assim, a amostra é composta por 44 empresas. 
e) Utilização de informações contábeis

Os dados contábeis revelam, como dificuldade, serem passíveis de distorções. No entanto, carregam como pontos fortes: a) estarem disponíveis nas demonstrações financeiras; b) permitirem a comparação dos resultados das pesquisas.

f) Horizonte de análise

Os dados da variável dependente referem-se aos exercícios de 2006 e 2007. Os investimentos em pessoas podem demandar um prazo maior para apresentar resultados. Assim, o horizonte de análise de dois anos, utilizado na pesquisa, pode não ser suficiente para captar resultados e/ou tendências, os quais só seriam detectados dentro de um período mais longo. 


\section{TRATAMENTO DOS DADOS}

\subsection{Criação dos índices}

O banco de dados do Progep contém informações sobre os processos de gestão de pessoas de todas as empresas que participam da pesquisa que elege as melhores empresas para se trabalhar no Brasil. Os dados utilizados neste trabalho foram extraídos dos questionários respondidos pelas 44 empresas da amostra, armazenadas no banco de dados do Progep. Eles referem-se ao salário mensal médio, salário variável médio, benefícios, carreira, educação e desenvolvimento. Essas informações são de 2006 e provêm de diretores, vice-presidentes e presidentes.

Os dados sobre benefícios, carreira, educação e desenvolvimento foram agrupados em três índices - benefícios, carreira e desenvolvimento - criados especialmente para esta pesquisa. As próximas seções detalham a criação de cada um desses índices.

\subsection{1 Índice de benefícios}

O índice de benefícios mede o acesso dos executivos a 12 benefícios: assistência médica; consultórios médicos nas instalações da empresa; assistência odontológica; subsídio para a compra de medicamentos; atendimento psicológico; seguro de vida em grupo; subsídio para a formação educacional; subsídio para a especialização profissional; subsídio para o estudo de idiomas; suporte à educação dos filhos; subsídio para a aquisição de moradia; financiamentos e empréstimos.

No banco de dados, as informações sobre os benefícios oferecidos aos executivos estão classificadas segundo a abrangência em:

Não (= a empresa não oferece esse benefício a seus executivos)

Parte (= a empresa oferece esse benefício a parte de seus executivos)

Todos (= a empresa oferece esse benefício a todos os seus executivos) 
Para criar o índice de benefícios, foram atribuídos pontos de 0 a 2, como segue:

$$
\begin{aligned}
& \text { Não }=0 \text { ponto } \\
& \text { Parte }=1 \text { ponto } \\
& \text { Todos }=2 \text { pontos }
\end{aligned}
$$

Assim, atribuem-se 2 pontos para cada benefício oferecido pela empresa a todos os seus executivos; 1 ponto para cada benefício concedido à parte de seus executivos; 0 ponto para cada benefício não oferecido a seus executivos.

Os pontos foram somados, e o resultado corresponde ao índice de benefícios da organização. A pontuação varia de 0 a 24, isto é, a empresa que não oferece nenhum dos 12 benefícios a seus executivos tem índice igual a 0 ; a companhia que oferece os 12 benefícios a todos os seus executivos tem índice igual a 24.

O Quadro 3 apresenta os itens do questionário de pesquisa do Progep, referentes aos benefícios, além do critério adotado pela autora para criar o índice de benefícios. O Apêndice 1 apresenta o índice de cada organização. 
Quadro 3 - Criação do índice de benefícios

\begin{tabular}{|c|c|}
\hline Itens & Critério de pontuação \\
\hline 1. A empresa oferece assistência médica & $\begin{array}{l}\text { Não }-0 \\
\text { Parte }-1 \\
\text { Todos - } 2\end{array}$ \\
\hline $\begin{array}{l}\text { 2. A empresa dispõe de consultórios médicos em } \\
\text { suas instalações }\end{array}$ & $\begin{array}{l}\text { Não }-0 \\
\text { Parte }-1 \\
\text { Todos }-2\end{array}$ \\
\hline 3. A empresa oferece assistência odontológica & $\begin{array}{l}\text { Não }-0 \\
\text { Parte }-1 \\
\text { Todos }-2\end{array}$ \\
\hline $\begin{array}{l}\text { 4. A empresa oferece subsídio para compra de } \\
\text { medicamentos }\end{array}$ & $\begin{array}{l}\text { Não }-0 \\
\text { Parte }-1 \\
\text { Todos }-2\end{array}$ \\
\hline 5. A empresa oferece atendimento psicológico & $\begin{array}{l}\text { Não }-0 \\
\text { Parte }-1 \\
\text { Todos }-2\end{array}$ \\
\hline 6. A empresa oferece seguro de vida em grupo & $\begin{array}{l}\text { Não }-0 \\
\text { Parte }-1 \\
\text { Todos }-2\end{array}$ \\
\hline $\begin{array}{l}\text { 7. A empresa oferece subsídio para formação } \\
\text { educacional do executivo }\left(1^{\circ}, 2^{\circ} \text { ou } 3^{\circ} \text { grau }\right)\end{array}$ & $\begin{array}{l}\text { Não }-0 \\
\text { Parte }-1 \\
\text { Todos }-2\end{array}$ \\
\hline $\begin{array}{l}\text { 8. A empresa oferece subsídio para especialização } \\
\text { profissional }\end{array}$ & $\begin{array}{l}\text { Não }-0 \\
\text { Parte }-1 \\
\text { Todos }-2 \\
\end{array}$ \\
\hline $\begin{array}{l}\text { 9. A empresa oferece subsídio para estudo de } \\
\text { idiomas }\end{array}$ & $\begin{array}{l}\text { Não }-0 \\
\text { Parte }-1 \\
\text { Todos }-2 \\
\end{array}$ \\
\hline $\begin{array}{l}\text { 10. A empresa oferece suporte à educação dos } \\
\text { filhos dos executivos }\end{array}$ & $\begin{array}{l}\text { Não }-0 \\
\text { Parte }-1 \\
\text { Todos }-2 \\
\end{array}$ \\
\hline $\begin{array}{l}\text { 11. A empresa oferece acesso a subsídio para } \\
\text { aquisição de moradia }\end{array}$ & $\begin{array}{l}\text { Não }-0 \\
\text { Parte }-1 \\
\text { Todos }-2\end{array}$ \\
\hline $\begin{array}{l}\text { 12. A Empresa oferece acesso a financiamentos e } \\
\text { empréstimos }\end{array}$ & $\begin{array}{l}\text { Não }-0 \\
\text { Parte }-1 \\
\text { Todos }-2 \\
\end{array}$ \\
\hline
\end{tabular}

FONTE: Elaborado pela autora.

\subsection{2 Índice de carreira}

O índice de carreira mede o acesso dos executivos a 25 mecanismos de estímulo e suporte à carreira. Esses mecanismos estão divididos em: planejamento e acompanhamento do desenvolvimento profissional; estímulo e suporte para o planejamento de carreira; recolocação de executivos demitidos; recrutamento interno; informações sobre possibilidades de carreira; preparação para aposentadoria. 
No banco de dados, essas informações sobre os mecanismos de estímulo e suporte à carreira estão classificadas segundo a abrangência em:

$$
\begin{aligned}
& \text { Não (= a empresa não oferece esse mecanismo a seus executivos) } \\
& \text { Parte (= a empresa oferece esse mecanismo a parte de seus executivos) } \\
& \text { Todos (= a empresa oferece esse mecanismo a todos os seus executivos) }
\end{aligned}
$$

Para criar o índice de carreira, foram atribuídos pontos de 0 a 2, como segue:

$$
\begin{aligned}
& \text { Não }=0 \text { ponto } \\
& \text { Parte }=1 \text { ponto } \\
& \text { Todos }=2 \text { pontos }
\end{aligned}
$$

Assim, atribuem-se 2 pontos para cada mecanismo de estímulo e suporte à carreira oferecido pela empresa a todos os seus executivos; 1 ponto para cada mecanismo de estímulo e suporte à carreira concedido a parte de seus executivos; 0 ponto para cada mecanismo de estímulo e suporte à carreira não oferecido a seus executivos.

Os pontos foram somados, e o resultado corresponde ao índice de carreira. A pontuação do índice varia de 0 a 50. A empresa que não oferece nenhum dos 25 mecanismos de estímulo e suporte à carreira a seus executivos tem índice de carreira igual a 0. Já aquela que oferece os 25 mecanismos de estímulo e suporte a todos os seus executivos tem índice igual a 50.

O Quadro 4 apresenta os itens do questionário de pesquisa do Progep, referentes aos mecanismos de estímulo e suporte à carreira, além do critério de pontuação adotado pela autora para criar o índice de carreira. O Apêndice 2 apresenta o índice de carreira de cada companhia. 
Quadro 4 - Criação do índice de carreira

\begin{tabular}{|c|c|}
\hline Itens & Critério de pontuação \\
\hline $\begin{array}{l}\text { - Processo formal de planejamento e } \\
\text { acompanhamento do desenvolvimento profissional } \\
\text { dos executivos }\end{array}$ & \\
\hline $\begin{array}{l}\text { 1. O processo é realizado regularmente, pelo } \\
\text { menos, uma vez por ano }\end{array}$ & $\begin{array}{l}\text { Não }-0 \\
\text { Parte }-1 \\
\text { Todos }-2\end{array}$ \\
\hline $\begin{array}{l}\text { 2. Como resultado do processo de avaliação, é } \\
\text { estabelecido um plano de desenvolvimento }\end{array}$ & $\begin{array}{l}\text { Não }-0 \\
\text { Parte }-1 \\
\text { Todos }-2\end{array}$ \\
\hline $\begin{array}{l}\text { 3. O processo envolve estabelecimento e } \\
\text { acompanhamento de objetivos e metas de } \\
\text { performance }\end{array}$ & $\begin{array}{l}\text { Não }-0 \\
\text { Parte }-1 \\
\text { Todos }-2 \\
\end{array}$ \\
\hline $\begin{array}{l}\text { 4. O processo envolve a avaliação do } \\
\text { desenvolvimento de competências }\end{array}$ & $\begin{array}{l}\text { Não }-0 \\
\text { Parte }-1 \\
\text { Todos }-2 \\
\end{array}$ \\
\hline $\begin{array}{l}\text { - Mecanismos formais para estimular e oferecer } \\
\text { suporte, com a finalidade de que o executivo } \\
\text { planeje sua carreira }\end{array}$ & \\
\hline $\begin{array}{l}\text { 5. Há cursos ou eventos para planejamento de } \\
\text { carreira }\end{array}$ & $\begin{array}{l}\text { Não }-0 \\
\text { Parte }-1 \\
\text { Todos }-2 \\
\end{array}$ \\
\hline $\begin{array}{l}\text { 6. Há biblioteca, manuais ou software para } \\
\text { planejamento de carreira }\end{array}$ & $\begin{array}{l}\text { Não }-0 \\
\text { Parte }-1 \\
\text { Todos }-2\end{array}$ \\
\hline $\begin{array}{l}\text { 7. Há aconselhamento de carreira por meio de } \\
\text { reuniões estruturadas com a chefia imediata ou } \\
\text { pessoas designadas pela empresa }\end{array}$ & $\begin{array}{l}\text { Não }-0 \\
\text { Parte }-1 \\
\text { Todos }-2\end{array}$ \\
\hline $\begin{array}{l}\text { 8. Há grupos de executivos assistidos por } \\
\text { profissionais da empresa ou especialmente } \\
\text { contratados para efetuar aconselhamento de } \\
\text { carreira }\end{array}$ & $\begin{array}{l}\text { Não }-0 \\
\text { Parte }-1 \\
\text { Todos }-2\end{array}$ \\
\hline 9. Há adoção da prática de counselling & $\begin{array}{l}\text { Não }-0 \\
\text { Parte }-1 \\
\text { Todos }-2\end{array}$ \\
\hline 10. Há adoção da prática de coaching & $\begin{array}{l}\text { Não }-0 \\
\text { Parte }-1 \\
\text { Todos }-2 \\
\end{array}$ \\
\hline 11. Há adoção da prática de mentoring & $\begin{array}{l}\text { Não }-0 \\
\text { Parte }-1 \\
\text { Todos }-2\end{array}$ \\
\hline $\begin{array}{l}\text { - Política de recolocação para os executivos } \\
\text { demitidos }\end{array}$ & \\
\hline $\begin{array}{l}\text { 12. A política de recolocação de demitidos é } \\
\text { aplicada aos executivos }\end{array}$ & $\begin{array}{l}\text { Não }-0 \\
\text { Parte }-1 \\
\text { Todos }-2\end{array}$ \\
\hline $\begin{array}{l}\text { 13. A empresa acompanha sistematicamente o } \\
\text { processo de recolocação de executivos demitidos }\end{array}$ & $\begin{array}{l}\text { Não }-0 \\
\text { Parte }-1 \\
\text { Todos }-2\end{array}$ \\
\hline - Programa formal de recrutamento interno & \\
\hline $\begin{array}{l}\text { 14. O programa de recrutamento interno é } \\
\text { oferecido aos executivos }\end{array}$ & $\begin{array}{l}\text { Não }-0 \\
\text { Parte }-1 \\
\text { Todos }-2 \\
\end{array}$ \\
\hline
\end{tabular}




\begin{tabular}{|c|c|}
\hline Itens & Critério de pontuação \\
\hline $\begin{array}{l}\text { 15. Os executivos participam do processo de } \\
\text { definição dos critérios de ascensão na carreira }\end{array}$ & $\begin{array}{l}\text { Não }-0 \\
\text { Parte }-1 \\
\text { Todos }-2\end{array}$ \\
\hline \multicolumn{2}{|l|}{$\begin{array}{l}\text { - Mecanismos formais para que os executivos } \\
\text { estejam informados sobre as suas possibilidades de } \\
\text { carreira }\end{array}$} \\
\hline $\begin{array}{l}\text { 16. O plano de carreira é estruturado, formalizado } \\
\text { e praticado }\end{array}$ & $\begin{array}{l}\text { Não }-0 \\
\text { Parte }-1 \\
\text { Todos }-2\end{array}$ \\
\hline $\begin{array}{l}\text { 17. Há informações completas sobre os processos } \\
\text { de carreira nos murais e/ou Intranet }\end{array}$ & $\begin{array}{l}\text { Não }-0 \\
\text { Parte }-1 \\
\text { Todos }-2\end{array}$ \\
\hline $\begin{array}{l}\text { 18. Os requisitos de acesso às posições previstas } \\
\text { no plano de carreira são conhecidos pelos } \\
\text { executivos }\end{array}$ & $\begin{array}{l}\text { Não }-0 \\
\text { Parte }-1 \\
\text { Todos }-2\end{array}$ \\
\hline $\begin{array}{l}\text { 19. As mudanças nos processos de carreira são } \\
\text { comunicadas, pelo menos, uma vez ao ano }\end{array}$ & $\begin{array}{l}\text { Não }-0 \\
\text { Parte }-1 \\
\text { Todos }-2\end{array}$ \\
\hline \multicolumn{2}{|l|}{ - Programa de preparação para aposentadoria } \\
\hline $\begin{array}{l}\text { 20. A empresa adota programa de preparação para } \\
\text { aposentadoria }\end{array}$ & $\begin{array}{l}\text { Não }-0 \\
\text { Parte }-1 \\
\text { Todos }-2 \\
\end{array}$ \\
\hline 21. A preparação envolve aspectos financeiros & $\begin{array}{l}\text { Não }-0 \\
\text { Parte }-1 \\
\text { Todos }-2\end{array}$ \\
\hline $\begin{array}{l}\text { 22. A preparação envolve transição de carreira } \\
\text { para outras atividades após o processo de } \\
\text { aposentadoria }\end{array}$ & $\begin{array}{l}\text { Não }-0 \\
\text { Parte }-1 \\
\text { Todos }-2 \\
\end{array}$ \\
\hline $\begin{array}{l}\text { 23. A preparação envolve assistência psicológica à } \\
\text { pessoa a ser aposentada }\end{array}$ & $\begin{array}{l}\text { Não }-0 \\
\text { Parte }-1 \\
\text { Todos }-2 \\
\end{array}$ \\
\hline $\begin{array}{l}\text { 24. A preparação envolve a família da pessoa a ser } \\
\text { aposentada }\end{array}$ & $\begin{array}{l}\text { Não }-0 \\
\text { Parte }-1 \\
\text { Todos }-2\end{array}$ \\
\hline $\begin{array}{l}\text { 25. A empresa mantém programa de } \\
\text { relacionamento e/ou contato com os aposentados }\end{array}$ & $\begin{array}{l}\text { Não }-0 \\
\text { Parte }-1 \\
\text { Todos }-2 \\
\end{array}$ \\
\hline
\end{tabular}

FONTE: Elaborado pela autora.

\subsection{3 Índice de desenvolvimento}

O índice de desenvolvimento mede o acesso dos executivos a 8 mecanismos de estímulo à educação e ao desenvolvimento profissional: programas educacionais que incorporam a identificação das competências críticas empresariais e humanas; compartilhamento de conhecimentos e troca de experiências; múltiplas formas de aprendizagem; programas que reflitam o compromisso da empresa com a cidadania empresarial; programas disseminadores 
da cultura organizacional; gerentes e líderes envolvidos com o processo de aprendizagem; sistemas eficazes de avaliação dos investimentos em educação e dos resultados obtidos; parcerias com instituições de ensino superior.

No banco de dados, essas informações sobre os mecanismos de estímulo à educação e ao desenvolvimento profissional estão classificadas, segundo a abrangência em:

Não (= a empresa não oferece esse mecanismo a seus executivos)

Parte (= a empresa oferece esse mecanismo a parte de seus executivos)

Todos (= a empresa oferece esse mecanismo a todos os seus executivos)

Para criar o índice de desenvolvimento, foram atribuídos pontos de 0 a 2, como segue:

$$
\begin{aligned}
& \text { Não }=0 \text { ponto } \\
& \text { Parte }=1 \text { ponto } \\
& \text { Todos }=2 \text { pontos }
\end{aligned}
$$

Assim, atribuem-se 2 pontos para cada mecanismo de estímulo à educação e ao desenvolvimento profissional oferecido pela empresa a todos os seus executivos; 1 ponto para cada mecanismo oferecido a parte de seus executivos; 0 ponto para cada mecanismo não oferecido a seus executivos.

Os pontos foram somados, e o resultado corresponde ao índice de desenvolvimento. A pontuação do índice varia de 0 a 16. A companhia que não oferece nenhum dos 8 mecanismos de estímulo à educação e ao desenvolvimento profissional a seus executivos tem índice de desenvolvimento igual a 0 . Já aquela que oferece os 8 mecanismos a todos os seus executivos tem índice de desenvolvimento igual a 16.

O Quadro 5 apresenta os itens do questionário de pesquisa do Progep, referentes aos mecanismos de estímulo à educação e ao desempenho profissional, além do critério de pontuação adotado pela autora para criar o índice de desenvolvimento. O Apêndice 3 apresenta o índice de desenvolvimento de cada companhia. 
Quadro 5 - Criação do índice de desenvolvimento

\begin{tabular}{|c|c|}
\hline Itens & Critério de pontuação \\
\hline $\begin{array}{l}\text { - Modelo de educação corporativa para apoiar o } \\
\text { desenvolvimento pessoal e profissional dos } \\
\text { executivos }\end{array}$ & \\
\hline $\begin{array}{l}\text { 1. As ações e programas educacionais são } \\
\text { concebidos com base na identificação das } \\
\text { competências críticas (empresariais e humanas) }\end{array}$ & $\begin{array}{l}\text { Não }-0 \\
\text { Parte }-1 \\
\text { Todos }-2 \\
\end{array}$ \\
\hline $\begin{array}{l}\text { 2. Há sistemas formais de gestão voltados para o } \\
\text { estímulo ao compartilhamento de conhecimentos e } \\
\text { à troca de experiências }\end{array}$ & $\begin{array}{l}\text { Não }-0 \\
\text { Parte }-1 \\
\text { Todos }-2\end{array}$ \\
\hline $\begin{array}{l}\text { 3. Há intensiva utilização de tecnologia aplicada à } \\
\text { educação }\end{array}$ & $\begin{array}{l}\text { Não }-0 \\
\text { Parte }-1 \\
\text { Todos }-2\end{array}$ \\
\hline $\begin{array}{l}\text { 4. Os programas reforçam o compromisso da } \\
\text { empresa com a cidadania empresarial }\end{array}$ & $\begin{array}{l}\text { Não }-0 \\
\text { Parte }-1 \\
\text { Todos }-2 \\
\end{array}$ \\
\hline $\begin{array}{l}\text { 5. Os programas são voltados ao fortalecimento e à } \\
\text { disseminação da cultura organizacional }\end{array}$ & $\begin{array}{l}\text { Não }-0 \\
\text { Parte }-1 \\
\text { Todos }-2\end{array}$ \\
\hline $\begin{array}{l}\text { 6. Os líderes e gestores responsabilizam-se pelo } \\
\text { processo de aprendizagem }\end{array}$ & $\begin{array}{l}\text { Não }-0 \\
\text { Parte }-1 \\
\text { Todos }-2 \\
\end{array}$ \\
\hline $\begin{array}{l}\text { 7. Na avaliação dos resultados dos investimentos } \\
\text { em educação, são considerados os objetivos do } \\
\text { negócio }\end{array}$ & $\begin{array}{l}\text { Não }-0 \\
\text { Parte }-1 \\
\text { Todos }-2\end{array}$ \\
\hline $\begin{array}{l}\text { 8. Há formação de parcerias com instituições de } \\
\text { ensino superior }\end{array}$ & $\begin{array}{l}\text { Não }-0 \\
\text { Parte }-1 \\
\text { Todos }-2 \\
\end{array}$ \\
\hline
\end{tabular}

FONTE: Elaborado pela autora

\subsection{Teste de igualdade de médias}

O teste $t$ para duas amostras independentes é utilizado quando se pretende comparar as médias de uma variável quantitativa em dois grupos diferentes de sujeitos (casos) e não se conhece as respectivas variâncias populacionais. $\mathrm{O}$ teste $t$ para amostras de dimensão inferior ou igual a 30 exige que os grupos em análise tenham distribuição normal (PESTANA; GAGEIRO, 2000).

O teste não-paramétrico de Mann-Whitney é uma alternativa ao teste $t$ para duas amostras independentes quando a amostra for pequena e/ou quando a hipótese de normalidade for violada (FÁVERO et al, 2009). 
O teste de Mann-Whitney é utilizado para verificar se dois grupos independentes foram extraídos de populações com médias iguais (BRUNI, 2007). É considerado um dos testes nãoparamétricos mais poderosos (SIEGEL; CASTELLAN, 2006, p. 153).

Segundo Fávero et al (2009, p. 163), a única exigência do teste é que "a variável deve ser medida em escala ordinal ou quantitativa". As hipóteses do teste de Mann-Whitney são (PESTANA; GAGEIRO, 2000):

$\mathrm{H}_{0}$ : as duas populações são iguais em tendência central

$\mathrm{H}_{1}$ : as duas populações não são iguais em tendência central

Esta pesquisa utilizou a mediana das variáveis de remuneração para dividir as 44 empresas da amostra em dois grupos: "baixo" e "alto". O grupo denominado "baixo" apresenta valores abaixo da mediana de: salário mensal médio, salário variável médio, índice de benefícios, índice de carreira e índice de desenvolvimento. O grupo denominado "alto" apresenta valores acima da mediana.

O teste de igualdade de médias foi aplicado para verificar se existe diferença no desempenho financeiro médio - medido pelos indicadores: crescimento das vendas, retorno sobre patrimônio líquido, margem líquida sobre as vendas, dos exercícios de 2006 e de 2007 - nos dois grupos: "baixo" e "alto".

A expectativa é que as diferenças entre as médias observadas nos dois grupos sejam significantes. Espera-se também que as médias no grupo "alto" apresentem valores superiores às médias no grupo "baixo". 


\subsection{Análise de correlação}

\subsubsection{Coeficiente de correlação de Pearson}

O coeficiente de correlação de Pearson é uma medida de associação linear entre duas variáveis, $\mathrm{x}$ e $\mathrm{y}$, e varia entre -1 e +1 . Valores próximos de -1 ou de +1 indicam uma forte associação linear. $\mathrm{O}$ valor -1 corresponde a uma perfeita relação linear negativa entre x e y, isto é, aumentos de uma variável estão associados a diminuições da outra variável. $\mathrm{O}$ valor +1 corresponde a uma perfeita relação linear positiva entre x e y, ou seja, a oscilação entre as variáveis tem o mesmo sentido. $\mathrm{O}$ valor 0 indica uma relação não linear entre $\mathrm{x}$ e y (ANDERSON et al, 2003; PESTANA; GAGEIRO, 2000).

O coeficiente de correlação de Pearson assume que os dados provêm de duas populações normais (ANDERSON et al, 2003). As hipóteses do teste são (HAIR et al, 2005b):

$\mathrm{H}_{0}$ : não há nenhuma associação entre duas variáveis

$\mathrm{H}_{1}$ : existe associação entre duas variáveis

O coeficiente de correlação é uma medida simétrica de associação. Assim, a correlação entre $\mathrm{x}$ e y é a mesma que entre y e x. O fato de existir uma relação entre duas variáveis não pressupõe uma relação de causalidade entre elas (ANDERSON et al, 2003).

\subsubsection{Coeficiente de correlação de Spearman}

O coeficiente de correlação de Spearman mede a intensidade da relação entre duas variáveis ordinais e é utilizado como alternativa ao coeficiente de correlação de Pearson. É considerada uma estatística mais conservadora, não exigindo que os dados provenham de duas populações normais (HAIR et al, 2005b; PESTANA; GAGEIRO, 2000). 
$\mathrm{O}$ coeficiente varia entre -1 e +1 . Quanto mais próximo estiver destes extremos, maior será a associação linear entre as variáveis. O sinal negativo da correlação significa que as variáveis variam em sentido contrário.

As hipóteses do teste são (HAIR et al, 2005b):

$\mathrm{H}_{0}$ : não existe diferença no ranqueamento dos dois fatores

$\mathrm{H}_{1}$ : existe diferença no ranqueamento dos dois fatores

Espera-se que os coeficientes de correlação de Pearson e de Spearman entre as variáveis de remuneração e as variáveis de desempenho financeiro sejam positivos e significantes.

\subsection{Análise de regressão}

A análise de regressão é uma técnica de dependência usada para estimar e/ou prever o comportamento de uma variável dependente métrica a partir de uma ou mais variáveis independentes (FÁVERO et al, 2009; GUJARATI, 2006; PESTANA; GAGEIRO, 2000). O modelo é chamado de "regressão linear simples" quando existe apenas uma variável independente; ou de "regressão linear múltipla" quando há mais do que uma variável independente.

Para testar a hipótese da pesquisa de que existe relação positiva e significante entre a remuneração dos executivos e o desempenho financeiro das empresas, aplica-se a análise de regressão linear. Essa técnica foi utilizada na maioria dos trabalhos anteriores que estudaram a relação entre remuneração e desempenho das empresas, como as pesquisas desenvolvidas por Attaway (2000); Ozkan (2007). Inicialmente, adota-se a análise de regressão linear simples para todos os pares de variáveis dependentes e independentes, com o objetivo de avaliar preliminarmente a relação entre as variáveis de desempenho financeiro e de remuneração. Em seguida, adota-se a análise de regressão múltipla entre as variáveis de desempenho financeiro, usadas alternadamente, e as de remuneração, usadas conjuntamente. 


\subsubsection{Regressão linear simples}

"O modelo de regressão linear simples analisa a relação entre duas variáveis de natureza quantitativa $x$ e $y$, cuja tendência é aproximadamente representada por uma linha reta" (PESTANA; GAGEIRO, 2000, p. 447).

O objetivo principal da análise de regressão é estimar a função de regressão populacional com base na função de regressão amostral (GUJARATI, 2006). A função de regressão populacional de duas variáveis pode ser expressa por (ANDERSON et al, 2003; GUJARATI, 2006; STOCK; WATSON, 2004):

$$
Y_{i}=\beta_{0}+\beta_{1} X_{i}+\mu_{i}
$$

Onde:

O subscrito $i$ representa o número de observações, $i=1, \ldots, \mathrm{n}$

$Y_{i}$ é a variável dependente

$X_{i}$ é a variável independente

$\beta_{0}+\beta_{1} \mathrm{X}$ é a reta de regressão da população

$\beta_{0}$ é o intercepto da reta de regressão da população

$\beta_{1}$ é a declividade da reta de regressão da população

$\mu_{i}$ é o termo de erro; mede a variabilidade em Y que não pode ser explicada pela relação linear entre $\mathrm{X}$ e $\mathrm{Y}$

A função de regressão amostral pode ser expressa por (GUJARATI, 2006; STOCK; WATSON, 2004):

$$
\begin{gathered}
\hat{Y}_{i}=\hat{\beta}_{0}+\hat{\beta}_{1} X_{i} \\
\hat{\mu}_{i}=Y_{i}-\hat{Y}_{i}
\end{gathered}
$$


Onde:

$\hat{Y}_{i}$ é o valor estimado de $Y_{i}$

$\hat{\beta}_{0}$ é o estimador de $\beta_{0}$

$\hat{\beta}_{1}$ é o estimador de $\beta_{1}$

$\hat{\mu}_{i}$ é a diferença entre $Y_{i}$ e seu valor previsto, isto é, $\hat{\mu}_{i}=Y_{i}-Y_{i}$

$i=1, \ldots, \mathrm{n}$

O método dos mínimos quadrados (MQO) estima os parâmetros, de modo a minimizar a soma dos quadrados dos erros. Os estimadores de MQO da declividade $\beta_{1}$ e do intercepto $\beta_{\mathrm{o}}$ são (STOCK; WATSON, 2004):

$$
\begin{gathered}
\hat{\beta}_{1}=\frac{s_{x y}}{s_{X}^{2}} \\
\hat{\beta}_{0}=\bar{Y}-\hat{\beta}_{1} \bar{X}
\end{gathered}
$$

Onde:

$$
\begin{aligned}
& s_{x y} \text { é a covariância } \\
& s_{x}^{2} \text { é a variância } \\
& \bar{Y}_{\text {é a média da variável Y }} \\
& \bar{X} \text { é a média da variável X }
\end{aligned}
$$

O coeficiente de determinação (R-quadrado) e o erro-padrão da regressão são dois indicadores para medir a qualidade do ajustamento de uma linha de regressão. O R-quadrado mede o percentual da variação total de Y explicada pelo modelo de regressão. Seu valor situa-se entre 0 e 1. Quanto mais próximo de 1, melhor o ajustamento. Já o erro-padrão é o desvio-padrão dos valores de Y em relação à linha de regressão estimada (GUJARATI, 2006).

Segundo Anderson et al (2003), o modelo de regressão linear simples requer a verificação das seguintes suposições: 
1. O termo $\mu$ é uma variável aleatória com um valor médio ou esperado de zero.

2. A variância de $\mu$ é a mesma para todos os valores de $\mathrm{x}$.

3. Os valores de $\mu$ são independentes.

4. O termo $\mu$ é uma variável aleatória normalmente distribuída.

Os testes utilizados para verificar esses pressupostos estão descritos na seção 4.4.3. O modelo geral de regressão linear simples utilizado na pesquisa é apresentado na seção 4.4.4.

\subsubsection{Regressão linear múltipla}

O modelo de regressão linear múltipla analisa a relação entre uma variável dependente e duas ou mais variáveis independentes. O modelo pode ser expresso por (FÁVERO et al, 2009; STOCK; WATSON, 2004):

$$
Y_{i}=\beta_{0}+\beta_{1} X_{1 i}+\beta_{2} X_{2 i}+\cdots+\beta_{k} X_{k i}+\mu_{i}
$$

Onde:

O subscrito $i$ representa o número de observações, $i=1, \ldots, \mathrm{n}$

$Y_{i}$ é a variável dependente

$X_{1 i}, X_{z i, \ldots,} X_{k i}$ são as variáveis independentes

$\beta_{0}$ é o intercepto da reta

$\beta_{0}, \beta_{1} \ldots \beta_{k}$ são os coeficientes de cada variável

$\mu_{i}$ é o termo de erro, também conhecido como resíduo

O método dos mínimos quadrados (MQO) também é utilizado para estimar os coeficientes no modelo de regressão múltipla. Os estimadores dos coeficientes $\beta_{0} \beta_{1, \ldots} \beta_{k}$ que minimizam a soma dos quadrados dos erros são representados por $\hat{\beta}_{0}, \hat{\beta}_{1}, \ldots, \hat{\beta}_{k}$ (STOCK; WATSON, 2004). Assim (STOCK; WATSON, 2004): 


$$
\begin{gathered}
\hat{Y_{i}}=\hat{\beta}_{0}+\hat{\beta}_{1} X_{1 i}+\hat{\beta}_{2} X_{2 i}+\cdots+\hat{\beta}_{k} X_{k i} \\
\hat{\mu}_{i}=Y_{i}-\hat{Y}_{i}
\end{gathered}
$$

Onde:

$i=1, \ldots, \mathrm{n}$

$\hat{Y}_{i}$ é o valor previsto de $\mathrm{Y}_{\mathrm{i}}$

$\hat{\beta}_{0}, \hat{\beta}_{1}, \ldots, \hat{\beta}_{k}$ são os estimadores de $\beta_{0}, \beta_{1}, \ldots \beta_{k}$

$\hat{\mu}_{i}$ é o resíduo de MQO para a $i$-ésima observação

O erro-padrão da regressão é "uma medida de dispersão da distribuição de Y em torno da reta" (STOCK; WATSON, 2004, p. 118). Quanto menor o erro-padrão, melhor o modelo estimado (CORRAR et al, 2007). O coeficiente de determinação R-quadrado é "a fração da variância da amostra de $Y_{i}$ explicada (ou prevista) pelos regressores" (STOCK; WATSON, 2004, p. 119). O R-quadrado ajustado (coeficiente de determinação ajustado) é uma medida modificada do R-quadrado "que considera o número de variáveis independentes incluídas no modelo e o tamanho da amostra" (CORRAR et al, 2007, p. 150).

Segundo Corrar et al (2007), as suposições do modelo de regressão linear múltipla são:

1. Normalidade dos resíduos;

2. Homoscedasticidade dos resíduos;

3. Linearidade dos coeficientes;

4. Ausência de autocorrelação serial nos resíduos;

5. Multicolinearidade entre as variáveis independentes.

Os testes utilizados para análise desses pressupostos estão descritos na seção 4.4.3. O modelo geral de regressão linear múltipla utilizado nesta pesquisa está descrito na seção 4.4.4. 


\subsubsection{Pressupostos na análise de regressão}

A avaliação dos pressupostos garante a integridade dos testes de ajustamento e de significância da análise de regressão (FÁ́VERO et al, 2009). Essa avaliação é feita com a análise dos resíduos. Os testes aqui utilizados para análise desses pressupostos são:

- Normalidade dos resíduos: "o conjunto dos resíduos produzidos em todo o intervalo das observações deve apresentar distribuição normal” (HAIR et al, 2005a, p. 152). O diagnóstico da normalidade dos resíduos é feito pelo teste Kolmogorov-Smirnov. Se pvalor $>\alpha$, aceita-se a hipótese nula, a distribuição tem comportamento normal (CORRAR et al, 2007).

- Homoscedasticidade dos resíduos: “o conjunto de resíduos referentes a cada observação de $\mathrm{X}$ deve ter variância constante ou homogênea em toda a extensão das variáveis independentes" (HAIR et al, 2005a, p. 152). O diagnóstico da homoscedasticidade é feito por meio do teste Pesarán-Pesarán. Esse teste regride o quadrado dos resíduos padronizados $(\text { Zre_1 })^{2}$ como função do quadrado dos valores estimados padronizados $\left(Z p r \_1\right)^{2}$. Se, na regressão, o coeficiente de $\left(Z p r \_1\right)^{2}$ não se mostrar estatisticamente significante, os resíduos são homoscedásticos (CORRAR et al, 2007).

- Linearidade: o diagnóstico da linearidade é feito com os diagramas de dispersão.

- Ausência de autocorrelação serial: "os resíduos são independentes entre si e só se observa o efeito de X sobre Y” (HAIR et al, 2005a, p. 154). O diagnóstico da ausência de autocorrelação serial é feito pelo teste Durbin-Watson. Para atender ao pressuposto, seu resultado deve ficar próximo de 2 (CORRAR et al, 2007).

- Multicolinearidade: é o exame de correlação existente entre as diversas variáveis independentes. O diagnóstico de multicolinearidade é feito pela medida VIF - Variance Inflation Factor / Fator de Inflação da Variância (CORRAR et al, 2007; HAIR et al, 2005a). Um valor de referência comum é um VIF menor ou igual a 10. Valores acima desse índice indicam multicolinearidade entre as variáveis independentes. 


\subsubsection{Modelos de regressão linear utilizados na pesquisa}

O modelo de regressão linear simples utilizado na pesquisa foi:

$$
\mathrm{DF}_{\mathrm{i}}=\beta_{0}+\beta_{1} \text { remuneração }_{\mathrm{i}}+\mu_{\mathrm{i}}
$$

Onde:

$i$ representa a $i$-ésima empresa;

DF representa as variáveis de desempenho financeiro utilizadas alternadamente: cven06, roe06, mven06, cven07, roe 07 , mven07;

remuneração representa as variáveis de remuneração utilizadas alternadamente: salmen, salvar, ibenef, icarr, idesen;

$\mu$ representa o termo de erro.

Já o modelo de regressão linear múltipla utilizado na pesquisa foi:

$$
\mathrm{DF}_{\mathrm{i}}=\beta_{0}+\beta_{1} \text { salmen }_{\mathrm{i}}+\beta_{2} \text { salvar }_{\mathrm{i}}+\beta_{3} \text { ibenef }_{\mathrm{i}}+\beta_{4} \text { icarr }_{\mathrm{i}}+\beta_{5} \text { idesen }_{\mathrm{i}}+\beta_{6} \text { porte }_{\mathrm{i}}+\mu_{\mathrm{i}}
$$

Onde:

$i$ representa a $i$-ésima empresa;

DF representa as variáveis de desempenho financeiro utilizadas alternadamente: cven06, roe 06 , mven06, cven 07 , roe 07 , mven07;

salmen = salário mensal médio;

salvar = salário variável médio;

ibenef = índice de benefícios;

icarr = índice de carreira;

idesen = índice de desenvolvimento;

porte - variável de controle $=$ logaritmo natural do número de funcionários;

$\mu=$ termo de erro. 
Os resultados encontrados nas pesquisas anteriores que estudaram a relação entre a remuneração dos executivos e o desempenho financeiro das empresas não foram conclusivos (BÁLKIN; GÓMEZ-MEJIA, 1987; BARKEMA; GÓMEZ-MEJIA, 1998). Algumas encontraram relações fracas; outras observaram relações não significantes entre as variáveis (BARKEMA; GÓMEZ-MEJIA, 1998).

A presente pesquisa aplica um conceito mais amplo de remuneração, pois considera não somente a remuneração financeira (salário mensal, salário variável e benefícios), mas também a não financeira (medida pelos índices de carreira e de desenvolvimento) como variável independente. Adicionalmente, como variável dependente, utiliza três indicadores contábeis de dois exercícios sociais. Considerando este cenário, espera-se que o modelo de regressão múltipla utilizado neste estudo seja estatisticamente significante, ou seja, mostre-se adequado para descrever a relação entre a remuneração dos executivos e o desempenho financeiro das empresas. Além disso, a expectativa é de que os coeficientes sejam significantes e maiores do que zero. Esse raciocínio estaria de acordo à teoria de que o sistema de remuneração é um instrumento eficiente para alinhar os interesses de acionistas e executivos e, quando bem estruturado, pode levar a empresa a atingir um desempenho financeiro superior. 


\section{ANÁLISE DOS RESULTADOS DA PESQUISA}

\subsection{Análise descritiva}

Em 2006, as 44 empresas industriais da amostra empregavam um total de 140.566 funcionários e foram responsáveis por um faturamento bruto de $\mathrm{R} \$ 246,7$ bilhões, cerca de $11 \%$ do PIB brasileiro do ano.

Segundo o critério adotado pelo Progep para classificar as organizações quanto ao porte (Quadro 6), das 44 pesquisadas da amostra, 9 (20,5\%) são de pequeno porte, 14 (31,8\%) são de médio porte e $21(47,7 \%)$ são de grande porte.

Quadro 6 - Critério do Progep para classificar as empresas quanto ao porte

\begin{tabular}{|l|l|}
\hline \multicolumn{1}{|c|}{ Número de funcionários } & \multicolumn{1}{c|}{ Porte da empresa } \\
\hline De 100 a 500 funcionários & Pequeno porte \\
\hline De 501 a 1500 funcionários & Médio porte \\
\hline Acima de 1500 funcionários & Grande porte \\
\hline FONTE: Elaborado pela autora &
\end{tabular}

As organizações pertencem a 14 setores diferentes, conforme mostrado na Tabela 1. Os três setores com maior número de empresas são: Químico e Petroquímico, com 22,7\%; Energia, com 15,9\%; Eletroeletrônico, com 11,4\%. 
Tabela 1 - Setor de atuação das empresas da amostra

\begin{tabular}{lcc}
\hline \multicolumn{1}{c}{ Setor de atuação } & n & \% \\
\hline Química e Petroquímica & 10 & 22,7 \\
Energia & 7 & 15,9 \\
Siderurgia e Metalurgia & 4 & 9,1 \\
Construção & 2 & 4,5 \\
Bens de consumo & 4 & 9,1 \\
Farmacêutico & 2 & 4,5 \\
Papel e Celulose & 1 & 2,3 \\
Eletroeletrônico & 5 & 11,4 \\
Auto-Indústria & 3 & 6,8 \\
Indústria Digital & 1 & 2,3 \\
Plástico & 1 & 2,3 \\
Confecções e Têxtil & 1 & 2,3 \\
Bens de Capital & 2 & 4,5 \\
Indústria Moveleira & 1 & 2,3 \\
Total & 44 & 100,0 \\
\hline
\end{tabular}

FONTE: Elaborado pela autora.

A análise descritiva das informações sobre benefícios, carreira, educação e desenvolvimento, coletadas no banco de dados do Progep, é apresentada a seguir. As tabelas indicam as frequências absolutas (n) e as frequências relativas (\%). Como já mencionado, essas informações estavam classificadas, no banco de dados, segundo a abrangência, em:

$$
\begin{aligned}
& \text { Não (= a empresa não oferece o item aos executivos) } \\
& \text { Parte (= a empresa oferece o item a parte dos executivos) } \\
& \text { Todos (= a empresa oferece o item a todos os executivos) }
\end{aligned}
$$

A Tabela 2 apresenta a oferta e a abrangência dos 12 benefícios. A assistência médica é oferecida por todas as empresas a todos os executivos. Trinta e uma delas disponibilizam, em suas instalações, consultório médico a todos os executivos. Já a assistência odontológica é ofertada a todos os executivos por $88,6 \%$ das organizações pesquisadas.

Em $84,1 \%$ das companhias, o subsídio para compra de medicamentos não é oferecido aos executivos. O atendimento psicológico é oferecido a todos os executivos por $68,2 \%$ das empresas. Enquanto outros $25 \%$ descartam esse tipo de benefício a seus executivos. 
Tabela 2 - Benefícios oferecidos aos executivos

\begin{tabular}{l|c|c|c|c|c|c}
\hline \multirow{2}{*}{ Benefícios } & \multicolumn{2}{c|}{ Não } & \multicolumn{2}{c}{ Parte } & \multicolumn{2}{c}{ Todos } \\
\cline { 2 - 7 } & n & \% & n & \% & n & \% \\
\hline \hline 1. Assistência médica & - & - & - & - & 44 & 100,0 \\
\hline $\begin{array}{l}\text { 2. Consultório médico nas instalações da } \\
\text { empresa }\end{array}$ & 10 & 22,7 & 3 & 6,8 & 31 & 70,5 \\
\hline 3. Assistência odontológica & 5 & 11,4 & - & - & 39 & 88,6 \\
\hline 4. Subsídio para compra de medicamentos & 37 & 84,1 & - & - & 7 & 15,9 \\
\hline 5. Atendimento psicológico & 11 & 25,0 & 3 & 6,8 & 30 & 68,2 \\
\hline 6. Seguro de vida em grupo & 3 & 6,8 & - & - & 41 & 93,2 \\
\hline 7. Subsídio para formação educacional & 18 & 40,9 & 3 & 6,8 & 23 & 52,3 \\
\hline 8. Subsídio para especialização & & & & & & \\
profissional & 2 & 4,5 & 7 & 15,9 & 35 & 79,5 \\
\hline 9. Subsídio para estudo de idiomas & 7 & 15,9 & 2 & 4,5 & 35 & 79,5 \\
\hline 10. Suporte à educação dos filhos & 26 & 59,1 & 4 & 9,1 & 14 & 31,8 \\
\hline 11. Subsídio para a aquisição de moradia & 38 & 86,4 & 1 & 2,3 & 5 & 11,4 \\
\hline 12. Financiamentos e empréstimos & 9 & 20,5 & 1 & 2,3 & 34 & 77,3 \\
\hline FONTE: Elaborado pela autora & & & & & &
\end{tabular}

FONTE: Elaborado pela autora.

O seguro de vida em grupo é oferecido a todos os executivos por 93,2\% das empresas, ao passo que o subsídio para formação educacional é disponibilizado a todos os executivos em $52,3 \%$ das organizações, não sendo ofertado em 40,9\% delas.

Subsídio para especialização profissional e para estudo de idiomas é oferecido por 79,5\% das empresas a todos os executivos. Já o suporte para a educação dos filhos não é ofertado por $59,1 \%$.

O subsídio para a aquisição de moradia não é oferecido em $86,4 \%$ dos casos, ao passo que o benefício financiamentos e empréstimos é disponibilizado a todos os executivos por 77,3\% das organizações.

As tabelas 3 a 8 apresentam a análise descritiva das informações sobre carreira. O processo de planejamento e acompanhamento do desenvolvimento profissional dos executivos é apresentado na Tabela 3. 
Tabela 3 - Processo de planejamento e acompanhamento do desenvolvimento profissional

\begin{tabular}{|c|c|c|c|c|c|c|}
\hline \multirow{2}{*}{$\begin{array}{l}\text { Processo de planejamento e } \\
\text { acompanhamento }\end{array}$} & \multicolumn{2}{|c|}{ Não } & \multicolumn{2}{|c|}{ Parte } & \multicolumn{2}{|c|}{ Todos } \\
\hline & n & $\%$ & $\mathbf{n}$ & $\%$ & $\mathbf{n}$ & $\%$ \\
\hline $\begin{array}{l}\text { O processo é realizado regularmente, pelo } \\
\text { menos, uma vez por ano }\end{array}$ & 7 & 15,9 & 1 & 2,3 & 36 & 81,8 \\
\hline $\begin{array}{l}\text { Como resultado do processo de avaliação, } \\
\text { é estabelecido um plano de } \\
\text { desenvolvimento }\end{array}$ & 7 & 15,9 & 1 & 2,3 & 36 & 81,8 \\
\hline $\begin{array}{l}\text { O processo envolve estabelecimento e } \\
\text { acompanhamento de objetivos e metas de } \\
\text { performance }\end{array}$ & 9 & 20,5 & 1 & 2,3 & 34 & 77,3 \\
\hline $\begin{array}{l}\text { O processo envolve a avaliação do } \\
\text { desenvolvimento de competências }\end{array}$ & 10 & 22,7 & 1 & 2,3 & 33 & 75,0 \\
\hline
\end{tabular}

FONTE: Elaborado pela autora

Trinta e seis empresas oferecem planejamento e acompanhamento do desenvolvimento profissional a todos os executivos. Esse processo é realizado regularmente, pelo menos, uma vez ao ano. Como resultado,elabora-se um plano de desenvolvimento.

Em 34 empresas, o processo envolve o estabelecimento e o acompanhamento de objetivos e metas de performance para todos os executivos. Já em outras 33, implica na avaliação do desenvolvimento de competências.

Os mecanismos de estímulo e suporte para o planejamento de carreira são apresentados na Tabela 4.

Em 50\% das empresas não são oferecidos aos executivos cursos ou eventos para planejamento de carreira; $54,5 \%$ delas são desprovidas de biblioteca, manuais ou software para planejamento de carreira.

O aconselhamento de carreira, por meio de reuniões estruturadas com a chefia imediata ou pessoas designadas, é oferecido a todos os executivos por $43,2 \%$ das empresas, sendo descartado por $40,9 \%$ delas.

Em 54,5\% das organizações, os executivos não são assistidos por profissionais internos ou contratados especialmente para fazer aconselhamento de carreira. O counselling, definido 
pelo Progep como uma prática para ajudar as pessoas em momentos de crise, é ofertado a todos os executivos por apenas $13,6 \%$ das empresas. A maioria $(72,7 \%)$ não disponibiliza essa prática a seus executivos.

Tabela 4 - Estímulo e suporte para o planejamento de carreira

\begin{tabular}{|c|c|c|c|c|c|c|}
\hline \multirow{2}{*}{$\begin{array}{l}\text { Suporte para o planejamento de } \\
\text { carreira }\end{array}$} & \multicolumn{2}{|c|}{ Não } & \multicolumn{2}{|c|}{ Parte } & \multicolumn{2}{|c|}{ Todos } \\
\hline & $\mathbf{n}$ & $\%$ & $\mathbf{n}$ & $\%$ & $\mathbf{n}$ & $\%$ \\
\hline $\begin{array}{l}\text { Há cursos ou eventos para planejamento } \\
\text { de carreira }\end{array}$ & 22 & 50,0 & 4 & 9,1 & 18 & 40,9 \\
\hline $\begin{array}{l}\text { Há biblioteca, manuais ou software para } \\
\text { planejamento de carreira }\end{array}$ & 24 & 54,5 & 2 & 4,5 & 18 & 40,9 \\
\hline $\begin{array}{l}\text { Há aconselhamento de carreira por meio } \\
\text { de reuniões estruturadas com a chefia } \\
\text { imediata ou pessoas designadas pela } \\
\text { empresa }\end{array}$ & 18 & 40,9 & 7 & 15,9 & 19 & 43,2 \\
\hline $\begin{array}{l}\text { Há grupos de executivos assistidos por } \\
\text { profissionais da empresa ou especialmente } \\
\text { contratados para efetuar aconselhamento } \\
\text { de carreira }\end{array}$ & 24 & 54,5 & 7 & 15,9 & 13 & 29,5 \\
\hline Há adoção da prática de counselling & 32 & 72,7 & 6 & 13,6 & 6 & 13,6 \\
\hline Há adoção da prática de coaching & 18 & 40,9 & 8 & 18,2 & 18 & 40,9 \\
\hline Há adoção da prática de mentoring & 32 & 72,7 & 6 & 13,6 & 6 & 13,6 \\
\hline
\end{tabular}

FONTE: Elaborado pela autora.

O coaching, definido como um processo que procura ajudar as pessoas a se desenvolverem para atingirem seus objetivos, é oferecido a todos os executivos por $40,9 \%$ das empresas. Já em outras 40,9\%, não é disponibilizado.

O mentoring, processo no qual um profissional sênior procura orientar um profissional menos experiente em seu desenvolvimento profissional, não é oferecido aos executivos em $72,7 \%$ dos casos.

A política de recolocação de executivos demitidos é oferecida a todos os executivos em 43,2\% das empresas. Mas, é acompanhada por apenas 36,4\% delas. Esse processo inexiste para 38,6\% das organizações, conforme revela a Tabela 5. 
Tabela 5 - Política de recolocação de executivos demitidos

\begin{tabular}{|c|c|c|c|c|c|c|}
\hline \multirow{2}{*}{$\begin{array}{c}\text { Recolocação para os executivos } \\
\text { demitidos }\end{array}$} & \multicolumn{2}{|c|}{ Não } & \multicolumn{2}{|c|}{ Parte } & \multicolumn{2}{|c|}{ Todos } \\
\hline & $\mathbf{n}$ & $\%$ & $\mathbf{n}$ & $\%$ & $\mathrm{n}$ & $\%$ \\
\hline $\begin{array}{l}\text { A política de recolocação de demitidos é } \\
\text { aplicada aos executivos }\end{array}$ & 17 & 38,6 & 8 & 18,2 & 19 & 43,2 \\
\hline $\begin{array}{l}\text { A empresa acompanha sistematicamente o } \\
\text { processo de recolocação de executivos } \\
\text { demitidos }\end{array}$ & 21 & 47,7 & 7 & 15,9 & 16 & 36,4 \\
\hline
\end{tabular}

FONTE: Elaborado pela autora.

O programa de recrutamento interno é ofertado a todos os executivos, em $54,5 \%$ das empresas. Enquanto 45,5\% delas não disponibilizam esse benefício. Em 54,5\%, todos os executivos participam do processo de definição dos critérios de ascensão na carreira (Tabela $6)$.

Tabela 6 - Programa de recrutamento interno

\begin{tabular}{l|c|c|c|c|c|c}
\hline \multicolumn{1}{c|}{ Recrutamento interno } & \multicolumn{2}{c|}{ Não } & \multicolumn{2}{c|}{ Parte } & \multicolumn{2}{c}{ Todos } \\
\cline { 2 - 7 } & n & \% & n & \% & n & \% \\
\hline \hline $\begin{array}{l}\text { O programa de recrutamento interno é } \\
\text { oferecido aos executivos }\end{array}$ & 20 & 45,5 & - & - & 24 & 54,5 \\
\hline $\begin{array}{l}\text { Os executivos participam do processo de } \\
\text { definição dos critérios de ascensão na } \\
\text { carreira }\end{array}$ & 16 & 36,4 & 4 & 9,1 & 24 & 54,5 \\
\hline
\end{tabular}

FONTE: Elaborado pela autora.

Em 43,2\% das empresas, não há acesso a um plano de carreira estruturado, formalizado e praticado, ao passo que, em 40,9\%, todos os executivos podem usufruir dessa opção (Tabela 7). Destaca-se que $61,4 \%$ das organizações não disponibilizam aos executivos informações completas sobre seus processos de carreira, nem por murais, nem pela Intranet.

Em 45,5\% dos casos, todos os executivos têm conhecimento dos requisitos de acesso às posições previstas no plano de carreira; em 36,4\%, não têm. Não são recebidas comunicações sobre as mudanças nos processos de carreira em 47,7\% das empresas; já em 43,2\%, essas mudanças são comunicadas a todos os executivos. 
Tabela 7 - Possibilidades de carreira

\begin{tabular}{l|c|c|c|c|c|c}
\hline \multirow{2}{*}{ Possibilidades de carreira } & \multicolumn{2}{|c|}{ Não } & \multicolumn{2}{c|}{ Parte } & \multicolumn{2}{c}{ Todos } \\
\cline { 2 - 7 } & n & \% & n & \% & n & \% \\
\hline $\begin{array}{l}\text { O plano de carreira é estruturado, } \\
\text { formalizado e praticado }\end{array}$ & 19 & 43,2 & 7 & 15,9 & 18 & 40,9 \\
\hline $\begin{array}{l}\text { Há informações completas sobre os } \\
\text { processos de carreira nos murais e/ou }\end{array}$ & 27 & 61,4 & 3 & 6,8 & 14 & 31,8 \\
Intranet & 16 & 36,4 & 8 & 18,2 & 20 & 45,5 \\
\hline $\begin{array}{l}\text { Os requisitos de acesso às posições } \\
\text { previstas no plano de carreira são } \\
\text { conhecidos pelos executivos }\end{array}$ & 21 & 47,7 & 4 & 9,1 & 19 & 43,2 \\
\hline $\begin{array}{l}\text { As mudanças nos processos de carreira } \\
\text { ão comunicadas aos executivos, pelo } \\
\text { menos, uma vez ao ano }\end{array}$ & & & & & & \\
\hline
\end{tabular}

FONTE: Elaborado pela autora.

Apenas $36,4 \%$ das empresas adotam programa de preparação para a aposentadoria e o oferecem a todos os executivos (Tabela 8). Em 34,1\%, essa preparação envolve aspectos financeiros; em 18,2\%, implica em transição de carreira para outras atividades, assistência psicológica ao executivo e a sua família. Observa-se que $25 \%$ das empresas mantêm programa de relacionamento e/ou contato com todos os executivos aposentados.

Tabela 8 - Programa de preparação para aposentadoria

\begin{tabular}{l|c|c|c|c|c|c}
\hline \multirow{2}{*}{ Preparação para aposentadoria } & \multicolumn{2}{|c|}{ Não } & \multicolumn{2}{c|}{ Parte } & \multicolumn{2}{c}{ Todos } \\
\cline { 2 - 7 } & $\mathbf{n}$ & $\mathbf{\%}$ & $\mathbf{n}$ & $\mathbf{\%}$ & $\mathbf{n}$ & $\mathbf{\%}$ \\
\hline $\begin{array}{l}\text { A empresa adota programa de preparação } \\
\text { para aposentadoria }\end{array}$ & 27 & 61,4 & 1 & 2,3 & 16 & 36,4 \\
\hline $\begin{array}{l}\text { A preparação envolve aspectos } \\
\text { financeiros }\end{array}$ & 29 & 65,9 & - & - & 15 & 34,1 \\
\hline $\begin{array}{l}\text { A preparação envolve transição de } \\
\text { carreira para outras atividades após o } \\
\text { processo de aposentadoria }\end{array}$ & 35 & 79,5 & 1 & 2,3 & 8 & 18,2 \\
\hline $\begin{array}{l}\text { A preparação envolve assistência } \\
\text { psicológica à pessoa a ser aposentada }\end{array}$ & 35 & 79,5 & 1 & 2,3 & 8 & 18,2 \\
\hline $\begin{array}{l}\text { A preparação envolve a família da pessoa } \\
\text { a ser aposentada }\end{array}$ & 35 & 79,5 & 1 & 2,3 & 8 & 18,2 \\
\hline $\begin{array}{l}\text { A empresa mantém programa de } \\
\text { relacionamento e/ou contato com os } \\
\text { aposentados }\end{array}$ & 33 & 75,0 & - & - & 11 & 25,0 \\
\hline
\end{tabular}

FONTE: Elaborado pela autora. 
A Tabela 9 apresenta as características do modelo de educação empregado para apoiar o desenvolvimento pessoal e profissional dos executivos. Em 35 empresas, todos têm acesso a ações e programas educacionais concebidos com base na identificação das competências críticas (empresariais e humanas). Vinte e cinco organizações oferecem, a todos os executivos, sistemas formais de gestão que estimulam o compartilhamento de conhecimentos e a troca de experiências.

Em 43,2\%, os executivos não utilizam tecnologia aplicada à educação; em 20,5\%, parte deles utiliza; em $36,4 \%$, todos a adotam.

Ressalta-se que, em 72,7\% dos casos, os programas de desenvolvimento profissional reforçam o compromisso da empresa com a cidadania empresarial. Assim, enfatizam a responsabilidade da empresa com o ambiente no qual está inserida, incluindo as pessoas com as quais se relaciona. Esses programas são voltados ao fortalecimento e à disseminação da cultura organizacional em $88,6 \%$ das ocorrências.

Tabela 9 - Desenvolvimento profissional

\begin{tabular}{|c|c|c|c|c|c|c|}
\hline \multirow[t]{2}{*}{ Desenvolvimento profissional } & \multicolumn{2}{|c|}{ Não } & \multicolumn{2}{|c|}{ Parte } & \multicolumn{2}{|c|}{ Todos } \\
\hline & $\mathbf{n}$ & $\%$ & $\mathbf{n}$ & $\%$ & $\mathbf{n}$ & $\%$ \\
\hline $\begin{array}{l}\text { As ações e programas educacionais são } \\
\text { concebidos com base na identificação das } \\
\text { competências críticas (empresariais e } \\
\text { humanas) }\end{array}$ & 7 & 15,9 & 2 & 4,5 & 35 & 79,5 \\
\hline $\begin{array}{l}\text { Há sistemas formais de gestão voltados } \\
\text { para o estímulo ao compartilhamento de } \\
\text { conhecimentos e à troca de experiências }\end{array}$ & 12 & 27,3 & 7 & 15,9 & 25 & 56,8 \\
\hline $\begin{array}{l}\text { Há intensiva utilização de tecnologia } \\
\text { aplicada à educação }\end{array}$ & 19 & 43,2 & 9 & 20,5 & 16 & 36,4 \\
\hline $\begin{array}{l}\text { Os programas reforçam o compromisso da } \\
\text { empresa com a cidadania empresarial }\end{array}$ & 8 & 18,2 & 4 & 9,1 & 32 & 72,7 \\
\hline $\begin{array}{l}\text { Os programas são voltados ao } \\
\text { fortalecimento e à disseminação da } \\
\text { cultura organizacional }\end{array}$ & 5 & 11,4 & - & - & 39 & 88,6 \\
\hline $\begin{array}{l}\text { Os líderes e gestores responsabilizam -se } \\
\text { pelo processo de aprendizagem }\end{array}$ & 4 & 9,1 & 8 & 18,2 & 32 & 72,7 \\
\hline $\begin{array}{l}\mathrm{Na} \text { avaliação dos resultados dos } \\
\text { investimentos em educação, são } \\
\text { considerados os objetivos do negócio }\end{array}$ & 9 & 20,5 & 5 & 11,4 & 30 & 68,2 \\
\hline $\begin{array}{l}\text { Há formação de parcerias com instituições } \\
\text { de ensino superior }\end{array}$ & 16 & 36,4 & 3 & 6,8 & 25 & 56,8 \\
\hline
\end{tabular}

FONTE: Elaborado pelo autor. 
Nota-se que, em 72,7\% das organizações, os líderes e gestores responsabilizam-se pelo processo de aprendizagem de todos os executivos. $\mathrm{Na}$ avaliação dos resultados dos investimentos em educação, 68,2\% das empresas levam em consideração os objetivos do negócio; em 56,8\% das ocorrências, todos os executivos têm acesso a parcerias com instituições de ensino superior.

\subsubsection{Análise descritiva das variáveis independentes}

As informações sobre benefícios, carreira, educação e desenvolvimento profissional foram agrupadas em três índices, conforme descrito no Capítulo 4. A Tabela 10 apresenta os índices de cada empresa da amostra.

O índice de benefícios mede o acesso dos executivos a 12 benefícios. Quanto maior o índice, mais bem colocada estará a empresa. Trata-se de uma proporção que considera um número mais elevado de benefícios para uma quantidade maior de executivos. Somente duas empresas oferecem todos os benefícios a todos os seus executivos (empresas \# 1 e 4).

O índice de carreira mede o acesso dos executivos a 25 mecanismos de estímulo e suporte à carreira. Nenhuma empresa atingiu a pontuação máxima de 50 pontos. A maior pontuação alcançada (48 pontos) foi obtida pela empresa \# 27.

O índice de desenvolvimento mede o acesso dos executivos a 8 mecanismos de estímulo à educação e ao desenvolvimento profissional. Somente 9 organizações (20,5\%) atingiram a pontuação máxima de 16 pontos (empresas \# 1, 7, 16, 17, 27, 33, 34, 37 e 43); três empresas (\# 18, 32 e 36) não oferecem qualquer estímulo à educação e ao desenvolvimento profissional de seus executivos. 
Tabela 10 - Valor dos índices para cada empresa da amostra

\begin{tabular}{|c|c|c|c|}
\hline $\begin{array}{c}\text { Empresas } \\
\#\end{array}$ & $\begin{array}{l}\text { Índice de } \\
\text { Benefícios }\end{array}$ & $\begin{array}{l}\text { Indice de } \\
\text { Carreira }\end{array}$ & $\begin{array}{c}\text { Índice de } \\
\text { Desenvolvimento }\end{array}$ \\
\hline 1 & 24 & 24 & 16 \\
\hline 2 & 19 & 34 & 14 \\
\hline 3 & 13 & 12 & 14 \\
\hline 4 & 24 & 28 & 14 \\
\hline 5 & 14 & 26 & 12 \\
\hline 6 & 18 & 23 & 13 \\
\hline 7 & 16 & 28 & 16 \\
\hline 8 & 15 & 20 & 10 \\
\hline 9 & 9 & 14 & 8 \\
\hline 10 & 14 & 14 & 14 \\
\hline 11 & 15 & 29 & 13 \\
\hline 12 & 18 & 26 & 10 \\
\hline 13 & 15 & 32 & 11 \\
\hline 14 & 16 & 16 & 10 \\
\hline 15 & 20 & 18 & 12 \\
\hline 16 & 12 & 43 & 16 \\
\hline 17 & 15 & 18 & 16 \\
\hline 18 & 14 & 2 & 0 \\
\hline 19 & 18 & 18 & 12 \\
\hline 20 & 20 & 35 & 14 \\
\hline 21 & 20 & 43 & 15 \\
\hline 22 & 14 & 14 & 8 \\
\hline 23 & 16 & 14 & 8 \\
\hline 24 & 12 & 10 & 8 \\
\hline 25 & 12 & 21 & 11 \\
\hline 26 & 16 & 12 & 14 \\
\hline 27 & 20 & 48 & 16 \\
\hline 28 & 14 & 22 & 14 \\
\hline 29 & 16 & 31 & 11 \\
\hline 30 & 19 & 36 & 12 \\
\hline 32 & 18 & 22 & 11 \\
\hline 32 & 20 & 8 & 0 \\
\hline 33 & 16 & 23 & 16 \\
\hline 34 & 18 & 2 & 16 \\
\hline 35 & 17 & 25 & 12 \\
\hline 36 & 14 & 31 & 0 \\
\hline 37 & 14 & 35 & 16 \\
\hline 38 & 13 & 29 & 14 \\
\hline 39 & 16 & 39 & 14 \\
\hline 40 & 20 & 13 & 11 \\
\hline 41 & 12 & 8 & 13 \\
\hline 42 & 19 & 17 & 12 \\
\hline 43 & 18 & 13 & 16 \\
\hline 44 & 15 & 34 & 8 \\
\hline
\end{tabular}

FONTE: Elaborado pela autora. 
A Tabela 11 revela as medidas descritivas dos três índices. O índice de benefícios médio foi de 16,23 pontos, com $50 \%$ das empresas apresentando valor igual ou inferior a 16 pontos. $\mathrm{O}$ valor do índice variou entre um mínimo de 9 e um máximo de 24 pontos.

O índice de carreira apresentou valor médio de 22,80 pontos, oscilando entre 2 e 48. Cinquenta por cento das empresas apresentaram valor igual ou inferior a 22,50 pontos. Lembrando que a pontuação máxima desse índice é de 50, conclui-se que há pouco estímulo e suporte para o crescimento profissional dos executivos. Salienta-se que a carreira oferecida pela empresa é um item muito valorizado por esses profissionais (FIA, 2007). Assim, trata-se de um contexto que sinaliza importantes oportunidades a serem exploradas pelas organizações.

Tabela 11 - Medidas descritivas dos índices

\begin{tabular}{lcccccc}
\hline & $\mathbf{n}$ & média & mediana & desvio-padrão & mínimo & máximo \\
\hline \hline Índice de benefícios & 44 & 16,23 & 16,00 & 3,15 & 9 & 24 \\
$\begin{array}{l}\text { Índice de carreira } \\
\begin{array}{l}\text { Índice de } \\
\text { desenvolvimento }\end{array}\end{array}$ & 44 & 22,80 & 22,50 & 10,87 & 2 & 48 \\
\hline
\end{tabular}

FONTE: Elaborado pela autora.

O índice de desenvolvimento apresentou valor médio de 11,50 pontos, variando de 0 a 16 . Cinquenta por cento das empresas indicaram escala igual ou inferior a 12 pontos. As organizações pesquisadas diferem bastante com relação a esse dado. Enquanto algumas não oferecem qualquer mecanismo de suporte à educação e ao desenvolvimento profissional, outras disponibilizam todos os 8 mecanismos (avaliados na pesquisa do Progep) a todos os seus executivos.

Do banco de dados do Progep, extraíram-se também informações sobre salário mensal médio e salário variável médio, recebidos pelos executivos em 2006. A média do salário mensal médio foi de $\mathrm{R} \$ 27.000,40$, variando entre $\mathrm{R} \$ 10.012,00$ e $\mathrm{R} \$ 52.000,00$. Já a média do salário variável médio foi de $\mathrm{R} \$ 141.767,47$ no ano de 2006 , o que equivale a cerca de $\mathrm{R} \$$ 11.813,96 ao mês. Algumas empresas não pagam salário variável a seus executivos, por isso, o valor mínimo corresponde a zero. A Tabela 12 apresenta as medidas descritivas dessas informações. 
Tabela 12 - Salário médio dos executivos em 2006

\begin{tabular}{lcccccc}
\hline & n & média & mediana & desvio-padrão & mínimo & máximo \\
\hline \hline $\begin{array}{l}\text { Salário mensal médio (em } \\
\text { reais) }\end{array}$ & 44 & 27000,40 & 25738,21 & 8914,11 & 10012,00 & 52000,00 \\
$\begin{array}{l}\text { Salário variável médio } \\
\text { (em reais) }\end{array}$ & 44 & 141767,47 & 107086,95 & 136590,00 & 0,00 & 480700,00 \\
\hline
\end{tabular}

FONTE: Elaborado pela autora.

\subsubsection{Análise descritiva das variáveis dependentes}

Do banco de dados da FIPECAFI - exercícios de 2006 e 2007 - foram coletadas informações sobre os indicadores contábeis: crescimento das vendas, retorno sobre patrimônio líquido e margem líquida sobre as vendas. A Tabela 13 apresenta as medidas descritivas desses indicadores.

Tabela 13 - Medidas descritivas dos indicadores contábeis

\begin{tabular}{|c|c|c|c|c|c|c|}
\hline & $\bar{n}$ & média & mediana & desvio-padrão & mínimo & máximo \\
\hline \multicolumn{7}{|l|}{ Crescimento das Vendas } \\
\hline $2006(\%)$ & 44 & 5,12 & 3,50 & 11,02 & $-19,1$ & 34,8 \\
\hline ROE $2006(\%)$ & 44 & 18,51 & 17,75 & 17,53 & $-44,8$ & 57,7 \\
\hline \multicolumn{7}{|l|}{ Margem Líquida sobre as } \\
\hline Vendas $2006(\%)$ & 44 & 6,52 & 5,05 & 9,82 & $-21,7$ & 42,8 \\
\hline \multicolumn{7}{|l|}{ Crescimento das Vendas } \\
\hline $2007(\%)$ & 44 & 4,96 & 4,30 & 17,63 & $-35,4$ & 66,0 \\
\hline ROE 2007 (\%) & 44 & 16,67 & 14,75 & 13,98 & $-23,8$ & 54,6 \\
\hline \multicolumn{7}{|l|}{ Margem Líquida sobre as } \\
\hline Vendas $2007(\%)$ & 44 & 6,51 & 4,15 & 8,31 & $-10,4$ & 42,5 \\
\hline
\end{tabular}

FONTE: Elaborado pela autora.

O crescimento das vendas de 2006 apresentou valor médio de 5,12\%, variando de $-19,1 \%$ a 34,8\%. O retorno sobre patrimônio líquido (ROE) de 2006 apresentou valor médio de $18,51 \%$, oscilando entre $-44,8 \%$ e $57,7 \%$. A margem líquida sobre as vendas de 2006 indicou valor médio de $6,52 \%$, variando de $-21,7 \%$ a $42,8 \%$. 
O valor médio do crescimento das vendas de 2007 foi de $4,96 \%$, ficando entre $-35,4 \%$ e $66 \%$. O valor médio do ROE de 2007 foi de 16,67\%, variando de $-23,8 \%$ a 54,6\%. A margem líquida sobre as vendas de 2007 apresentou valor médio de 6,51\%; ela oscilou entre $-10,4 \%$ e $42,5 \%$.

\subsubsection{Análise descritiva da variável de controle}

Outra informação coletada no banco de dados do Progep foi o número de funcionários em 2006. Como a variável apresentava grande variação, de um mínimo de 131 a um máximo de 20.228 funcionários, optou-se pela transformação logarítmica da variável. A Tabela 14 expõe as medidas descritivas antes e após a transformação.

Tabela 14 - Medidas descritivas da variável de controle

\begin{tabular}{lcccccc}
\hline & n & média & mediana & desvio-padrão & mínimo & máximo \\
\hline \hline Número de funcionários & 44 & 3194,68 & 1359 & 4097,92 & 131 & 20228 \\
Porte (ln n ${ }^{\circ}$ funcionários) & 44 & 7,40 & 7,21 & 1,21 & 4,88 & 9,91 \\
\hline
\end{tabular}

FONTE: Elaborado pela autora.

O Quadro 7 apresenta as siglas das variáveis utilizadas nos testes estatísticos de: igualdade de médias, análise de correlação e análise de regressão linear.

Quadro 7 - Sigla das variáveis utilizadas nos testes

\begin{tabular}{|l|l|}
\hline \multicolumn{1}{|c|}{ Nome da variável } & \multicolumn{1}{c|}{ Sigla } \\
\hline Salário Mensal Médio & salmen \\
\hline Salário Variável Médio & salvar \\
\hline Índice de Benefícios & ibenef \\
\hline Índice de Carreira & icarr \\
\hline Índice de Desenvolvimento & idesen \\
\hline Crescimento das Vendas - 2006 & cven06 \\
\hline Retorno sobre Patrimônio Líquido - 2006 & roe06 \\
\hline Margem Líquida sobre as Vendas - 2006 & mven06 \\
\hline Crescimento das Vendas - 2007 & cven07 \\
\hline Retorno sobre Patrimônio Líquido - 2007 & roe2007 \\
\hline Margem Líquida sobre as Vendas - 2007 & mven07 \\
\hline Porte & porte \\
\hline
\end{tabular}

FONTE: Elaborado pela autora 


\subsection{Teste de igualdade de médias}

Conforme descrito na seção 4.2, utilizou-se a mediana das variáveis de remuneração para dividir as 44 empresas da amostra em dois grupos: "baixo" e "alto". O grupo denominado "baixo" apresenta valores abaixo da mediana em: salário mensal médio, salário variável médio, índice de benefícios, índice de carreira e índice de desenvolvimento. O grupo denominado "alto" apresenta valores acima da mediana.

O teste $t$ para duas amostras independentes é aplicado para testar se as médias dos dois grupos são significativamente diferentes. O teste exige que as duas amostras tenham distribuição normal. Para verificar a aderência de cada grupo à normalidade, utilizou-se o teste de Kolmogorov-Smirnov (K-S), com correção de Lilliefors.

A Tabela 15 mostra que a normalidade não se verifica em todos os grupos analisados. Os grupos salvar alto, ibenef baixo, ibenef alto, idesen baixo e idesen alto não apresentam distribuição normal (p-valor menor do que 5\%). Assim, o teste paramétrico $t$ para duas amostras independentes não pode ser aplicado. A alternativa é a utilização do teste nãoparamétrico de Mann-Whitney para duas amostras independentes.

Tabela 15 - Teste K-S com correção de Lilliefors

\begin{tabular}{ll|r}
\hline \multicolumn{2}{c|}{ grupo } & p-valor \\
\hline \hline \multirow{2}{*}{ salmen } & baixo & 0,129 \\
& alto & 0,200 \\
\hline \multirow{2}{*}{ salvar } & baixo & 0,200 \\
& alto & 0,003 \\
\hline \multirow{2}{*}{ ibenef } & baixo & 0,007 \\
& alto & 0,005 \\
\hline \multirow{2}{*}{ icarr } & baixo & 0,200 \\
& alto & 0,200 \\
\hline \multirow{2}{*}{ idesen } & baixo & 0,000 \\
& alto & 0,000 \\
\hline FONTE: Elaborado pela autora.
\end{tabular}


O teste de Mann-Whitney foi aplicado para testar se existe diferença no desempenho financeiro médio dos grupos "baixo" e "alto". Tal desempenho é medido pelos indicadores contábeis: crescimento das vendas, retorno sobre patrimônio líquido, margem líquida sobre as vendas, dos exercícios de 2006 e de 2007. A hipótese nula é que não existe diferença na média observada dos dois grupos. O nível de significância adotado é de 5\%.

\section{- Salário mensal médio e variáveis de desempenho financeiro}

O grupo salmen baixo é formado por empresas com valores de salmen abaixo da mediana; o grupo salmen alto é formado por empresas com valores acima da mediana. As tabelas 16 e 17 apresentam os resultados do teste de Mann-Whitney - grupo salmen baixo versus grupo salmen alto. A Tabela 16 mostra as médias dos postos (mean rank) e as somas dos postos (sum of ranks); a Tabela 17 expõe as estatísticas do teste.

A média de cven06 apresenta diferença nos dois grupos. A média no grupo salmen baixo é menor do que a média no grupo salmen alto. Essa diferença não é estatisticamente significante, dado que o p-valor $(=0,439)$ é maior do que 0,05 .

A média de roe06 também apresenta diferença nos dois grupos: no salmen baixo, ela é maior do que aquela do salmen alto. O p-valor $(=0,699)$, maior do que $5 \%$, indica que essa diferença não é significante.

A média de mven06 apresenta pequena diferença nos dois grupos: no salmen baixo, é ligeiramente menor do que no grupo salmen alto. Essa diferença não é estatisticamente significante, a $5 \%$ (p-valor $=0,814)$.

A média de cven07 apresenta diferença nos dois grupos: no salmen baixo, ela é menor do que no salmen alto. O p-valor $(=0,398)$, maior do que $5 \%$, indica que essa diferença não é significante. 
Tabela 16 - Teste de Mann-Whitney - grupo salmen baixo versus grupo salmen alto

\begin{tabular}{|c|c|c|c|c|}
\hline \multicolumn{5}{|c|}{ Ranks } \\
\hline & salmen & $\mathrm{N}$ & Mean Rank & Sum of Ranks \\
\hline \multirow[t]{3}{*}{ cven06 } & baixo & 22 & 21,00 & 462,00 \\
\hline & alto & 22 & 24,00 & 528,00 \\
\hline & Total & 44 & & \\
\hline \multirow[t]{3}{*}{ roe06 } & baixo & 22 & 23,25 & 511,50 \\
\hline & alto & 22 & 21,75 & 478,50 \\
\hline & Total & 44 & & \\
\hline \multirow[t]{3}{*}{ mven06 } & baixo & 22 & 22,05 & 485,00 \\
\hline & alto & 22 & 22,95 & 505,00 \\
\hline & Total & 44 & & \\
\hline \multirow[t]{3}{*}{ cven07 } & baixo & 22 & 20,86 & 459,00 \\
\hline & alto & 22 & 24,14 & 531,00 \\
\hline & Total & 44 & & \\
\hline \multirow[t]{3}{*}{ roe07 } & baixo & 22 & 21,14 & 465,00 \\
\hline & alto & 22 & 23,86 & 525,00 \\
\hline & Total & 44 & & \\
\hline \multirow[t]{3}{*}{ mven07 } & baixo & 22 & 19,98 & 439,50 \\
\hline & alto & 22 & 25,02 & 550,50 \\
\hline & Total & 44 & & \\
\hline
\end{tabular}

FONTE: SPSS.

A média de roe07 é diferente nos dois grupos: no salmen baixo é menor do que no salmen alto. Essa diferença não é significante a $5 \%$ (p-valor $=0,481)$.

Também a média de mven07 é diferente nos dois grupos: no salmen baixo é menor do que no salmen alto. $\mathrm{O}$ p-valor $(=0,193)$, maior do que 0,05 , indica que a diferença não é significante. 
Tabela 17 - Estatísticas do teste de Mann-Whitney - grupo salmen baixo versus grupo salmen alto

Test Statistics ${ }^{\mathrm{a}}$

\begin{tabular}{|l|r|r|r|r|r|r|}
\hline & \multicolumn{1}{|c|}{ cven06 } & roe06 & mven06 & cven07 & roe07 & mven07 \\
\hline Mann-Whitney U & 209,000 & 225,500 & 232,000 & 206,000 & 212,000 & 186,500 \\
Wilcoxon W & 462,000 & 478,500 & 485,000 & 459,000 & 465,000 & 439,500 \\
Z &,- 775 &,- 387 &,- 235 &,- 845 &,- 704 & $-1,303$ \\
Asymp. Sig. (2-tailed) &, 439 &, 699 &, 814 &, 398 &, 481 &, 193 \\
\hline
\end{tabular}

a. Grouping Variable: salmen

FONTE: SPSS.

As diferenças observadas nas médias dos grupos salmen baixo e salmen alto não se mostraram significantes. As estatísticas do teste de Mann-Whitney apresentaram p-valor maior do que $5 \%$ para todos os indicadores financeiros. Assim, não se pode rejeitar $\mathrm{H}_{0}$, o desempenho financeiro médio é semelhante nos grupos salmen baixo e salmen alto.

\section{- Salário variável médio e variáveis de desempenho financeiro}

O grupo salvar baixo é formado por empresas com valores de salvar abaixo da mediana, enquanto o grupo salvar alto é formado por aquelas com valores acima da mediana. As tabelas 18 e 19 apresentam os resultados do teste de Mann-Whitney - grupo salvar baixo versus grupo salvar alto. A Tabela 18 mostra as médias, e a Tabela 19 indica as estatísticas do teste.

A média de cven06 no grupo salvar baixo é ligeiramente maior do que aquela do salvar alto. A diferença não é significante, pois o p-valor $(=0,824)$ é maior do que 0,05 .

A média de roe06 no grupo salvar baixo é menor do que no grupo salvar alto. O p-valor (= 0,489), maior do que $5 \%$, indica que essa diferença não é significante.

A média de mven06 apresenta diferença nos dois grupos: no salvar baixo, é menor do que no salvar alto. Essa diferença não é significante a $5 \%$ (p-valor $=0,240)$. 
Tabela 18 - Teste de Mann- Whitney - grupo salvar baixo versus grupo salvar alto

\begin{tabular}{|c|c|c|c|c|}
\hline \multicolumn{5}{|c|}{ Ranks } \\
\hline & salvar & $\mathrm{N}$ & Mean Rank & Sum of Ranks \\
\hline \multirow[t]{3}{*}{ cven06 } & baixo & 22 & 22,93 & 504,50 \\
\hline & alto & 22 & 22,07 & 485,50 \\
\hline & Total & 44 & & \\
\hline \multirow[t]{3}{*}{ roe06 } & baixo & 22 & 21,16 & 465,50 \\
\hline & alto & 22 & 23,84 & 524,50 \\
\hline & Total & 44 & & \\
\hline \multirow[t]{3}{*}{ mven06 } & baixo & 22 & 20,23 & 445,00 \\
\hline & alto & 22 & 24,77 & 545,00 \\
\hline & Total & 44 & & \\
\hline \multirow[t]{3}{*}{ cven07 } & baixo & 22 & 20,95 & 461,00 \\
\hline & alto & 22 & 24,05 & 529,00 \\
\hline & Total & 44 & & \\
\hline \multirow[t]{3}{*}{ roe07 } & baixo & 22 & 20,98 & 461,50 \\
\hline & alto & 22 & 24,02 & 528,50 \\
\hline & Total & 44 & & \\
\hline \multirow[t]{3}{*}{ mven07 } & baixo & 22 & 21,00 & 462,00 \\
\hline & alto & 22 & 24,00 & 528,00 \\
\hline & Total & 44 & & \\
\hline
\end{tabular}

FONTE: SPSS.

A média de cven07, do grupo salvar baixo, é menor do que aquela do salvar alto. Nota-se uma diferença não significante, pois o p-valor $(=0,425)$ é maior do que 0,05 .

A média de roe07 também apresenta diferença nos dois grupos: no salvar baixo é menor do que no salvar alto. $\mathrm{O}$ p-valor $(=0,432)$, maior do que $5 \%$, indica que essa diferença não é significante. 
A média de mven07 no salvar baixo é menor do que no salvar alto. Trata-se de uma diferença não significante, pois o p-valor $(=0,438)$ é maior do que $5 \%$.

Tabela 19 - Estatísticas do teste de Mann-Whitney - grupo salvar baixo versus grupo salvar alto Test Statistics ${ }^{\mathrm{a}}$

\begin{tabular}{|l|r|r|r|r|r|r|}
\hline & \multicolumn{1}{|c|}{ cven06 } & \multicolumn{1}{c|}{ roe06 } & \multicolumn{1}{c|}{ mven06 } & \multicolumn{1}{c|}{ cven07 } & \multicolumn{1}{c|}{ roe07 } & mven07 \\
\hline Mann-Whitney U & 232,500 & 212,500 & 192,000 & 208,000 & 208,500 & 209,000 \\
Wilcoxon W & 485,500 & 465,500 & 445,000 & 461,000 & 461,500 & 462,000 \\
Z &,- 223 &,- 692 & $-1,174$ &,- 798 &,- 786 &,- 775 \\
Asymp. Sig. (2-tailed) &, 824 &, 489 &, 240 &, 425 &, 432 &, 438 \\
\hline
\end{tabular}

a. Grouping Variable: salvar FONTE: SPSS.

As diferenças observadas nas médias dos grupos salvar baixo e salvar alto revelaram-se não significantes. As estatísticas do teste de Mann-Whitney apresentaram p-valor maior do que $5 \%$ para todos os indicadores contábeis. Assim, não se pode rejeitar $\mathrm{H}_{0}$, o desempenho financeiro médio é semelhante nos grupos salvar baixo e salvar alto.

\section{- Índice de benefícios e variáveis de desempenho financeiro}

O grupo ibenef baixo é formado por empresas com valores de ibenef abaixo da mediana; o grupo ibenef alto é formado por empresas com valores acima da mediana. As tabelas 20 e 21 apresentam os resultados do teste de Mann-Whitney - grupo ibenef baixo versus grupo ibenef alto. A Tabela 20 mostra as médias, e a Tabela 21 indica as estatísticas do teste.

A média de cven06 apresenta diferença nos dois grupos: no ibenef baixo é menor do que aquela do grupo ibenef alto. Dado que o p-valor $(=0,272)$ é maior do que $5 \%$, essa diferença não é significante. 
A média de roe06 no grupo ibenef baixo é menor do que aquela do ibenef alto. O p-valor (= $0,124)$, maior do que 0,05 , indica que essa diferença não é significante.

Tabela 20 -Teste de Mann-Whitney - grupo ibenef baixo versus grupo ibenef alto

\begin{tabular}{|ll|r|r|r|}
\hline & ibenef & N & Mean Rank & Sum of Ranks \\
\hline cven06 & baixo & 26 & 20,73 & 539,00 \\
& alto & 18 & 25,06 & 451,00 \\
& Total & 44 & & \\
\hline roe06 & baixo & 26 & 20,02 & 520,50 \\
& alto & 18 & 26,08 & 469,50 \\
& Total & 44 & & \\
\hline mven06 & baixo & 26 & 20,10 & 522,50 \\
& alto & 18 & 25,97 & 467,50 \\
& Total & 44 & & \\
\hline cven07 & baixo & 26 & 24,52 & 637,50 \\
& alto & 18 & 19,58 & 352,50 \\
& Total & 44 & & 519,50 \\
\hline roe07 & baixo & 26 & 20,17 & 524,50 \\
& alto & 18 & 25,86 & 465,50 \\
& Total & 44 & & \\
\hline mven07 & baixo & 26 & 21,94 & 570,50 \\
& alto & 18 & 23,31 & \\
& Total & 44 & & \\
\hline
\end{tabular}

FONTE: SPSS.

A média de mven06 também apresenta diferença nos 2 grupos: no grupo ibenef baixo ela é menor do que no ibenef alto. No entanto, essa diferença não é significante. O p-valor (= $0,136)$ é maior do que $5 \%$.

A média de cven07 no grupo ibenef baixo é maior do que no ibenef alto. $\mathrm{O}$ p-valor $(=0,210)$, maior do que $5 \%$, indica que essa diferença não é significante. 
Outra a apresentar diferença nos dois grupos é a média de roe07: no ibenef baixo ela é menor do que no ibenef alto. Dado que o p-valor $(=0,149)$ é maior do que $5 \%$, essa diferença não é significante.

A média de mven07 no grupo ibenef baixo é menor do que a média no grupo ibenef alto. Trata-se de diferença não significante, dado que o p-valor $(=0,729)$ é maior do que $5 \%$.

Tabela 21 - Estatísticas do teste de Mann-Whitney - grupo ibenef baixo versus grupo ibenef alto Test Statistics ${ }^{\mathrm{a}}$

\begin{tabular}{|l|r|r|r|r|r|r|}
\hline & \multicolumn{1}{|c|}{ cven06 } & \multicolumn{1}{c|}{ roe06 } & mven06 & cven07 & roe07 & mven07 \\
\hline Mann-Whitney U & 188,000 & 169,500 & 171,500 & 181,500 & 173,500 & 219,500 \\
Wilcoxon W & 539,000 & 520,500 & 522,500 & 352,500 & 524,500 & 570,500 \\
Z & $-1,098$ & $-1,540$ & $-1,492$ & $-1,254$ & $-1,444$ &,- 346 \\
Asymp. Sig. (2-tailed) &, 272 &, 124 &, 136 &, 210 &, 149 &, 729 \\
\hline
\end{tabular}

a. Grouping Variable: ibenef FONTE: SPSS.

As diferenças observadas nas médias dos grupos ibenef baixo e ibenef alto não se mostraram significantes. As estatísticas do teste de Mann-Whitney apresentaram p-valor maior do que $5 \%$ para todos os indicadores contábeis. Assim, não se pode rejeitar $\mathrm{H}_{0}$, o desempenho financeiro médio é semelhante nos grupos ibenef baixo e ibenef alto.

\section{- Índice de carreira e variáveis de desempenho}

O grupo icarr baixo é formado por empresas com valores de icarr abaixo da mediana; o grupo icarr alto é constituído por empresas com valores acima da mediana. As tabelas 22 e 23 elencam os resultados do teste de Mann-Whitney - grupo icarrr baixo versus grupo icarr alto. A Tabela 22 lista as médias; a Tabela 23 expõe as estatísticas do teste. 
A média de cven06 no grupo icarr baixo é maior do que no icarr alto. A diferença não é significante, pois o p-valor $(=0,432)$ é maior do que 0,05 .

Também a média de roe06 no grupo icarr baixo é maior do que no icarr alto. Essa diferença não é significante, dado que o p-valor $(=0,418)$ é maior do que $5 \%$.

Tabela 22 - Teste de Mann-Whitney - grupo icarr baixo versus grupo icarr alto

\begin{tabular}{|ll|r|r|r|}
\hline & icarr & N & Mean Rank & Sum of Ranks \\
\hline cven06 & baixo & 22 & 24,02 & 528,50 \\
& alto & 22 & 20,98 & 461,50 \\
& Total & 44 & & \\
\hline roe06 & baixo & 22 & 24,07 & 529,50 \\
& alto & 22 & 20,93 & 460,50 \\
& Total & 44 & & \\
\hline mven06 & baixo & 22 & 21,73 & 478,00 \\
& alto & 22 & 23,27 & 512,00 \\
& Total & 44 & & \\
\hline cven07 & baixo & 22 & 22,55 & 496,00 \\
& alto & 22 & 22,45 & 494,00 \\
& Total & 44 & & \\
\hline roe07 & baixo & 22 & 23,11 & 508,50 \\
& alto & 22 & 21,89 & 481,50 \\
& Total & 44 & & 505,50 \\
\hline mven07 & baixo & 22 & 22,02 & \\
& alto & 22 & 22,98 & \\
& Total & 44 & & \\
\hline
\end{tabular}

FONTE: SPSS.

A média de mven06 apresenta diferença nos dois grupos: no icarr baixo é menor do que no grupo icarr alto. O p-valor $(=0,690)$, maior do que $5 \%$, indica que essa diferença não é significante. 
A média de cven07 no grupo icarr baixo é ligeiramente maior do que no grupo icarr alto. A diferença não é significante, pois o p-valor $(=0,981)$ é maior do que 0,05 .

A média de roe07 no grupo icarr baixo é maior do que no icarr alto. A diferença não é significante, pois o p-valor $(=0,751)$ é maior do que $5 \%$.

A média de mven07 no grupo icarr baixo é ligeiramente menor do que no icarr alto. Trata-se de diferença não significante, dado que o p-valor $(=0,805)$ é maior do que $5 \%$.

Tabela 23 - Estatísticas do teste de Mann-Whitney - grupo icarr baixo versus grupo icarr alto Test Statistics ${ }^{\mathrm{a}}$

\begin{tabular}{|l|r|r|r|r|r|r|}
\hline & \multicolumn{1}{|c|}{ cven06 } & roe06 & mven06 & cven07 & roe07 & mven07 \\
\hline Mann-Whitney U & 208,500 & 207,500 & 225,000 & 241,000 & 228,500 & 231,500 \\
Wilcoxon W & 461,500 & 460,500 & 478,000 & 494,000 & 481,500 & 484,500 \\
Z &,- 786 &,- 810 &,- 399 &,- 023 &,- 317 &,- 247 \\
Asymp. Sig. (2-tailed) &, 432 &, 418 &, 690 &, 981 &, 751 &, 805 \\
\hline
\end{tabular}

a. Grouping Variable: icarr FONTE: SPSS.

As diferenças observadas nas médias dos grupos icarr baixo e icarr alto não se mostraram significantes. As estatísticas do teste de Mann-Whitney apresentaram p-valor maior do que $5 \%$ para todos os indicadores contábeis. Assim, não se pode rejeitar $\mathrm{H}_{0}$, o desempenho financeiro médio é semelhante nos grupos icarr baixo e icarr alto.

\section{- Índice de desenvolvimento e variáveis de desempenho financeiro}

O grupo idesen baixo é formado por empresas com valores de idesen abaixo da mediana; o grupo idesen alto é formado por empresas com valores acima da mediana. As tabelas 24 e 25 
elencam os resultados do teste de Mann-Whitney - grupo idesen baixo versus grupo idesen alto. A Tabela 24 mostra as médias; a Tabela 25 sinaliza as estatísticas do teste.

A média de cven06 no grupo idesen baixo é menor do que aquela do idesen alto. A diferença não é significante, pois o p-valor $(=0,335)$ é maior do que 0,05 .

A média de roe06 no grupo idesen baixo é maior do que no idesen alto. Dado que o p-valor (= 0,130 ) é maior do que $5 \%$, essa diferença não é significante.

Tabela 24 -Teste de Mann-Whitney - grupo idesen baixo versus grupo idesen alto

\begin{tabular}{|c|c|c|c|c|}
\hline \multicolumn{5}{|c|}{ Ranks } \\
\hline & idesen & $\mathrm{N}$ & Mean Rank & Sum of Ranks \\
\hline \multirow[t]{3}{*}{ cven06 } & baixo & 23 & 20,72 & 476,50 \\
\hline & alto & 21 & 24,45 & 513,50 \\
\hline & Total & 44 & & \\
\hline \multirow[t]{3}{*}{ roe06 } & baixo & 23 & 25,30 & 582,00 \\
\hline & alto & 21 & 19,43 & 408,00 \\
\hline & Total & 44 & & \\
\hline \multirow[t]{3}{*}{ mven06 } & baixo & 23 & 23,57 & 542,00 \\
\hline & alto & 21 & 21,33 & 448,00 \\
\hline & Total & 44 & & \\
\hline \multirow[t]{3}{*}{ cven07 } & baixo & 23 & 23,48 & 540,00 \\
\hline & alto & 21 & 21,43 & 450,00 \\
\hline & Total & 44 & & \\
\hline \multirow[t]{3}{*}{ roe07 } & baixo & 23 & 24,57 & 565,00 \\
\hline & alto & 21 & 20,24 & 425,00 \\
\hline & Total & 44 & & \\
\hline \multirow[t]{3}{*}{ mven07 } & baixo & 23 & 19,78 & 455,00 \\
\hline & alto & 21 & 25,48 & 535,00 \\
\hline & Total & 44 & & \\
\hline
\end{tabular}

FONTE: SPSS. 
A média de mven06, no grupo idesen baixo, é maior do que no idesen alto. No entanto, essa diferença não é significante. O p-valor $(=0,565)$ é maior do que $5 \%$.

Também a média de cven07 no grupo idesen baixo é maior do que no idesen alto. A diferença não é significante, pois o p-valor $(=0,597)$ é maior do que 0,05 .

A média de roe07 apresenta diferença nos dois grupos: a do idesen baixo é maior do que aquela do idesen alto. $\mathrm{O}$ p-valor $(=0,264)$, maior do que $5 \%$, indica que essa diferença não é significante.

A média de mven07 no grupo idesen baixo é menor do que aquela do idesen alto. Essa diferença não é significante, dado que o p-valor $(=0,142)$ é maior do que $5 \%$.

Tabela 25 - Estatísticas do teste de Mann-Whitney - grupo idesen baixo versus grupo idesen alto

Test Statistics ${ }^{\text {a }}$

\begin{tabular}{|l|r|r|r|r|r|r|}
\hline & \multicolumn{1}{|c|}{ cven06 } & \multicolumn{1}{c|}{ roe06 } & mven06 & cven07 & \multicolumn{1}{c|}{ roe07 } & mven07 \\
\hline Mann-Whitney U & 200,500 & 177,000 & 217,000 & 219,000 & 194,000 & 179,000 \\
Wilcoxon W & 476,500 & 408,000 & 448,000 & 450,000 & 425,000 & 455,000 \\
Z &,- 963 & $-1,516$ &,- 576 &,- 529 & $-1,116$ & $-1,469$ \\
Asymp. Sig. (2-tailed) &, 335 &, 130 &, 565 &, 597 &, 264 &, 142 \\
\hline
\end{tabular}

a. Grouping Variable: idesen

FONTE: SPSS.

As diferenças observadas nas médias dos grupos idesen baixo e idesen alto não se mostraram significantes. As estatísticas do teste de Mann-Whitney apresentaram p-valor maior do que $5 \%$ para todos os indicadores contábeis. Assim, não se pode rejeitar $\mathrm{H}_{0}$, o desempenho financeiro médio é semelhante nos grupos idesen baixo e idesen alto. 
O teste de Mann-Whitney para duas amostras independentes foi aplicado com o objetivo de verificar se existia diferença no desempenho financeiro médio nos grupos "baixo" e "alto". Tal desempenho foi medido pelos indicadores contábeis: crescimento das vendas, retorno sobre patrimônio líquido, margem líquida sobre as vendas, dos exercícios de 2006 e de 2007. Os resultados não permitem rejeitar $\mathrm{H}_{0}$, a $5 \%$. O desempenho financeiro médio é semelhante nos dois grupos.

\subsection{Análise de correlação}

O coeficiente de correlação é um valor compreendido entre -1 e +1 . O Quadro 8 apresenta a interpretação do valor do coeficiente utilizada nesta pesquisa. Para os coeficientes negativos, a interpretação é idêntica.

Quadro 8 - Interpretação do coeficiente de correl
\begin{tabular}{|c|c|}
\hline Coeficiente & Grau de associação \\
\hline \hline igual a 0 & nula \\
\hline de 0,01 a 0,19 & muito fraca \\
\hline de 0,20 a 0,39 & fraca \\
\hline de 0,40 a 0,59 & moderadamente forte \\
\hline de 0,60 a 0,79 & forte \\
\hline de 0,80 a 0,99 & muito forte \\
\hline igual a 1 & perfeita \\
\hline
\end{tabular}

Fonte: Elaborado pela autora.

\subsubsection{Análise de correlação de Pearson}

O coeficiente de correlação de Pearson foi utilizado para verificar se existia associação linear significante entre as variáveis de remuneração e as variáveis de desempenho financeiro. $\mathrm{O}$ nível de significância adotado é de 10\%. A Tabela 26 mostra os coeficientes de correlação das variáveis da pesquisa. 
Tabela 26- Matriz de correlações de Pearson

\begin{tabular}{|c|c|c|c|c|c|c|c|c|c|c|c|c|}
\hline & $\begin{array}{c}1 \\
\text { salmen }\end{array}$ & $\begin{array}{c}\mathbf{2} \\
\text { salvar }\end{array}$ & $\begin{array}{c}3 \\
\text { ibenef }\end{array}$ & $\begin{array}{c}4 \\
\text { icarr }\end{array}$ & $\begin{array}{c}5 \\
\text { idesen }\end{array}$ & $\begin{array}{c}6 \\
\text { cven } \\
06\end{array}$ & $\begin{array}{c}7 \\
\text { roe06 }\end{array}$ & $\begin{array}{c}8 \\
\text { mven } \\
06\end{array}$ & $\begin{array}{c}9 \\
\text { cven } \\
07 \\
\end{array}$ & $\begin{array}{c}10 \\
\text { roe07 }\end{array}$ & $\begin{array}{c}11 \\
\text { mven } \\
07\end{array}$ & $\begin{array}{c}12 \\
\text { porte }\end{array}$ \\
\hline 1 & $\begin{array}{c}1 \\
44\end{array}$ & & & & & & & & & & & \\
\hline 2 & $\begin{array}{c}, 641 \# \\
, 000 \\
44\end{array}$ & $\begin{array}{c}1 \\
44\end{array}$ & & & & & & & & & & \\
\hline 3 & $\begin{array}{c}-, 110 \\
, 478 \\
44\end{array}$ & $\begin{array}{c}-, 049 \\
, 751 \\
44\end{array}$ & $\begin{array}{c}1 \\
44\end{array}$ & & & & & & & & & \\
\hline 4 & $\begin{array}{c}, 202 \\
, 187 \\
44\end{array}$ & $\begin{array}{c}, 291 \\
, 055 \\
44\end{array}$ & $\begin{array}{c}, 167 \\
278 \\
44\end{array}$ & $\begin{array}{c}1 \\
44\end{array}$ & & & & & & & & \\
\hline 5 & $\begin{array}{c}, 028 \\
, 855 \\
44\end{array}$ & $\begin{array}{c}-, 039 \\
, 804 \\
44\end{array}$ & $\begin{array}{c}, 209 \\
, 173 \\
44\end{array}$ & $\begin{array}{c}, 278 \\
, 067 \\
44\end{array}$ & $\begin{array}{c}1 \\
44\end{array}$ & & & & & & & \\
\hline 6 & $\begin{array}{c}, 077 \\
, 620 \\
44\end{array}$ & $\begin{array}{c}, 120 \\
, 437 \\
44\end{array}$ & $\begin{array}{c}, 188 \\
, 222 \\
44\end{array}$ & $\begin{array}{c}-, 268 \\
, 079 \\
44\end{array}$ & $\begin{array}{c}-, 117 \\
, 449 \\
44\end{array}$ & $\begin{array}{c}1 \\
44 \\
\end{array}$ & & & & & & \\
\hline 7 & $\begin{array}{c}, 051 \\
, 741 \\
44\end{array}$ & $\begin{array}{c}, 077 \\
, 619 \\
44\end{array}$ & $\begin{array}{c}, 060 \\
, 701 \\
44\end{array}$ & $\begin{array}{c}-, 272 \\
, 074 \\
44\end{array}$ & $\begin{array}{c}-, 305^{*} \\
, 044 \\
44\end{array}$ & $\begin{array}{c}, 541 \# \\
, 000 \\
44\end{array}$ & $\begin{array}{c}1 \\
44 \\
\end{array}$ & & & & & \\
\hline 8 & $\begin{array}{c}, 156 \\
, 312 \\
44\end{array}$ & $\begin{array}{c}, 091 \\
, 556 \\
44\end{array}$ & $\begin{array}{c}, 144 \\
, 350 \\
44\end{array}$ & $\begin{array}{c}-, 063 \\
, 682 \\
44\end{array}$ & $\begin{array}{c}027 \\
, 864 \\
44\end{array}$ & $\begin{array}{c}, 322^{*} \\
, 033 \\
44\end{array}$ & $\begin{array}{c}, 660 \# \\
, 000 \\
44\end{array}$ & $\begin{array}{c}1 \\
44\end{array}$ & & & & \\
\hline 9 & $\begin{array}{c}, 112 \\
471 \\
44\end{array}$ & $\begin{array}{c}, 084 \\
, 587 \\
44\end{array}$ & $\begin{array}{c}-, 087 \\
, 573 \\
44\end{array}$ & $\begin{array}{c}-, 001 \\
, 994 \\
44\end{array}$ & $\begin{array}{c}-, 088 \\
, 570 \\
44\end{array}$ & $\begin{array}{c}, 022 \\
, 885 \\
44\end{array}$ & $\begin{array}{c}, 079 \\
, 609 \\
44\end{array}$ & $\begin{array}{c}, 207 \\
, 177 \\
44\end{array}$ & 44 & & & \\
\hline 10 & $\begin{array}{c}, 097 \\
, 530 \\
44\end{array}$ & $\begin{array}{c}, 068 \\
660 \\
44\end{array}$ & $\begin{array}{c}, 063 \\
685 \\
44\end{array}$ & $\begin{array}{c}-, 190 \\
216 \\
44\end{array}$ & $\begin{array}{c}-, 191 \\
, 214 \\
44\end{array}$ & $\begin{array}{c}, 471 \# \\
, 001 \\
44\end{array}$ & $\begin{array}{c}, 736 \# \\
, 000 \\
44\end{array}$ & $\begin{array}{c}, 574 \# \\
, 000 \\
44\end{array}$ & $\begin{array}{c}, 181 \\
240 \\
44\end{array}$ & $\begin{array}{c}1 \\
44\end{array}$ & & \\
\hline 11 & $\begin{array}{c}, 122 \\
431 \\
44\end{array}$ & $\begin{array}{c}, 038 \\
, 808 \\
44\end{array}$ & $\begin{array}{c}, 036 \\
, 819 \\
44\end{array}$ & $\begin{array}{c}-, 123 \\
, 426 \\
44\end{array}$ & $\begin{array}{c}, 202 \\
, 188 \\
44\end{array}$ & $\begin{array}{c}351^{*} \\
, 019 \\
44\end{array}$ & $\begin{array}{c}, 482 \# \\
, 001 \\
44\end{array}$ & $\begin{array}{c}, 762 \# \\
, 000 \\
44\end{array}$ & $\begin{array}{c}, 002 \\
, 991 \\
44\end{array}$ & $\begin{array}{c}643 \# \\
, 000 \\
44\end{array}$ & $\begin{array}{c}1 \\
44\end{array}$ & \\
\hline 12 & $\begin{array}{c}, 243 \\
, 111 \\
44\end{array}$ & $\begin{array}{c}, 576 \# \\
, 000 \\
44\end{array}$ & $\begin{array}{c}, 127 \\
410 \\
44\end{array}$ & $\begin{array}{c}, 181 \\
, 240 \\
44\end{array}$ & $\begin{array}{c}197 \\
, 201 \\
44\end{array}$ & $\begin{array}{c}, 026 \\
, 868 \\
44\end{array}$ & $\begin{array}{c}-, 160 \\
, 299 \\
44\end{array}$ & $\begin{array}{c}-, 039 \\
, 801 \\
44\end{array}$ & $\begin{array}{c}210 \\
, 171 \\
44\end{array}$ & $\begin{array}{c}-, 008 \\
, 961 \\
44\end{array}$ & $\begin{array}{c}-, 009 \\
, 951 \\
44\end{array}$ & 44 \\
\hline
\end{tabular}

\#. Correlation is significant at the 0,01 level (2-tailed).

*. Correlation is significant at the 0,05 level (2-tailed).

Obs: A primeira linha apresenta o coeficiente de correlação de Pearson; a segunda, o p-valor do teste de significância bilateral; a terceira apresenta o número de observações.

FONTE: Elaborado pela autora.

A variável salmen está significativamente correlacionada com a variável salvar. O coeficiente é positivo e forte $(\mathrm{r}=0,641)$. Já o coeficiente de correlação entre salvar e icarr mostra uma associação positiva, fraca e significante, a 10\% ( $\mathrm{r}=0,291)$. A correlação entre salvar e porte é positiva, significante e moderadamente forte $(r=0,576)$. 
Com nível de significância de 10\%, o coeficiente mostra uma associação da variável icarr com as seguintes variáveis: idesen - positiva e fraca $(r=0,278)$; cven06 - negativa e fraca $(r$ $=-0,268)$; e roe06 - negativa e fraca $(\mathrm{r}=-0,272)$.

A variável idesen está significativamente correlacionada com roe06. O coeficiente é negativo e fraco $(r=-0,305)$.

A variável cven06 está correlacionada com as seguintes variáveis: roe06 - positiva e moderadamente forte $(\mathrm{r}=0,541)$; mven06 - positiva e fraca, a 5\% $(\mathrm{r}=0,322)$; roe07 positiva e moderadamente forte, a $1 \%(\mathrm{r}=0,471)$; mven07 - positiva e fraca, a $5 \%(\mathrm{r}=$ $0,351)$.

As seguintes variáveis correlacionam-se significativamente com a variável roe06, a mencionar: mven06 - positiva e forte $(r=0,660)$; roe07 - positiva e forte $(r=0,736)$; mven07 - positiva e moderadamente forte $(r=0,482)$.

O coeficiente mostra uma correlação significativa, positiva e moderadamente forte entre as variáveis mven06 e roe07 $(\mathrm{r}=0,574)$. Aponta também uma correlação positiva, forte e significativa entre mven06 e mven07 $(r=0,762)$.

A variável roe07 está significativamente correlacionada com mven07. O coeficiente é positivo e forte $(r=0,643)$.

Os demais coeficientes apresentam p-valor maior do que $10 \%$. Portanto, não se pode rejeitar a hipótese nula. Não há associação entre os demais pares de variáveis.

Os resultados da análise de correlação de Pearson revelam a existência de correlação significativa entre as seguintes variáveis de remuneração e desempenho financeiro: icarr e cven06; icarr e roe06; idesen e roe06. Os coeficientes dessas correlações mostraram-se negativos e fracos. A associação negativa entre as variáveis indica que aumentos em uma variável estão associados a diminuições em outra. 


\subsubsection{Análise de correlação de Spearman}

Para aumentar a confiabilidade dos resultados, utilizou-se o coeficiente de correlação de Spearman. O nível de significância adotado é de 10\%. A Tabela 27 apresenta os coeficientes de correlação das variáveis da pesquisa.

O coeficiente de correlação mostra uma associação positiva, significante e forte entre salmen e salvar $(\rho=0,627)$. Já o coeficiente entre salvar e icarr é positivo, fraco e significante a $5 \%$ $(\rho=0,344)$. A variável salvar está significativamente correlacionada com a variável porte. $\mathrm{O}$ coeficiente é positivo e moderadamente forte $(\rho=0,462)$.

A $10 \%$, ibenef apresenta uma associação positiva e fraca, com mven06 $(\rho=0,262)$. Já idesen demonstra uma associação negativa e fraca, com roe06 $(\rho=-0,268)$.

A variável cven06 está significativamente correlacionada com as variáveis: roe06 coeficiente positivo e moderadamente forte $(\rho=0,434)$; roe07 - coeficiente positivo e moderadamente forte $(\rho=0,459)$; mven07 - coeficiente positivo e moderadamente forte $(\rho=$ 0,499). O coeficiente entre cven06 e mven06 é positivo, fraco e significante, a 5\% ( $\rho=$ $0,329)$.

O coeficiente de correlação mostra uma associação significante entre roe06 e as variáveis: mven06 - positiva e forte $(\rho=0,656)$; roe07 - positiva e forte $(\rho=0,633)$; mven07 - positiva e moderadamente forte $(\rho=0,404)$.

A variável mven06 está significativamente correlacionada com as variáveis: roe07 coeficiente positivo e moderadamente forte $(\rho=0,441)$; mven07 - coeficiente positivo e forte $(\rho=0,604)$.

A 5\%, a variável cven07 apresenta uma associação positiva e fraca com a variável roe07 ( $\rho=$ 0,309). A $10 \%$, cven07 está correlacionada com porte. O coeficiente é positivo e fraco ( $\rho=$ $0,290)$. 
As variáveis roe07 e mven07 estão significativamente correlacionadas. O coeficiente é positivo e forte $(\rho=0,622)$.

Os demais coeficientes apresentam p-valor maior do que $10 \%$. Assim, não se pode rejeitar a hipótese nula. Não há associação entre os demais pares de variáveis.

Tabela 27 - Matriz de correlações de Spearman

\begin{tabular}{|c|c|c|c|c|c|c|c|c|c|c|c|c|}
\hline & $\begin{array}{c}1 \\
\text { salmen }\end{array}$ & $\begin{array}{c}2 \\
\text { salvar }\end{array}$ & $\begin{array}{c}3 \\
\text { ibenef }\end{array}$ & $\begin{array}{c}4 \\
\text { icarr }\end{array}$ & $\begin{array}{c}5 \\
\text { idesen }\end{array}$ & $\begin{array}{c}6 \\
\text { cven } \\
06 \\
\end{array}$ & $\begin{array}{c}7 \\
\text { roe06 }\end{array}$ & $\begin{array}{c}8 \\
\text { mven } \\
06 \\
\end{array}$ & $\begin{array}{c}9 \\
\text { cven } \\
07 \\
\end{array}$ & $\begin{array}{c}10 \\
\text { roe07 }\end{array}$ & $\begin{array}{c}11 \\
\text { mven } \\
07\end{array}$ & $\begin{array}{c}12 \\
\text { porte }\end{array}$ \\
\hline 1 & $\begin{array}{c}1 \\
44\end{array}$ & & & & & & & & & & & \\
\hline 2 & $\begin{array}{c}\text {,627\# } \\
, 000 \\
44\end{array}$ & $\begin{array}{c}1 \\
44\end{array}$ & & & & & & & & & & \\
\hline 3 & $\begin{array}{c}-, 109 \\
, 438 \\
44\end{array}$ & $\begin{array}{c}-, 022 \\
, 888 \\
44\end{array}$ & $\begin{array}{c}1 \\
44 \\
\end{array}$ & & & & & & & & & \\
\hline 4 & $\begin{array}{c}, 204 \\
, 184 \\
44\end{array}$ & $\begin{array}{c}344^{*} \\
, 022 \\
44\end{array}$ & $\begin{array}{c}, 149 \\
, 335 \\
44\end{array}$ & $\begin{array}{c}1 \\
44\end{array}$ & & & & & & & & \\
\hline 5 & $\begin{array}{c}061 \\
, 693 \\
44 \\
\end{array}$ & $\begin{array}{c}-, 033 \\
, 832 \\
44 \\
\end{array}$ & $\begin{array}{c}194 \\
, 208 \\
44 \\
\end{array}$ & $\begin{array}{c}, 248 \\
, 105 \\
44 \\
\end{array}$ & $\begin{array}{r}1 \\
44 \\
\end{array}$ & & & & & & & \\
\hline 6 & $\begin{array}{c}, 093 \\
, 549 \\
44 \\
\end{array}$ & $\begin{array}{c}100 \\
, 520 \\
44 \\
\end{array}$ & $\begin{array}{c}, 171 \\
, 268 \\
44 \\
\end{array}$ & $\begin{array}{c}-, 238 \\
, 120 \\
44 \\
\end{array}$ & $\begin{array}{c}, 079 \\
, 612 \\
44 \\
\end{array}$ & $\begin{array}{r}1 \\
44 \\
\end{array}$ & & & & & & \\
\hline 7 & $\begin{array}{c}, 031 \\
, 841 \\
44\end{array}$ & $\begin{array}{c}130 \\
, 399 \\
44\end{array}$ & $\begin{array}{c}, 087 \\
, 573 \\
44\end{array}$ & $\begin{array}{c}-, 238 \\
, 120 \\
44\end{array}$ & $\begin{array}{c}-, 268 \\
, 078 \\
44\end{array}$ & $\begin{array}{c}, 434 \# \\
, 003 \\
44\end{array}$ & $\begin{array}{c}1 \\
44\end{array}$ & & & & & \\
\hline 8 & $\begin{array}{c}091 \\
, 558 \\
44\end{array}$ & $\begin{array}{c}, 183 \\
, 233 \\
44 \\
\end{array}$ & $\begin{array}{c}, 262 \\
, 086 \\
44 \\
\end{array}$ & $\begin{array}{c}, 065 \\
, 674 \\
44 \\
\end{array}$ & $\begin{array}{c}-, 021 \\
, 893 \\
44\end{array}$ & $\begin{array}{c}, 329 * \\
, 029 \\
44\end{array}$ & $\begin{array}{c}, 656 \# \\
, 000 \\
44 \\
\end{array}$ & $\begin{array}{c}1 \\
44 \\
\end{array}$ & & & & \\
\hline 9 & $\begin{array}{c}, 170 \\
, 271 \\
44\end{array}$ & $\begin{array}{c}, 191 \\
, 215 \\
44\end{array}$ & $\begin{array}{c}-, 128 \\
, 407 \\
44\end{array}$ & $\begin{array}{c}, 059 \\
, 702 \\
44\end{array}$ & $\begin{array}{c}-, 046 \\
, 769 \\
44\end{array}$ & $\begin{array}{c}, 152 \\
, 324 \\
44\end{array}$ & $\begin{array}{c}, 055 \\
, 722 \\
44\end{array}$ & $\begin{array}{c}, 031 \\
, 839 \\
44\end{array}$ & $\begin{array}{c}1 \\
44\end{array}$ & & & \\
\hline 10 & $\begin{array}{c}, 086 \\
, 577 \\
44 \\
\end{array}$ & $\begin{array}{c}, 094 \\
, 543 \\
44 \\
\end{array}$ & $\begin{array}{c}, 112 \\
, 469 \\
44 \\
\end{array}$ & $\begin{array}{c}-, 130 \\
, 400 \\
44\end{array}$ & $\begin{array}{c}-, 165 \\
, 285 \\
44\end{array}$ & $\begin{array}{c}\text {,459\# } \\
, 002 \\
44 \\
\end{array}$ & $\begin{array}{c}633 \# \\
, 000 \\
44 \\
\end{array}$ & $\begin{array}{c}\text {,441\# } \\
, 003 \\
44 \\
\end{array}$ & $\begin{array}{c}309 * \\
, 041 \\
44 \\
\end{array}$ & $\begin{array}{r}1 \\
44 \\
\end{array}$ & & \\
\hline 11 & $\begin{array}{c}, 115 \\
, 457 \\
44\end{array}$ & $\begin{array}{c}, 099 \\
, 524 \\
44\end{array}$ & $\begin{array}{c}, 063 \\
, 687 \\
44\end{array}$ & $\begin{array}{c}, 026 \\
, 869 \\
44\end{array}$ & $\begin{array}{c}, 233 \\
, 128 \\
44\end{array}$ & $\begin{array}{c}, 499 \# \\
, 001 \\
44\end{array}$ & $\begin{array}{c}404 \# \\
, 007 \\
44\end{array}$ & $\begin{array}{c}\text {,604\# } \\
, 000 \\
44\end{array}$ & $\begin{array}{c}, 152 \\
, 324 \\
44\end{array}$ & $\begin{array}{c}\text {,622\# } \\
, 000 \\
44\end{array}$ & $\begin{array}{c}1 \\
44\end{array}$ & \\
\hline 12 & $\begin{array}{c}, 176 \\
, 253 \\
44 \\
\end{array}$ & $\begin{array}{c}, 462 \# \\
, 002 \\
44 \\
\end{array}$ & $\begin{array}{c}135 \\
, 382 \\
44 \\
\end{array}$ & $\begin{array}{c}219 \\
, 153 \\
44 \\
\end{array}$ & $\begin{array}{c}101 \\
, 512 \\
44 \\
\end{array}$ & $\begin{array}{c}, 105 \\
, 499 \\
44 \\
\end{array}$ & $\begin{array}{c}-, 063 \\
, 683 \\
44 \\
\end{array}$ & $\begin{array}{c}, 077 \\
, 619 \\
44 \\
\end{array}$ & $\begin{array}{c}, 290 \\
, 057 \\
44 \\
\end{array}$ & $\begin{array}{c}069 \\
, 656 \\
44 \\
\end{array}$ & $\begin{array}{c}, 142 \\
, 357 \\
44\end{array}$ & $\begin{array}{c}1 \\
44 \\
\end{array}$ \\
\hline
\end{tabular}

\#. Correlation is significant at the 0,01 level (2-tailed).

*. Correlation is significant at the 0,05 level (2-tailed).

Obs: A primeira linha apresenta o coeficiente de correlação de Spearman; a segunda, o p-valor do teste de significância bilateral; a terceira apresenta o número de observações.

FONTE: Elaborado pela autora. 
Os resultados da análise de correlação de Spearman apontam a existência de correlação significativa entre as seguintes variáveis de remuneração e desempenho financeiro: ibenef e mven06; idesen e roe06. O coeficiente de correlação de Spearman entre ibenef e mven06 é positivo e fraco; entre idesen e roe06, é negativo e fraco.

\subsection{Análise de regressão linear}

Para testar a hipótese de que existe relação positiva e significante entre a remuneração dos executivos e o desempenho financeiro das empresas, utilizou-se a análise de regressão. Inicialmente, desenvolveu-se uma série de regressões simples para avaliar, de maneira preliminar, a relação entre as variáveis de remuneração (variável independente) e de desempenho financeiro das empresas (variável dependente). Foram desenvolvidas regressões simples para todos os pares de variáveis dependentes e independentes. Conforme mencionado na seção 4.4.4, o modelo geral de regressão linear simples empregado na pesquisa foi:

$$
\mathrm{DF}_{\mathrm{i}}=\beta_{0}+\beta_{1} \text { remuneração }_{\mathrm{i}}+\mu_{\mathrm{i}}
$$

Onde:

$i$ representa a $i$-ésima empresa;

DF representa as variáveis de desempenho financeiro utilizadas alternadamente: cven06, roe06, mven06, cven07, roe07, mven07;

remuneração representa as variáveis de remuneração utilizadas alternadamente: salmen, salvar, ibenef, icarr, idesen;

$\mu$ representa o termo de erro.

Para a análise da adequação dos modelos aos pressupostos da análise de regressão, foram realizados os seguintes testes: 
- Kolmogorov-Smirnov: para verificar a normalidade da distribuição dos resíduos;

- Pesarán-Pesarán: para verificar a homoscedasticidade dos resíduos;

- Durbin-Watson: para verificar a ausência de autocorrelação de resíduos.

Em seguida, foram desenvolvidas regressões múltiplas utilizando simultaneamente todas as variáveis de remuneração como variável independente e as variáveis de desempenho financeiro, alternadamente, como dependentes. O porte foi utilizado como variável de controle. O modelo geral de regressão linear múltipla empregado - conforme seção 4.4 .4 foi:

$$
\mathrm{DF}_{\mathrm{i}}=\beta_{0}+\beta_{1} \text { salmen }_{\mathrm{i}}+\beta_{2} \text { salvar }_{\mathrm{i}}+\beta_{3} \text { ibenef }_{\mathrm{i}}+\beta_{4} \text { icarr }_{\mathrm{i}}+\beta_{5} \text { idesen }_{\mathrm{i}}+\beta_{6} \text { porte }_{\mathrm{i}}+\mu_{\mathrm{i}}
$$

Onde:

$i$ representa a $i$-ésima empresa;

DF representa as variáveis de desempenho financeiro utilizadas alternadamente: cven06, roe06, mven06, cven07, roe 07 , mven07;

salmen = salário mensal médio;

salvar = salário variável médio;

ibenef = índice de benefício;

icarr = índice de carreira;

idesen = índice de desenvolvimento;

porte - variável de controle $=$ logaritmo natural do número de funcionários;

$\mu=$ termo de erro.

Para a análise da adequação dos modelos aos pressupostos da análise de regressão foram realizados, além dos testes já mencionados na análise de regressão simples, o VIF (Variance Inflation Factor - Fator de Inflação da Variância), para verificar a ausência de multicolinearidade. $\mathrm{O}$ valor habitualmente considerado como limite, acima do qual existe multicolinearidade, é 10 . 
Becker e Gerhart (1996) sugerem que os pesquisadores, ao apresentarem os resultados dos modelos de regressão, insiram os coeficientes. O objetivo deste processo seria esclarecer a direção e a magnitude do efeito das variáveis de remuneração sobre aquelas de desempenho financeiro.

\subsubsection{Análise de regressão linear simples}

Dos 30 modelos testados, somente 3 apresentaram significância estatística, ou seja, o p-valor do teste $\mathrm{F}$ revelou valor menor do que 10\%, nível de significância adotado. Esses modelos são exibidos a seguir, e os demais são listados no Apêndice 4.

\section{- Crescimento das vendas de 2006 e índice de carreira}

As tabelas 28 a 30 apresentam os resultados da regressão linear simples, estimada com o método dos mínimos quadrados, utilizando como variável dependente o crescimento das vendas de 2006 e, como variável independente, o índice de carreira:

$$
\operatorname{cven}_{06} 6_{\mathrm{i}}=\beta_{0}+\beta_{1} \text { icarr }_{\mathrm{i}}+\mu_{\mathrm{i}}
$$

O coeficiente de correlação $(R)$ reflete o grau de associação entre a variável dependente cven06 e a independente icarr, que é de 0,268. O R-quadrado (coeficiente de determinação) indica que $7,2 \%$ da variação na dependente cven06 é explicada pelas oscilações ocorridas na independente icarr (Tabela 28). 
Tabela 28 - Resumo do modelo de regressão - cven06 e icarr

Model Summary

\begin{tabular}{|l|r|r|r|c|}
\hline Model & \multicolumn{1}{|c|}{$\mathrm{R}$} & R Square & \multicolumn{1}{|c|}{$\begin{array}{c}\text { Adjusted R } \\
\text { Square }\end{array}$} & $\begin{array}{c}\text { Std. Error of the } \\
\text { Estimate }\end{array}$ \\
\hline 1 &, $268^{\mathrm{a}}$ &, 072 &, 050 & 10,7458 \\
\hline
\end{tabular}

a. Predictors: (Constant), icarr FONTE: SPSS.

A Tabela 29 apresenta o resultado do teste $\mathrm{F}$, que verifica a significância do modelo geral. As hipóteses testadas são:

$$
\begin{aligned}
& \mathrm{H}_{0}: \text { R-quadrado }=0 \\
& \mathrm{H}_{1}: \text { R-quadrado }>0
\end{aligned}
$$

Pelo p-valor igual a 0,079 (menor do que 10\%), constata-se que o modelo apresenta um Rquadrado diferente de zero, ou seja, o modelo é significante.

Tabela 29 - ANOVA do modelo de regressão - cven06 e icarr

\begin{tabular}{|ll|r|r|r|r|r|}
\hline \multicolumn{2}{|c|}{ ANOVA $^{\mathbf{b}}$} \\
\hline 1 & Sum of Squares & \multicolumn{1}{|c|}{ df } & Mean Square & F & \multicolumn{1}{c|}{ Sig. } \\
\hline & Regression & 374,421 & 1 & 374,421 & 3,243 &, $079^{\mathrm{a}}$ \\
& Residual & 4849,825 & 42 & 115,472 & & \\
& Total & 5224,245 & 43 & & & \\
\hline
\end{tabular}
a. Predictors: (Constant), icarr
b. Dependent Variable: cven06
FONTE: SPSS

A Tabela 30 exibe o resultado do teste $t$, que verifica a significância de cada um dos coeficientes do modelo de regressão. As hipóteses testadas são:

$\mathrm{H}_{0}$ : os coeficientes são iguais a zero

$\mathrm{H}_{1}$ : os coeficientes não são iguais a zero 
Pelo exame do p-valor (menor do que 10\%), constata-se que os coeficientes são diferentes de zero. Tanto a constante quanto a variável icarr fazem parte do modelo que tem cven06 como dependente. $\mathrm{O}$ coeficiente da variável icarr apresenta sinal negativo, contrário às expectativas iniciais.

Tabela 30 - Coeficientes do modelo de regressão - cven06 e icarr

\begin{tabular}{|c|c|c|c|c|c|c|}
\hline \multicolumn{7}{|c|}{ Coefficients $^{\mathrm{a}}$} \\
\hline \multirow{2}{*}{\multicolumn{2}{|c|}{ Model }} & \multicolumn{2}{|c|}{ Unstandardized Coefficients } & \multirow{2}{*}{$\begin{array}{c}\text { Standardized } \\
\text { Coefficients } \\
\text { Beta }\end{array}$} & \multirow[b]{2}{*}{$\mathrm{t}$} & \multirow[b]{2}{*}{ Sig. } \\
\hline & & B & Std. Error & & & \\
\hline 1 & (Constant) & 11,307 & 3,800 & & 2,976 &, 005 \\
\hline & icarr &,- 272 & ,151 &,- 268 & $-1,801$ & ,079 \\
\hline
\end{tabular}

a. Dependent Variable: cven06

FONTE: SPSS.

A análise dos pressupostos do modelo de regressão linear inicia-se com a avaliação da normalidade dos resíduos. O diagnóstico é feito por meio do teste Kolmogorov-Smirnov. O pvalor igual a 0,992 (maior do que 10\%) permite aceitar a hipótese nula, a distribuição é normal.

O pressuposto da homoscedasticidade dos resíduos é verificado por meio do teste PesaránPesarán. O resultado da regressão tendo o quadrado dos resíduos padronizados como variável dependente e o quadrado dos valores estimados padronizados como variável independente, não permite que se rejeite a hipótese nula, os resíduos são homoscedásticos.

O diagnóstico da linearidade é feito com o diagrama de dispersão, que comprova a relação de linearidade entre a variáveis dependente e independente. A avaliação da ausência de autocorrelação serial é feita pelo teste Durbin-Watson, que apresenta valor igual a 1,832 valor próximo de 2 - indicando ausência de autocorrelação serial dos resíduos. 
Como todos os pressupostos são atendidos, as estimativas são consistentes. Assim, os resultados apontam a existência de relação entre o índice de carreira e o crescimento das vendas de 2006. Essa relação é fraca, e o coeficiente do índice de carreira apresenta sinal negativo.

\section{- Retorno sobre patrimônio líquido de 2006 e índice de carreira}

As tabelas 31 a 33 apresentam os resultados da regressão linear simples, estimada com o método dos mínimos quadrados. Utilizam como variável dependente o retorno sobre patrimônio líquido de 2006 e, como variável independente, o índice de carreira:

$$
\operatorname{roe}_{0} 6_{\mathrm{i}}=\beta_{0}+\beta_{1} \text { icarri }_{\mathrm{i}}+\mu_{\mathrm{i}}
$$

O coeficiente de correlação $(\mathrm{R})$ reflete o grau de associação entre as variáveis dependente roe06 e independente icarr, que é de 0,272. O R-quadrado (coeficiente de determinação) indica que $7,4 \%$ da variação na dependente roe06 é explicada pelas oscilações ocorridas na independente icarr (Tabela 31).

Tabela 31 - Resumo do modelo de regressão - roe06 e icarr

\begin{tabular}{|l|r|r|r|c|}
\hline & \multicolumn{1}{|c|}{ Model Summary } \\
\hline Model & \multicolumn{1}{c|}{$\mathrm{R}$} & R Square & \multicolumn{1}{c|}{$\begin{array}{c}\text { Adjusted R } \\
\text { Square }\end{array}$} & $\begin{array}{c}\text { Std. Error of the } \\
\text { Estimate }\end{array}$ \\
\hline 1 &, $272^{\mathrm{a}}$ &, 074 &, 052 & 17,0730 \\
\hline
\end{tabular}

a. Predictors: (Constant), icarr FONTE: SPSS.

A Tabela 32 apresenta o resultado do teste $\mathrm{F}$, que verifica a significância do modelo geral. As hipóteses testadas são: 
$\mathrm{H}_{0}: \mathrm{R}$-quadrado $=0$

$\mathrm{H}_{1}$ : R-quadrado $>0$

Pelo p-valor igual a 0,074 (menor do que 10\%), constata-se que o modelo apresenta um Rquadrado diferente de zero, ou seja, o modelo é significante.

Tabela 32 - ANOVA do modelo de regressão - roe06 e icarr

\begin{tabular}{|c|c|c|c|c|c|c|}
\hline \multicolumn{7}{|c|}{ ANOVA $^{b}$} \\
\hline & & Sum of Squares & $\mathrm{df}$ & Mean Square & $\mathrm{F}$ & Sig. \\
\hline \multirow[t]{3}{*}{1} & Regression & 977,918 & 1 & 977,918 & 3,355 &, $074^{\mathrm{a}}$ \\
\hline & Residual & 12242,454 & 42 & 291,487 & & \\
\hline & Total & 13220,372 & 43 & & & \\
\hline
\end{tabular}

a. Predictors: (Constant), icarr

b. Dependent Variable: roe06 FONTE: SPSS.

A Tabela 33 apresenta a significância estatística dos coeficientes. O p-valor do teste $t$ de cada um deles mostra que tanto a constante quanto a variável icarr fazem parte do modelo que tem roe06 como variável dependente. $\mathrm{O}$ coeficiente de icarr exibe sinal negativo.

Tabela 33 - Coeficientes do modelo de regressão - roe06 e icarr

\section{Coefficients $^{\mathrm{a}}$}

\begin{tabular}{|c|c|c|c|c|c|c|}
\hline \multirow{2}{*}{\multicolumn{2}{|c|}{ Model }} & \multicolumn{2}{|c|}{ Unstandardized Coefficients } & \multirow{2}{*}{$\begin{array}{c}\begin{array}{c}\text { Standardized } \\
\text { Coefficients }\end{array} \\
\text { Beta }\end{array}$} & \multirow[b]{2}{*}{$\mathrm{t}$} & \multirow[b]{2}{*}{ Sig. } \\
\hline & & B & Std. Error & & & \\
\hline \multirow[t]{2}{*}{1} & (Constant) & 28,516 & 6,037 & & 4,724 & 000 \\
\hline & icarr &,- 439 &, 240 &,- 272 & $-1,832$ & 074 \\
\hline
\end{tabular}

a. Dependent Variable: roe06 FONTE: SPSS. 
A análise dos pressupostos do modelo de regressão linear inicia-se com a avaliação da normalidade dos resíduos. O diagnóstico é feito por meio do teste Kolmogorov-Smirnov. O pvalor igual a 0,688 (maior do que 10\%) permite aceitar a hipótese nula, a distribuição é normal.

O pressuposto da homoscedasticidade dos resíduos é verificado por meio do teste PesaránPesarán. O resultado da regressão tendo o quadrado dos resíduos padronizados como variável dependente e o quadrado dos valores estimados padronizados como independente, não permite que se rejeite a hipótese nula, os resíduos são homoscedásticos.

O diagnóstico da linearidade é feito pelo diagrama de dispersão, que comprova a relação de linearidade entre as variáveis dependente e independente. A avaliação da ausência de autocorrelação serial é feita pelo teste Durbin-Watson, que apresenta valor igual a 2,130 valor próximo de 2 - indicando ausência de autocorrelação serial dos resíduos.

Como todos os pressupostos são atendidos, as estimativas são consistentes. Assim, os resultados apontam uma relação fraca entre o índice de carreira e o retorno sobre patrimônio líquido de 2006. O coeficiente do índice de carreira apresenta sinal negativo.

\section{- Retorno sobre patrimônio líquido de 2006 e índice de desenvolvimento}

As tabelas 34 a 36 apresentam os resultados da regressão linear simples, estimada com o método dos mínimos quadrados. Adotam como variável dependente o retorno sobre patrimônio líquido de 2006 e, como variável independente, o índice de desenvolvimento:

$$
\text { roe } 06_{\mathrm{i}}=\beta_{0}+\beta_{1} \text { idesen }_{\mathrm{i}}+\mu_{\mathrm{i}}
$$

O coeficiente de correlação $(\mathrm{R})$ reflete o grau de associação entre as variáveis dependente roe06 e independente idesen, que é de 0,305. O R-quadrado (coeficiente de determinação) indica que 9,3\% da variação na variável dependente roe06 é explicada pelas oscilações ocorridas na independente idesen (Tabela 34). 
Tabela 34 - Resumo do modelo de regressão - roe06 e idesen

\begin{tabular}{|c|c|c|c|c|}
\hline \multicolumn{5}{|c|}{ Model Summary } \\
\hline Model & $\mathrm{R}$ & R Square & $\begin{array}{l}\text { Adjusted R } \\
\text { Square }\end{array}$ & $\begin{array}{l}\text { Std. Error of the } \\
\text { Estimate }\end{array}$ \\
\hline 1 &, $305^{\mathrm{a}}$ & 093 & ,072 & 16,8948 \\
\hline
\end{tabular}

a. Predictors: (Constant), idesen FONTE: SPSS.

A Tabela 35 apresenta o resultado do teste F, que verifica a significância do modelo geral. As hipóteses testadas são:

$$
\begin{aligned}
& \mathrm{H}_{0}: \text { R-quadrado }=0 \\
& \mathrm{H}_{1}: \text { R-quadrado }>0
\end{aligned}
$$

Pelo p-valor igual a 0,044 (menor do que 5\%), constata-se que o modelo apresenta um Rquadrado diferente de zero, ou seja, o modelo é significante.

Tabela 35 - ANOVA do modelo de regressão - roe06 e idesen

\begin{tabular}{|c|c|c|c|c|c|c|}
\hline \multicolumn{2}{|c|}{ Model } & Sum of Squares & $\mathrm{df}$ & Mean Square & F & Sig. \\
\hline \multirow[t]{3}{*}{1} & Regression & 1232,163 & 1 & 1232,163 & 4,317 &, $044^{\circ}$ \\
\hline & Residual & 11988,209 & 42 & 285,434 & & \\
\hline & Total & 13220,372 & 43 & & & \\
\hline
\end{tabular}

ANOVA $^{b}$

a. Predictors: (Constant), idesen

b. Dependent Variable: roe06 FONTE: SPSS.

A Tabela 36 informa a significância estatística dos coeficientes. O p-valor do teste $t$ de cada coeficiente revela que tanto a constante quanto a variável idesen fazem parte do modelo que tem roe06 como variável dependente. O coeficiente da variável idesen exibe sinal negativo. 
Tabela 36 - Coeficientes do modelo de regressão - roe06 e idesen

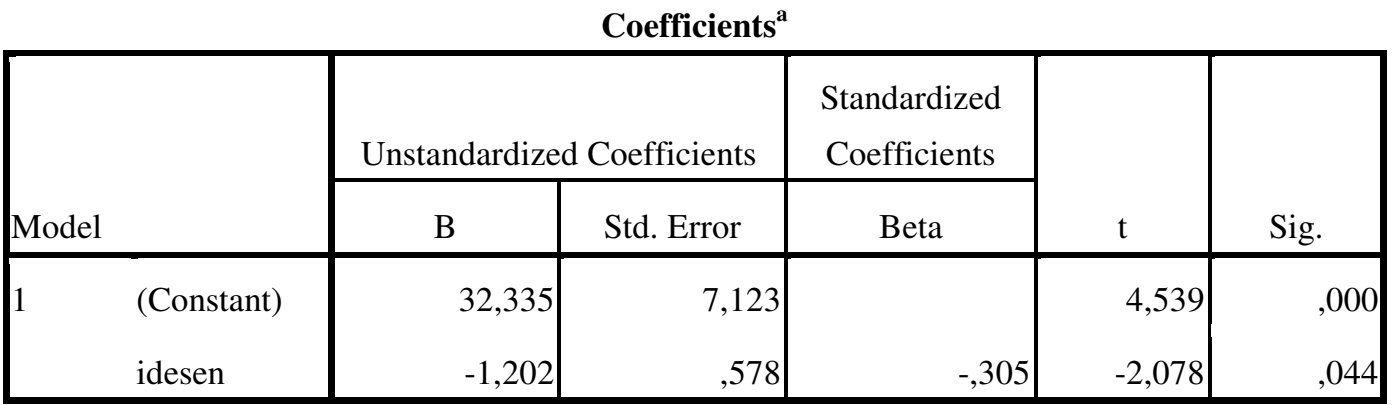

a. Dependent Variable: roe06

FONTE: SPSS.

A análise dos pressupostos do modelo de regressão linear inicia-se com a avaliação da normalidade dos resíduos. O diagnóstico é feito por meio do teste Kolmogorov-Smirnov. O pvalor igual a 0,428 (maior do que 10\%) permite aceitar a hipótese nula, a distribuição é normal.

O pressuposto da homoscedasticidade dos resíduos é verificado por meio do teste PesaránPesarán. O resultado da regressão tendo o quadrado dos resíduos padronizados como variável dependente e o quadrado dos valores estimados padronizados como independente, não permite que se rejeite a hipótese nula, os resíduos são homoscedásticos.

O diagnóstico da linearidade é feito pelo diagrama de dispersão que comprova a relação de linearidade entre as variáveis dependente e independente. A avaliação da ausência de autocorrelação serial é feita pelo teste Durbin-Watson, que apresenta valor igual a 1,933 valor próximo de 2 - revelando ausência de autocorrelação serial dos resíduos.

Como todos os pressupostos são atendidos, as estimativas são consistentes. Assim, os resultados apontam a existência de relação fraca entre o índice de desenvolvimento e o retorno sobre patrimônio líquido de 2006. O coeficiente do índice de desenvolvimento apresenta sinal negativo. 


\subsubsection{Análise de regressão linear múltipla}

O procedimento simultâneo (Enter) foi utilizado em todos os 6 modelos de regressão linear múltipla. Ou seja, todas as variáveis independentes foram incluídas, mesmo que, eventualmente, algumas delas não sejam significantes (FÁVERO et al, 2009).

Para analisar o modelo de regressão múltipla, adotou-se a sequência de passos sugerida por Hair et al (2005a). O primeiro passo avalia os pressupostos do modelo; o segundo testa o seu poder explicativo; o terceiro analisa a significância dos coeficientes. O nível de significância adotado é de $10 \%$.

\section{- Crescimento das vendas de 2006 e remuneração}

As tabelas 37 a 39 apresentam os resultados da regressão múltipla, estimada com o método dos mínimos quadrados, tendo cven06 como variável dependente:

$$
\text { cven } 06_{i}=\beta_{0}+\beta_{1} \text { salmen }_{i}+\beta_{2} \text { salvar }_{i}+\beta_{3} \text { ibenef }_{i}+\beta_{4} \text { icarr }_{i}+\beta_{5} \text { idesen }_{i}+\beta_{6} \text { porte }_{i}+\mu_{i}
$$

A análise dos pressupostos do modelo de regressão inicia-se com a avaliação da normalidade dos resíduos. O diagnóstico é feito pelo teste Kolmogorov Smirnov. O p-valor igual a 0,887 permite aceitar a hipótese nula, a distribuição é normal.

O pressuposto da homoscedasticidade dos resíduos é verificado por meio do teste PesaránPesarán. O resultado da regressão tendo o quadrado dos resíduos padronizados como variável dependente e o quadrado dos valores estimados padronizados como variável independente, não permite que se rejeite a hipótese nula, os resíduos são homoscedásticos.

A ausência de autocorrelação serial é verificada pelo teste Durbin-Watson. O resultado igual a 1,943 - valor próximo de 2 - indica ausência de autocorrelação serial dos resíduos. O exame de multicolinearidade é feito pela medida VIF, que apresenta valor menor do que 3. Tal dado indica multicolinearidade dentro de limites aceitáveis. Como todos os pressupostos foram atendidos, as estimativas são consistentes. 
O próximo passo testa o poder explicativo do modelo. $\mathrm{O}$ valor de R-quadrado de 0,193 significa que $19,3 \%$ da variação no cven06 são explicados pelo conjunto de variáveis na regressão. O modelo apresenta um R-quadrado ajustado de 6,2\% e um erro-padrão igual a 10,67 (Tabela 37).

Tabela 37 - Resumo do modelo de regressão múltipla - cven06

\begin{tabular}{|l|r|r|r|c|}
\hline & & & \multicolumn{1}{|c|}{ Model Summary } \\
\hline Model & $\mathrm{R}$ & R Square & \multicolumn{1}{c|}{$\begin{array}{c}\text { Square } \\
\text { R }\end{array}$} & $\begin{array}{c}\text { Std. Error of the } \\
\text { Estimate }\end{array}$ \\
\hline 1 &, $439^{\mathrm{a}}$ &, 193 &, 062 & 10,6738 \\
\hline
\end{tabular}

a. Predictors: (Constant), idesen, salmen, ibenef, porte, icarr, salvar FONTE: SPSS.

O teste $\mathrm{F}$ verifica a significância do modelo geral. As hipóteses testadas são:

$$
\begin{aligned}
& \mathrm{H}_{0}: \text { R-quadrado }=0 \\
& \mathrm{H}_{1}: \text { R-quadrado }>0
\end{aligned}
$$

O p-valor igual a 0,213 (maior do que 10\%), mostrado na Tabela 38, não permite rejeitar a hipótese nula. O comportamento de alteração de cada uma das variáveis independentes não influencia em nada o comportamento da variável dependente (FÁVERO et al, 2009).

Tabela 38 - ANOVA do modelo de regressão múltipla - cven06

\begin{tabular}{|c|c|c|c|c|c|c|}
\hline \multicolumn{2}{|c|}{ Model } & Sum of Squares & df & Mean Square & $\mathrm{F}$ & Sig. \\
\hline \multirow[t]{3}{*}{1} & Regression & 1008,864 & 6 & 168,144 & 1,476 &, $213^{\mathrm{a}}$ \\
\hline & Residual & 4215,382 & 37 & 113,929 & & \\
\hline & Total & 5224,245 & 43 & & & \\
\hline
\end{tabular}

ANOVA $^{\text {b }}$

a. Predictors: (Constant), idesen, salmen, ibenef, porte, icarr, salvar

b. Dependent Variable: cven06

FONTE: SPSS. 
A Tabela 39 apresenta a significância de cada um dos coeficientes isoladamente. A análise do p-valor indica que somente os coeficientes das variáveis ibenef e icarr são significantes. O coeficiente de icarr apresenta sinal negativo.

Tabela 39 - Coeficientes do modelo de regressão múltipla - cven06

\begin{tabular}{|c|c|c|c|c|c|c|}
\hline \multicolumn{7}{|c|}{ Coefficients $^{\mathrm{a}}$} \\
\hline \multirow{2}{*}{\multicolumn{2}{|c|}{ Model }} & \multicolumn{2}{|c|}{ Unstandardized Coefficients } & \multirow{2}{*}{$\begin{array}{l}\text { Standardized } \\
\text { Coefficients } \\
\text { Beta }\end{array}$} & \multirow[b]{2}{*}{$\mathrm{t}$} & \multirow[b]{2}{*}{ Sig. } \\
\hline & & B & Std. Error & & & \\
\hline 1 & (Constant) & 1,379 & 15,295 & & ,090 & ,929 \\
\hline & porte &,- 962 & 1,780 &,- 105 &,- 540 & ,592 \\
\hline & salmen & $3,690 \mathrm{E}-5$ &, 000 & ,030 & , 150 & 882 \\
\hline & salvar & $2,284 \mathrm{E}-5$ & 000 & ,283 & 1,146 & ,259 \\
\hline & ibenef & 1,016 & ,543 & 290 & 1,870 & ,069 \\
\hline & icarr &,- 379 & ,167 &,- 374 & $-2,276$ & ,029 \\
\hline & idesen &,- 106 & ,406 &,- 043 &,- 262 & ,795 \\
\hline
\end{tabular}

a. Dependent Variable: cven06 FONTE: SPSS.

Os resultados do modelo de regressão múltipla, estimado com o método dos mínimos quadrados, tendo crescimento das vendas de 2006 como variável dependente, apontam que não existe relação significante entre as variáveis independentes e a dependente. Assim, os resultados não apresentam evidências que comprovem a hipótese de que existe relação positiva e significante entre a remuneração dos executivos e o desempenho financeiro das empresas. 


\section{- Retorno sobre patrimônio líquido de 2006 e remuneração}

As tabelas 40 a 42 apresentam os resultados da regressão múltipla, estimada com o método dos mínimos quadrados, tendo roe06 como variável dependente:

$$
\text { roe } 06_{\mathrm{i}}=\beta_{0}+\beta_{1} \text { salmen }_{\mathrm{i}}+\beta_{2} \text { salvar }_{\mathrm{i}}+\beta_{3} \text { ibenef }_{\mathrm{i}}+\beta_{4} \text { icarr }_{\mathrm{i}}+\beta_{5} \text { idesen }_{\mathrm{i}}+\beta_{6} \text { porte }_{\mathrm{i}}+\mu_{\mathrm{i}}
$$

A análise dos pressupostos do modelo de regressão inicia-se com a avaliação da normalidade dos resíduos. O diagnóstico é feito pelo teste Kolmogorov Smirnov. O p-valor igual a 0,826 permite aceitar a hipótese nula, a distribuição é normal.

O pressuposto da homoscedasticidade dos resíduos é verificado por meio do teste PesaránPesarán. O resultado da regressão tendo o quadrado dos resíduos padronizados como variável dependente e o quadrado dos valores estimados padronizados como variável independente, não permite que se rejeite a hipótese nula, os resíduos são homoscedásticos.

A ausência de autocorrelação serial é verificada pelo teste Durbin-Watson. O resultado igual a 2,121 - valor próximo de 2 - indica ausência de autocorrelação serial dos resíduos. O exame de multicolinearidade é feito pela medida VIF, que apresenta valor menor do que 3 e indica multicolinearidade dentro de limites aceitáveis. Como todos os pressupostos foram atendidos, as estimativas são consistentes.

O próximo passo testa o poder explicativo do modelo. $\mathrm{O}$ valor de R-quadrado de 0,223 significa que $22,3 \%$ da variação no roe06 são explicados pelo conjunto de variáveis na regressão. O modelo apresenta um R-quadrado ajustado de 9,7\% e um erro-padrão igual a 16,66 (Tabela 40). 
Tabela 40 - Resumo do modelo de regressão múltipla - roe06

Model Summary

\begin{tabular}{|l|r|r|r|c|}
\hline Model & \multicolumn{1}{|c|}{$\mathrm{R}$} & R Square & \multicolumn{1}{|c|}{$\begin{array}{c}\text { Adjusted R } \\
\text { Square }\end{array}$} & $\begin{array}{c}\text { Std. Error of the } \\
\text { Estimate }\end{array}$ \\
\hline 1 &, $472^{\mathrm{a}}$ &, 223 &, 097 & 16,6615 \\
\hline
\end{tabular}

a. Predictors: (Constant), idesen, salmen, ibenef, porte, icarr, salvar FONTE: SPSS.

O teste $\mathrm{F}$ verifica a significância do modelo geral. As hipóteses testadas são:

$$
\begin{aligned}
& \mathrm{H}_{0}: \text { R-quadrado }=0 \\
& \mathrm{H}_{1}: \text { R-quadrado }>0
\end{aligned}
$$

O p-valor igual a 0,132 (maior do que 10\%), mostrado na Tabela 41, não permite rejeitar a hipótese nula. O comportamento de alteração de cada uma das variáveis independentes não influencia em nada o comportamento da variável dependente (FÁVERO et al, 2009).

\begin{tabular}{|c|c|c|c|c|c|c|}
\hline \multicolumn{7}{|c|}{ ANOVA $^{b}$} \\
\hline & & Sum of Squares & $\mathrm{df}$ & Mean Square & $\mathrm{F}$ & Sig. \\
\hline \multirow[t]{3}{*}{1} & Regression & 2948,957 & 6 & 491,493 & 1,770 &, $132^{\mathrm{a}}$ \\
\hline & Residual & 10271,415 & 37 & 277,606 & & \\
\hline & Total & 13220,372 & 43 & & & \\
\hline
\end{tabular}

Tabela 41 - ANOVA do modelo de regessão múltipla - roe06

a. Predictors: (Constant), idesen, salmen, ibenef, porte, icarr, salvar

b. Dependent Variable: roe06

FONTE: SPSS.

A Tabela 42 apresenta a significância de cada um dos coeficientes isoladamente. A análise do p-valor indica que somente a constante e o coeficiente da variávels icarr são significantes. O coeficiente de icarr apresenta sinal negativo. 
Tabela 42 - Coeficientes do modelo de regressão múltipla - roe06

\begin{tabular}{|c|c|c|c|c|c|c|}
\hline \multicolumn{7}{|c|}{ Coefficients ${ }^{\mathrm{a}}$} \\
\hline & & Unstandardize & Coefficients & $\begin{array}{l}\text { Standardized } \\
\text { Coefficients }\end{array}$ & & \\
\hline \multicolumn{2}{|c|}{ Model } & B & Std. Error & Beta & $\mathrm{t}$ & Sig. \\
\hline 1 & (Constant) & 44,720 & 23,875 & & 1,873 & ,069 \\
\hline & porte & $-4,122$ & 2,779 &,- 283 & $-1,483$ & , 146 \\
\hline & salmen & $-9,230 \mathrm{E}-6$ & , 000 &,- 005 &,- 024 & ,981 \\
\hline & salvar & $4,256 \mathrm{E}-5$ & , 000 & ,332 & 1,368 & 180 \\
\hline & ibenef & 1,126 & , 848 & 202 & 1,328 & 192 \\
\hline & icarr &,- 476 & ,260 &,- 295 & $-1,833$ & ,075 \\
\hline & idesen &,- 774 & ,633 &,- 197 & $-1,222$ & 229 \\
\hline
\end{tabular}

a. Dependent Variable: roe06

FONTE: SPSS.

Os resultados do modelo de regressão múltipla, estimado com o método dos mínimos quadrados e com retorno sobre patrimônio líquido de 2006 como variável dependente, demonstram que não existe relação significante entre as variáveis independentes e a dependente. Assim, não apresentam evidências que possam comprovar a hipótese da pesquisa de que existe relação positiva e significante entre a remuneração dos executivos e o desempenho financeiro das empresas.

\section{- Margem líquida sobre vendas de 2006 e remuneração}

As tabelas 43 a 45 apresentam os resultados da regressão múltipla, estimada com o método dos mínimos quadrados e com mven06 como variável dependente:

$$
\text { mven06 }_{\mathrm{i}}=\beta_{0}+\beta_{1} \text { salmen }_{\mathrm{i}}+\beta_{2} \text { salvar }_{\mathrm{i}}+\beta_{3} \text { ibenef }_{\mathrm{i}}+\beta_{4} \text { icarr }_{\mathrm{i}}+\beta_{5} \text { idesen }_{\mathrm{i}}+\beta_{6} \text { porte }_{\mathrm{i}}+\mu_{\mathrm{i}}
$$


A análise dos pressupostos do modelo de regressão inicia-se com a avaliação da normalidade dos resíduos. O diagnóstico é feito pelo teste Kolmogorov Smirnov. O p-valor igual a 0,344 permite aceitar a hipótese nula, a distribuição é normal.

O pressuposto da homoscedasticidade dos resíduos é verificado por meio do teste PesaránPesarán. O resultado da regressão tendo o quadrado dos resíduos padronizados como variável dependente e o quadrado dos valores estimados padronizados como variável independente, não permite que se rejeite a hipótese nula, os resíduos são homoscedásticos.

A ausência de autocorrelação serial é verificada pelo teste Durbin-Watson. O resultado igual a 1,691 - valor próximo de 2 - indica ausência de autocorrelação serial dos resíduos. O exame de multicolinearidade é feito pela medida VIF, que apresenta valor menor do que 3. Tal dado indica multicolinearidade dentro de limites aceitáveis. Como todos os pressupostos foram atendidos, as estimativas são consistentes.

$\mathrm{O}$ próximo passo testa o poder explicativo do modelo. $\mathrm{O}$ valor de R-quadrado de 0,086 significa que $8,6 \%$ da variação na mven06 são explicados pelo conjunto de variáveis na regressão. O modelo apresenta um R-quadrado ajustado negativo e igual a 6,3\% e um erropadrão igual a 10,12 (Tabela 43).

Tabela 43 - Resumo de modelo de regressão múltipla - mven06

\begin{tabular}{|l|r|r|r|c|}
\hline & & & \multicolumn{1}{|c|}{ Model Summary } \\
Model & $\mathrm{R}$ & R Square & \multicolumn{1}{c|}{$\begin{array}{c}\text { Square } \\
\text { Square }\end{array}$} & $\begin{array}{c}\text { Std. Error of the } \\
\text { Estimate }\end{array}$ \\
\hline 1 &, $293^{\mathrm{a}}$ &, 086 &,- 063 & 10,1186 \\
\hline
\end{tabular}

a. Predictors: (Constant), idesen, salmen, ibenef, porte, icarr, salvar FONTE: SPSS.

O teste $\mathrm{F}$ verifica a significância do modelo geral. As hipóteses testadas são:

$$
\begin{aligned}
& \mathrm{H}_{0}: \text { R-quadrado }=0 \\
& \mathrm{H}_{1}: \text { R-quadrado }>0
\end{aligned}
$$


O p-valor igual a 0,745 (maior do que $10 \%$ ), mostrado na Tabela 44, não permite rejeitar a hipótese nula. O comportamento de alteração de cada uma das variáveis independentes não influencia em nada o comportamento da variável dependente (FÁVERO et al, 2009).

Tabela 44 - ANOVA do modelo de regressão múltipla - mven06

ANOVA $^{b}$

\begin{tabular}{|rr|r|r|r|r|r|}
\hline \multicolumn{1}{|r|}{} & & Sum of Squares & df & Mean Square & F & \multicolumn{1}{c|}{ Sig. } \\
\hline 1 & Regression & 355,311 & 6 & 59,219 &, 578 &, $745^{\mathrm{a}}$ \\
& Residual & 3788,280 & 37 & 102,386 & & \\
& Total & 4143,592 & 43 & & & \\
\hline
\end{tabular}

a. Predictors: (Constant), idesen, salmen, ibenef, porte, icarr, salvar

b. Dependent Variable: mven06

FONTE: SPSS.

A Tabela 45 relaciona a significância de cada um dos coeficientes isoladamente. A análise do p-valor indica que nenhum coeficiente é significante.

Tabela 45 - Coeficientes do modelo de regressão múltipla - mven06

Coefficients $^{\mathrm{a}}$

\begin{tabular}{|c|c|c|c|c|c|c|}
\hline \multirow{2}{*}{\multicolumn{2}{|c|}{ Model }} & \multicolumn{2}{|c|}{ Unstandardized Coefficients } & \multirow{2}{*}{$\begin{array}{c}\text { Standardized } \\
\text { Coefficients }\end{array}$} & \multirow[b]{2}{*}{$\mathrm{t}$} & \multirow[b]{2}{*}{ Sig. } \\
\hline & & B & Std. Error & & & \\
\hline \multirow[t]{7}{*}{1} & (Constant) & 2,172 & 14,499 & &, 150 & ,882 \\
\hline & porte & $-1,411$ & 1,688 &,- 173 &,- 836 & ,409 \\
\hline & salmen &, 000 & ,000 &, 154 &, 728 & ,471 \\
\hline & salvar & $1,085 \mathrm{E}-5$ &, 000 &, 151 &, 574 & ,569 \\
\hline & ibenef & ,636 &, 515 & ,204 & 1,236 &, 224 \\
\hline & icarr &,- 144 & , 158 &,- 159 &,- 910 & ,369 \\
\hline & idesen &, 140 & ,385 & ,064 &, 365 &, 717 \\
\hline
\end{tabular}

a. Dependent Variable: mven06 FONTE: SPSS. 
Os resultados do modelo de regressão múltipla, estimado com o método dos mínimos quadrados, tendo margem líquida sobre as vendas de 2006 como variável dependente, apontam que não existe relação significante entre as variáveis independentes e a dependente. Assim, não apresentam evidências que comprovem a hipótese de que existe relação positiva e significante entre a remuneração dos executivos e o desempenho financeiro das empresas.

\section{- Crescimento das vendas de 2007 e remuneração}

As tabelas 46 a 48 apresentam os resultados da regressão múltipla, estimada com o método dos mínimos quadrados, tendo cven07 como variável dependente:

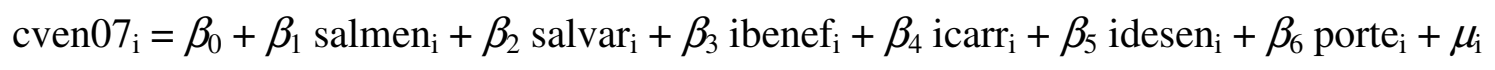

A análise dos pressupostos do modelo de regressão inicia-se com a avaliação da normalidade dos resíduos. O diagnóstico é feito pelo teste Kolmogorov Smirnov. O p-valor igual a 0,314 permite aceitar a hipótese nula, a distribuição é normal.

O pressuposto da homoscedasticidade dos resíduos é verificado por meio do teste PesaránPesarán. O resultado da regressão tendo o quadrado dos resíduos padronizados como variável dependente e o quadrado dos valores estimados padronizados como independente, não permite que se rejeite a hipótese nula, os resíduos são homoscedásticos.

A ausência de autocorrelação serial é verificada pelo teste Durbin-Watson. O resultado igual a 2,009 - valor próximo de 2 - indica ausência de autocorrelação serial dos resíduos. O exame de multicolinearidade é feito pela medida VIF, que apresenta valor menor do que 3. Esta informação denota uma multicolinearidade dentro de limites aceitáveis. Como todos os pressupostos foram atendidos, as estimativas são consistentes. 
O próximo passo testa o poder explicativo do modelo. $\mathrm{O}$ valor de R-quadrado de 0,094 significa que $9,4 \%$ da variação no cven07 são explicados pelo conjunto de variáveis na regressão. O modelo apresenta um R-quadrado ajustado negativo e igual a 5,3\% e um erropadrão igual a 18,09 (Tabela 46).

Tabela 46 - Resumo do modelo de regressão múltipla - cven07

Model Summary

\begin{tabular}{|l|r|r|r|c|}
\hline Model & \multicolumn{1}{|c|}{$\mathrm{R}$} & R Square & $\begin{array}{c}\text { Adjusted R } \\
\text { Square }\end{array}$ & $\begin{array}{c}\text { Std. Error of the } \\
\text { Estimate }\end{array}$ \\
\hline 1 &, $307^{\mathrm{a}}$ &, 094 &,- 053 & 18,0904 \\
\hline
\end{tabular}

a. Predictors: (Constant), idesen, salmen, ibenef, porte, icarr, salvar FONTE: SPSS.

O teste F verifica a significância do modelo geral. As hipóteses testadas são:

$$
\begin{aligned}
& \mathrm{H}_{0}: \text { R-quadrado }=0 \\
& \mathrm{H}_{1}: \text { R-quadrado }>0
\end{aligned}
$$

O p-valor igual a 0,697 (maior do que 10\%), mostrado na Tabela 47, não permite rejeitar a hipótese nula. O comportamento de alteração de cada uma das variáveis independentes não influencia em nada o comportamento da variável dependente (FÁVERO et al, 2009).

\begin{tabular}{|c|c|c|c|c|c|c|}
\hline \multicolumn{7}{|c|}{ ANOVA $^{b}$} \\
\hline & & Sum of Squares & df & Mean Square & $\mathrm{F}$ & Sig. \\
\hline \multirow[t]{3}{*}{1} & Regression & 1257,250 & 6 & 209,542 & ,640 &, $697^{\mathrm{a}}$ \\
\hline & Residual & 12108,657 & 37 & 327,261 & & \\
\hline & Total & 13365,906 & 43 & & & \\
\hline
\end{tabular}

Tabela 47 - ANOVA do modelo de regressão múltipla - cven07

a. Predictors: (Constant), idesen, salmen, ibenef, porte, icarr, salvar

b. Dependent Variable: cven07

FONTE: SPSS. 
A Tabela 48 apresenta a significância de cada um dos coeficientes isoladamente. A análise do p-valor indica que somente o coeficiente da variável porte é significante.

Tabela 48 - Coeficientes do modelo de regressão múltipla - cven07

\begin{tabular}{|c|c|c|c|c|c|c|}
\hline \multicolumn{7}{|c|}{ Coefficients $^{\text {a }}$} \\
\hline \multirow{2}{*}{\multicolumn{2}{|c|}{ Model }} & \multicolumn{2}{|c|}{ Unstandardized Coefficients } & \multirow{2}{*}{$\begin{array}{c}\text { Standardized } \\
\text { Coefficients } \\
\text { Beta }\end{array}$} & \multirow[b]{2}{*}{$\mathrm{t}$} & \multirow[b]{2}{*}{ Sig. } \\
\hline & & B & Std. Error & & & \\
\hline \multirow[t]{7}{*}{1} & (Constant) & $-22,542$ & 25,922 & &,- 870 & ,390 \\
\hline & porte & 5,095 & 3,018 &, 348 & 1,689 &, 100 \\
\hline & salmen & 000 &, 000 &, 172 & ,819 & ,418 \\
\hline & salvar & $-3,196 \mathrm{E}-5$ &, 000 &,- 248 &,- 946 & ,350 \\
\hline & ibenef &,- 544 & ,921 &,- 097 &,- 591 & ,558 \\
\hline & icarr &, 055 & 282 &, 034 &, 194 & 847 \\
\hline & idesen &,- 634 & 688 &,- 160 &,- 922 & 363 \\
\hline
\end{tabular}

a. Dependent Variable: cven07

FONTE: SPSS.

Os resultados do modelo de regressão múltipla, estimado com o método dos mínimos quadrados e com crescimento das vendas de 2007 como variável dependente, revelam que não existe relação significante entre as variáveis independentes e a dependente. Assim, não apresentam evidências que comprovem a hipótese de que existe relação positiva e significante entre a remuneração dos executivos e o desempenho financeiro das empresas. 


\section{- Retorno sobre patrimônio liquido de 2007 e remuneração}

As tabelas 49 a 51 apresentam os resultados da regressão múltipla, estimada com o método dos mínimos quadrados e com roe07 como variável dependente:

$$
\operatorname{roe}_{0} 7_{\mathrm{i}}=\beta_{0}+\beta_{1} \text { salmen }_{\mathrm{i}}+\beta_{2} \text { salvar }_{\mathrm{i}}+\beta_{3} \text { ibenef }_{\mathrm{i}}+\beta_{4} \text { icarr }_{\mathrm{i}}+\beta_{5} \text { idesen }_{\mathrm{i}}+\beta_{6} \text { porte }_{\mathrm{i}}+\mu_{\mathrm{i}}
$$

A análise dos pressupostos do modelo de regressão inicia-se com a avaliação da normalidade dos resíduos. O diagnóstico é feito pelo teste Kolmogorov Smirnov. O p-valor igual a 0,627 permite aceitar a hipótese nula, a distribuição é normal.

O pressuposto da homoscedasticidade dos resíduos é verificado por meio do teste PesaránPesarán. O resultado da regressão tendo o quadrado dos resíduos padronizados como variável dependente e o quadrado dos valores estimados padronizados como variável independente, não permite que se rejeite a hipótese nula, os resíduos são homoscedásticos.

A ausência de autocorrelação serial é verificada pelo teste Durbin-Watson. O resultado igual a 2,160 - valor próximo de 2 - constata ausência de autocorrelação serial dos resíduos. O exame de multicolinearidade é feito pela medida VIF, que apresenta valor menor do que 3. Esse dado evidencia multicolinearidade dentro de limites aceitáveis. Como todos os pressupostos foram atendidos, as estimativas são consistentes.

O próximo passo testa o poder explicativo do modelo. O valor de R-quadrado de 0,097 significa que $9,7 \%$ da variação no roe07 são explicados pelo conjunto de variáveis na regressão. O modelo apresenta um R-quadrado ajustado negativo e igual a 4,9\% e um erropadrão igual a 14,32 (Tabela 49). 
Tabela 49 - Resumo do modelo de regressão múltipla - roe07

\section{Model Summary}

\begin{tabular}{|l|r|r|r|c|}
\hline Model & \multicolumn{1}{|c|}{$\mathrm{R}$} & R Square & \multicolumn{1}{c|}{$\begin{array}{c}\text { Adjusted R } \\
\text { Square }\end{array}$} & $\begin{array}{c}\text { Std. Error of the } \\
\text { Estimate }\end{array}$ \\
\hline 1 &, $312^{\mathrm{a}}$ &, 097 &,- 049 & 14,3157 \\
\hline
\end{tabular}

a. Predictors: (Constant), idesen, salmen, ibenef, porte, icarr, salvar FONTE: SPSS.

O teste $\mathrm{F}$ verifica a significância do modelo geral. As hipóteses testadas são:

$$
\begin{aligned}
& \mathrm{H}_{0}: \text { R-quadrado }=0 \\
& \mathrm{H}_{1}: \text { R-quadrado }>0
\end{aligned}
$$

O p-valor igual a 0,680 (maior do que 10\%), exposto na Tabela 50, não permite rejeitar a hipótese nula. O comportamento de alteração de cada uma das variáveis independentes não influencia em nada o comportamento da variável dependente (FÁVERO et al, 2009).

Tabela 50 - ANOVA do modelo de regressão múltipla - roe07

\begin{tabular}{|ll|r|r|r|r|r|}
\hline \multicolumn{2}{|c|}{ ANOVA $^{\mathbf{b}}$} & \\
\hline 1 & & Sum of Squares & df & Mean Square & F & \multicolumn{1}{c|}{ Sig. } \\
\hline & Regression & 815,545 & 6 & 135,924 &, 663 &, $680^{\mathrm{a}}$ \\
& Residual & 7582,737 & 37 & 204,939 & & \\
& Total & 8398,282 & 43 & & & \\
\hline
\end{tabular}

a. Predictors: (Constant), idesen, salmen, ibenef, porte, icarr, salvar

b. Dependent Variable: roe07

FONTE: SPSS.

A Tabela 51 apresenta a significância de cada um dos coeficientes isoladamente. A análise do p-valor informa que nenhum coeficiente é significante. 
Tabela 51 - Coeficientes do modelo de regressão múltipla - roe07

\begin{tabular}{|c|c|c|c|c|c|c|}
\hline \multicolumn{7}{|c|}{ Coefficients $^{\mathrm{a}}$} \\
\hline \multirow{2}{*}{\multicolumn{2}{|c|}{ Model }} & \multicolumn{2}{|c|}{ Unstandardized Coefficients } & \multirow{2}{*}{$\begin{array}{c}\text { Standardized } \\
\text { Coefficients } \\
\text { Beta } \\
\end{array}$} & \multirow[b]{2}{*}{$\mathrm{t}$} & \multirow[b]{2}{*}{ Sig. } \\
\hline & & B & Std. Error & & & \\
\hline \multirow[t]{7}{*}{1} & (Constant) & 13,588 & 20,513 & & ,662 &, 512 \\
\hline & porte &,- 293 & 2,388 &,- 025 &,- 123 & ,903 \\
\hline & salmen &, 000 &, 000 &, 126 &, 597 &, 554 \\
\hline & salvar & $6,649 \mathrm{E}-6$ &, 000 &, 065 & 249 & ,805 \\
\hline & ibenef & 674 & ,728 &, 152 & ,926 & ,361 \\
\hline & icarr &,- 271 & ,223 &,- 211 & $-1,214$ & ,232 \\
\hline & idesen &,- 502 &, 544 &,- 160 &,- 923 & ,362 \\
\hline
\end{tabular}

a. Dependent Variable: roe07

FONTE: SPSS.

Os resultados do modelo de regressão múltipla, estimado com o método dos mínimos quadrados, tendo retorno sobre patrimônio líquido de 2007 como variável dependente, indicam que não existe relação significante entre as variáveis independentes e a dependente. Assim, não apresentam evidências que possam comprovar a hipótese de que existe relação positiva e significante entre a remuneração dos executivos e o desempenho financeiro das empresas.

\section{- Margem líquida sobre as vendas de 2007 e remuneração}

As tabelas 52 a 54 apresentam os resultados da regressão múltipla, estimada com o método dos mínimos quadrados e com mven07 como variável dependente:

$$
\text { mven07 }_{\mathrm{i}}=\beta_{0}+\beta_{1} \text { salmen }_{\mathrm{i}}+\beta_{2} \text { salvar }_{\mathrm{i}}+\beta_{3} \text { ibenef }_{\mathrm{i}}+\beta_{4} \text { icarr }_{\mathrm{i}}+\beta_{5} \text { idesen }_{\mathrm{i}}+\beta_{6} \text { porte }_{\mathrm{i}}+\mu_{\mathrm{i}}
$$


A análise dos pressupostos do modelo de regressão inicia-se com a avaliação da normalidade dos resíduos. O diagnóstico é feito pelo teste Kolmogorov Smirnov. O p-valor igual a 0,477 permite aceitar a hipótese nula, a distribuição é normal.

O pressuposto da homoscedasticidade dos resíduos é verificado por meio do teste PesaránPesarán. O resultado da regressão tendo o quadrado dos resíduos padronizados como variável dependente e o quadrado dos valores estimados padronizados como variável independente, não permite que se rejeite a hipótese nula, os resíduos são homoscedásticos.

A ausência de autocorrelação serial é verificada pelo teste Durbin-Watson. O resultado igual a 1,667 - valor próximo de 2 - indica ausência de autocorrelação serial dos resíduos. O exame de multicolinearidade é feito pela medida VIF, que apresenta valor menor do que 3 . Tal índice denota multicolinearidade dentro de limites aceitáveis. Como todos os pressupostos foram atendidos, as estimativas são consistentes.

O próximo passo testa o poder explicativo do modelo. $\mathrm{O}$ valor de R-quadrado de 0,111 significa que $11,1 \%$ da variação na mven07 são explicados pelo conjunto de variáveis na regressão. O modelo apresenta um R-quadrado ajustado negativo e igual a 3,3\% e um erropadrão igual a 8,44 (Tabela 52).

Tabela 52 - Resumo do modelo de regressão múltipla - mven07

\begin{tabular}{|l|r|r|r|r|}
\hline & & & \multicolumn{1}{|c|}{ Model Summary } \\
\hline Model & $\mathrm{R}$ & R Square & \multicolumn{1}{c|}{$\begin{array}{c}\text { Square } \\
\text { Square }\end{array}$} & $\begin{array}{c}\text { Std. Error of the } \\
\text { Estimate }\end{array}$ \\
\hline 1 &, $333^{\mathrm{a}}$ &, 111 &,- 033 & 8,4429 \\
\hline
\end{tabular}

a. Predictors: (Constant), idesen, salmen, ibenef, porte, icarr, salvar FONTE: SPSS.

O teste F verifica a significância do modelo geral. As hipóteses testadas são:

$$
\begin{aligned}
& \mathrm{H}_{0}: \text { R-quadrado }=0 \\
& \mathrm{H}_{1}: \text { R-quadrado }>0
\end{aligned}
$$


O p-valor igual a 0,599 (maior do que 10\%) é exposto na Tabela 53 e não permite rejeitar a hipótese nula. O comportamento de alteração de cada uma das variáveis independentes não influencia em nada o comportamento da variável dependente (FÁVERO et al, 2009).

Tabela 53 - ANOVA do modelo de regressão múltipla - mven07

ANOVA $^{b}$

\begin{tabular}{|rr|r|r|r|r|r|}
\hline \multicolumn{1}{|r|}{} & & Sum of Squares & df & Mean Square & F & \multicolumn{1}{c|}{ Sig. } \\
\hline 1 & Regression & 329,121 & 6 & 54,854 &, 770 &, $599^{\mathrm{a}}$ \\
& Residual & 2637,431 & 37 & 71,282 & & \\
& Total & 2966,552 & 43 & & & \\
\hline
\end{tabular}

a. Predictors: (Constant), idesen, salmen, ibenef, porte, icarr, salvar

b. Dependent Variable: mven07

FONTE: SPSS.

A Tabela 54 apresenta a significância de cada um dos coeficientes isoladamente. A análise do p-valor revela que nenhum coeficiente é significante.

Tabela 54 - Coeficientes do modelo de regressão múltipla - mven07

Coefficients $^{\mathrm{a}}$

\begin{tabular}{|c|c|c|c|c|c|c|}
\hline \multirow{2}{*}{\multicolumn{2}{|c|}{ Model }} & \multicolumn{2}{|c|}{ Unstandardized Coefficients } & \multirow{2}{*}{$\begin{array}{c}\text { Standardized } \\
\text { Coefficients } \\
\text { Beta }\end{array}$} & \multirow[b]{2}{*}{$\mathrm{t}$} & \multirow[b]{2}{*}{ Sig. } \\
\hline & & B & Std. Error & & & \\
\hline \multirow[t]{7}{*}{1} & (Constant) & 4,574 & 12,098 & & ,378 & ,708 \\
\hline & porte &,- 851 & 1,408 &,- 123 &,- 604 &, 550 \\
\hline & salmen &, 000 & ,000 &, 127 & ,610 &, 546 \\
\hline & salvar & $6,863 \mathrm{E}-6$ & ,000 &, 113 & ,435 & ,666 \\
\hline & ibenef & ,139 & ,430 &, 053 &, 323 & ,748 \\
\hline & icarr &,- 189 & , 132 &,- 248 & $-1,437$ & , 159 \\
\hline & idesen &, 532 & ,321 & ,285 & 1,657 &, 106 \\
\hline
\end{tabular}

a. Dependent Variable: mven07 FONTE: SPSS. 
Os resultados do modelo de regressão múltipla, estimado com o método dos mínimos quadrados, tendo margem líquida sobre as vendas de 2007 como variável dependente, indicam que não existe uma relação significante entre as variáveis independentes e a dependente. Assim, não apresentam evidências que possam comprovar a hipótese de que existe relação positiva e significante entre a remuneração dos executivos e o desempenho financeiro das empresas.

\subsection{Resumo dos resultados}

Além da remuneração financeira, outros fatores valorizados pelos executivos são: a perspectiva de crescimento profissional, materializada por meio da carreira profissional na empresa; a perspectiva de desenvolvimento pessoal e profissional, proporcionada por programas de treinamento e de educação.

A análise descritiva dos índices de carreira e de desenvolvimento mostrou que as organizações têm oferecido pouco estímulo e suporte para o crescimento profissional, a educação e o desenvolvimento de seus executivos. Considerando uma pontuação máxima de 50 no índice de carreira, metade das empresas tiveram valor igual ou inferior a 22,50 pontos. A análise revelou que se oferece pouco incentivo, principalmente em itens como: planejamento de carreira, possibilidades de carreira e preparação para a aposentadoria. Já com relação ao índice de desenvolvimento, 6,8\% das empresas não disponibilizavam qualquer mecanismo de estímulo à educação e ao desenvolvimento profissional de seus executivos.

As 44 empresas da amostra foram divididas em 2 grupos, utilizando a mediana das variáveis de remuneração. O grupo denominado "baixo" é formado pelas empresas com valores de remuneração abaixo da mediana; o grupo denominado "alto", por aquelas com valores de remuneração acima da mediana. O teste de Mann-Whitney foi aplicado para testar se existia diferença no desempenho financeiro médio nos 2 grupos "baixo" e "alto". Dentre as diferenças observadas, destacam-se: 
- A média do crescimento das vendas de 2006 no grupo índice de carreira "baixo" era maior do que a média no grupo índice de carreira "alto";

- A média do retorno sobre patrimônio líquido de 2006 no grupo índice de carreira "baixo" era maior do que aquela no grupo índice de carreira "alto";

- A média do retorno sobre patrimônio líquido de 2006 era maior no grupo índice de desenvolvimento "baixo" do que no grupo índice de desenvolvimento "alto".

Tais diferenças, observadas no teste de Mann-Whitney, não eram significantes. Assim, o desempenho financeiro é semelhante nos 2 grupos. A expectativa era encontrar diferenças significantes nas médias observadas: o grupo "alto" apresentando desempenho financeiro médio superior ao do grupo "baixo".

A análise de correlação foi utilizada para verificar se existiam associações lineares significantes entre as variáveis de remuneração e de desempenho financeiro. A análise de correlação de Pearson apresentou coeficientes de correlação significantes, negativos e fracos entre:

- índice de carreira e crescimento das vendas de 2006;

- índice de carreira e retorno sobre patrimônio líquido de 2006;

- $\quad$ índice de desenvolvimento e retorno sobre patrimônio líquido de 2006.

A associação fraca entre remuneração de executivos e desempenho financeiro corrobora os resultados de pesquisas anteriores, por exemplo, a de Attaway (2000). Já a associação negativa entre as variáveis indica que aumentos em uma variável estão associados a diminuições em outra. Tal associação negativa não coincide com as expectativas iniciais deste estudo. 
A análise de correlação de Spearman apresentou:

- coeficiente de correlação significante, positivo e fraco entre índice de benefícios e margem líquida sobre as vendas de 2006;

- coeficiente de correlação significante, negativo e fraco entre índice de desenvolvimento e retorno sobre patrimônio líquido de 2006.

A associação positiva concorda com as expectativas preliminares desta pesquisa, indicando que as duas variáveis movem-se na mesma direção. A associação fraca está de acordo com estudos anteriores, como já mencionado. A associação negativa diverge das expectativas iniciais deste trabalho.

Ressalta-se que a relação entre as variáveis índice de desenvolvimento e retorno sobre patrimônio líquido de 2006 apareceu tanto na análise de correlação de Pearson quanto na de Spearman. Em ambas, o coeficiente era fraco e negativo.

Merece destaque a ausência de associação entre a variável salário mensal médio e as variáveis de desempenho financeiro, bem como entre a variável salário variável médio e aquelas de desempenho financeiro. Este fenômeno pode ser um indicativo de que as organizações não estão estruturando o sistema de remuneração dos executivos de maneira adequada.

A análise de regressão linear simples foi utilizada com o objetivo de avaliar preliminarmente a relação entre as variáveis de remuneração (independentes) e as variáveis de desempenho financeiro (dependentes). Foram desenvolvidos modelos para todos os pares de variáveis, utilizando o método dos mínimos quadrados. Somente três deles apresentaram significância estatística:

- índice de carreira e crescimento das vendas de 2006 apresentou baixo poder de explicação $(\mathrm{R}$-quadrado $=7,2 \%)$ e coeficiente negativo; 
- índice de carreira e retorno sobre patrimônio líquido de 2006 apresentou baixo poder de explicação (R-quadrado $=7,4 \%$ ) e coeficiente negativo;

- índice de desenvolvimento e retorno sobre patrimônio líquido de 2006 apresentou baixo poder de explicação $(\mathrm{R}$-quadrado $=9,3 \%)$ e coeficiente negativo.

Os três modelos atenderam a todos os pressupostos da análise de regressão. As relações entre as variáveis:

- índice de carreira e crescimento das vendas de 2006,

- índice de carreira e retorno sobre patrimônio líquido de 2006,

- índice de desenvolvimento e retorno sobre patrimônio líquido de 2006

apareceram nos resultados dos testes de Mann-Whitney, na análise de correlação de Pearson e na análise de regressão linear simples. Neste contexto, vale salientar:

- no teste de Mann-Whitney, as diferenças não são significantes;

- o coeficiente de correlação de Pearson é fraco e negativo;

- na análise de regressão simples, o poder de explicação é baixo, e os coeficientes são negativos.

O Quadro 9 apresenta o resumo dos resultados destes testes. 
Quadro 9 - Resumo dos resultados

\begin{tabular}{l|c|c|c|c}
\hline \multirow{1}{c|}{ Relações } & \multicolumn{4}{c}{ Testes } \\
\cline { 2 - 5 } & Mann-Whitney & $\begin{array}{c}\text { Correlação de } \\
\text { Pearson }\end{array}$ & $\begin{array}{c}\text { Correlação de } \\
\text { Spearman }\end{array}$ & $\begin{array}{c}\text { Regressão } \\
\text { simples }\end{array}$ \\
\hline $\begin{array}{l}\text { índice de benefícios e } \\
\text { margem líquida sobre as } \\
\text { vendas de 2006 }\end{array}$ & $\mathrm{X}$ & $\mathrm{X}$ & \\
\hline $\begin{array}{l}\text { índice de carreira e } \\
\text { crescimento das vendas de } \\
2006\end{array}$ & $\mathrm{X}$ & $\mathrm{X}$ & $\mathrm{X}$ \\
\hline $\begin{array}{l}\text { índice de carreira e retorno } \\
\text { sobre patrimônio líquido de } \\
2006\end{array}$ & $\mathrm{X}$ & $\mathrm{X}$ & $\mathrm{X}$ & $\mathrm{X}$ \\
\hline $\begin{array}{l}\text { índice de desenvolvimento e } \\
\text { retorno sobre patrimônio } \\
\text { líquido de 2006 }\end{array}$ & & & $\mathrm{X}$ \\
\hline
\end{tabular}

FONTE: Elaborado pela autora.

Por fim, para testar a hipótese de que existe relação positiva e significante entre a remuneração dos executivos e o desempenho financeiro das empresas, no contexto do mercado brasileiro, foi utilizada a análise de regressão linear múltipla. Seis modelos foram desenvolvidos. Para tanto, utilizaram-se: todas as variáveis de remuneração como variável independente; as variáveis de desempenho financeiro, alternadamente, como variável dependente; porte das empresas como variável de controle. Foi adotado o procedimento Enter.

Os resultados da análise de regressão linear múltipla não permitem comprovar a hipótese de que, no contexto do mercado brasileiro, existe relação positiva e significante entre a remuneração dos executivos e o desempenho financeiro das empresas. 


\section{CONCLUSÕES E CONSIDERAÇÕES FINAIS}

A remuneração dos executivos tem atraído a atenção da mídia. Recentemente, o caso dos "bônus milionários" foi notícia nos principais meios de comunicação de todo o mundo. Executivos - na maioria, americanos - receberam somas vultosas em dinheiro, apesar de terem contribuído para a ruína das companhias que administravam.

A abordagem mais utilizada nas pesquisas sobre remuneração de executivos é a teoria do principal-agente (CONYON, 2006) ou teoria de agência. Segundo esta, o principal (acionista) contrata um agente (executivo) para administrar sua empresa, delegando-lhe autoridade. Se ambas as partes da relação procuram maximizar sua utilidade, existem boas razões para acreditar que o agente nem sempre agirá de acordo com os melhores interesses do principal (JENSEN; MECKLING, 1976).

Vários autores consideram o sistema de remuneração um mecanismo eficiente para alinhar os interesses de acionistas e executivos, e limitar possíveis divergências (AGGARWAL; SAMWICK, 1999; DEVERS et al, 2007; SHIM; LEE, 2003; TOSI et al, 2000). A remuneração variável atrelada a metas de desempenho pode ajudar a direcionar o comportamento dos executivos para ações que elevem os níveis de desempenho financeiro.

A globalização, o acirramento da concorrência e a sofisticação dos instrumentos financeiros aumentaram a demanda por profissionais qualificados. Para atraí-los e retê-los, as organizações passaram a pagar somas cada vez maiores de remuneração variável e/ou bônus.

A disputa por melhores talentos levou as grandes corporações, principalmente americanas, a transformar os bônus em instrumentos de "sedução" (MANO et al, 2009). Com a promessa de garantir a independência financeira, essas companhias passaram a criar mecanismos desvinculados da entrega de resultados, para atrair os executivos talentosos (Ibid.). Dentre os instrumentos criados, pode-se citar (Ibid.):

- "bônus de entrada": na assinatura do contrato de admissão, os executivos tinham assegurados salários elevados, independente do resultado apresentado; 
- "bônus de rescisão": os executivos tinham salários assegurados em caso de demissão antes do prazo estipulado em contrato.

Essa tendência, que começou nos Estados Unidos, espalhou-se para outros países. Na busca por resultados mais rápidos, riscos elevados foram assumidos. Era legítimo "vender o futuro para comprar o presente" (MANO et al, 2009, p. 26).

No período de 2000 a 2007, por exemplo, o aumento de $160 \%$ no faturamento das cinco principais empresas do setor financeiro dos Estados Unidos provocou uma elevação no valor de salários e benefícios dos executivos em $68 \%$, apesar de o lucro no período ter diminuído em 23\% (MANO et al, 2009).

Diante de uma situação favorável aos atores envolvidos, nenhuma medida foi tomada para corrigir a situação. O crescimento da economia mundial elevou a receita das organizações: os analistas de mercado elogiavam o desempenho das companhias; os acionistas estavam satisfeitos com a valorização rápida de seus papéis; os executivos ganhavam bônus milionários (MANO et al, 2009). Com a queda da atividade econômica, o problema dos "supersalários", desvinculados do desempenho, veio à tona.

É nesta conjuntura - em que se privilegia o imediatismo, o curto prazo, em detrimento do longo prazo - que os resultados deste estudo são interpretados. O objetivo desta tese é investigar a relação entre a remuneração dos executivos e o desempenho financeiro das empresas, no contexto do mercado brasileiro.

A amostra não-probabilística é formada por 44 empresas industriais, selecionadas dentre as eleitas como "As 150 Melhores Empresas para Você Trabalhar" no Brasil, em 2007. Os dados são secundários. Aqueles que se referem à remuneração foram extraídos do banco de dados do Progep, da FIA; os referentes ao desempenho financeiro foram coletados do banco de dados da FIPECAFI.

Para operacionalizar a variável independente remuneração, são utilizados, além do salário mensal médio e do salário variável médio, três índices criados especialmente para este estudo: benefícios, carreira e desenvolvimento. $\mathrm{O}$ índice de benefícios mede o acesso dos executivos a 12 benefícios; o índice de carreira mede o acesso a 25 mecanismos de estímulo e suporte à 
carreira; o índice de desenvolvimento mede o acesso a 8 mecanismos de estímulo à educação e ao desenvolvimento profissional. Os denominados executivos, neste trabalho, são os diretores, vice-presidentes e presidentes. Os dados são do exercício de 2006.

Para operacionalizar a variável desempenho financeiro são utilizados três indicadores contábeis - crescimento das vendas, retorno sobre patrimônio líquido e margem líquida sobre as vendas - dos exercícios sociais de 2006 e 2007. O porte da companhia é utilizado como variável de controle e é medido pelo logaritmo natural do número de funcionários. Um conjunto de testes estatísticos - de igualdade de médias, análise de correlação e análise de regressão - é aplicado para investigar a relação.

A análise descritiva das variáveis de remuneração indicou que as organizações estavam oferecendo poucos mecanismos de estímulo ao crescimento profissional - materializado pela carreira na empresa - e à educação e ao desenvolvimento de seus executivos. Os investimentos em carreira e em desenvolvimento são considerados de longo prazo, pois demandam certo tempo para gerar resultados. Se, no momento em que a pesquisa foi realizada, as companhias estavam privilegiando o curto prazo, esses resultados da análise descritiva são consistentes.

O teste de Mann-Whitney apontou algumas diferenças de médias entre os dois grupos "baixo" e "alto" -, apesar de não serem significantes. Dentre as diferenças apontadas destacam-se:

- a média do crescimento das vendas de 2006 no grupo índice de carreira "baixo" é maior do que no grupo índice de carreira "alto",

- a média do retorno sobre patrimônio líquido de 2006 no grupo índice de carreira "baixo" é maior do que no grupo índice de carreira "alto",

- a média do retorno sobre patrimônio líquido de 2006 no grupo índice de desenvolvimento "baixo" é maior do que no grupo índice de desenvolvimento "alto". 
Tais resultados divergem da visão inicial deste estudo, a qual esperava que o grupo denominado "alto" apresentasse médias de desempenho financeiro superiores às do grupo denominado "baixo".

A análise de correlação de Pearson apontou existência de associação significante, fraca e negativa entre as variáveis:

- índice de carreira e crescimento das vendas de 2006;

- índice de carreira e retorno sobre patrimônio líquido de 2006;

- índice de desenvolvimento e retorno sobre patrimônio líquido de 2006.

A associação significante, fraca e negativa entre índice de desenvolvimento e retorno sobre patrimônio líquido de 2006 foi confirmada pela análise de correlação de Spearman. Trata-se de resultados compatíveis com as diferenças observadas no teste de Mann-Whitney.

Constatou-se que não há relação entre a variável salário mensal médio e aquelas de desempenho financeiro, tampouco entre a variável salário variável médio e as de desempenho financeiro. Tal ausência pode ser um sinal de que o sistema de remuneração dos executivos não está sendo estruturado de maneira adequada.

A análise de regressão linear simples confirmou a existência de relação entre:

- índice de carreira e crescimento das vendas de 2006;

- índice de carreira e retorno sobre patrimônio líquido de 2006;

- índice de desenvolvimento e retorno sobre patrimônio líquido de 2006. 
Esses modelos apresentaram baixo poder de explicação e coeficiente negativo para as variáveis índice de carreira e índice de desenvolvimento. Os investimentos em carreira e em desenvolvimento são de longo prazo, e o período utilizado, na pesquisa, para avaliar o desempenho financeiro abrangeu dois exercícios sociais. Tal fator - a duração do investimento e da pesquisa - é uma possível justificativa para o sinal negativo dos coeficientes. As condições podem não ter sido apropriadas para captar a influência. Talvez, fosse necessário utilizar um horizonte de tempo maior.

Os resultados da análise de regressão linear múltipla não permitiram comprovar a hipótese da pesquisa de que existe relação positiva e significante entre a remuneração dos executivos e o desempenho financeiro das empresas, no contexto do mercado brasileiro. Esperava-se que a utilização de abordagem diferente da utilizada nos estudos anteriores, com o emprego de conceitos mais amplos - criação de três índices, uso de três indicadores contábeis de dois exercícios sociais - possibilitasse a comprovação da hipótese. Porém, esta expectativa não foi confirmada.

Além do objetivo principal de investigar a relação entre a remuneração dos executivos e o desempenho financeiro das empresas, no contexto do mercado brasileiro, esta tese tinha como objetivos adicionais: sistematizar a literatura existente sobre a referida relação; conhecer as características do sistema de remuneração dos executivos das companhias brasileiras. $\mathrm{O}$ primeiro objetivo foi atendido no Capítulo 2, com a apresentação dos principais resultados e características das pesquisas realizadas. O segundo, no Capítulo 5, pela análise descritiva das informações extraídas do banco de dados do Progep.

Este trabalho apresenta algumas limitações. O método de amostragem para selecionar as empresas é não-probabilístico. Assim, não é possível generalizar os resultados encontrados para a população. Além disso, consideram-se as organizações selecionadas como benchmarking em gestão de pessoas. Dessa maneira, pode ser que elas não representem as empresas industriais em geral.

Outra limitação refere-se à forma como as variáveis da pesquisa foram operacionalizadas. Apesar de este estudo utilizar conceitos mais amplos do que as pesquisas anteriores, outras definições operacionais para as variáveis podem ser adotadas. 
O tamanho da amostra também é uma limitação. Devido à dificuldade para se obter, no Brasil, os dados contábeis corporativos, a amostra é composta por 44 empresas. O fato de aquelas de capital fechado - categoria predominante no universo empresarial brasileiro - não serem obrigadas a divulgar suas demonstrações financeiras, dificulta a realização de trabalhos que necessitem desses dados. Adicionalmente, a própria utilização de informações contábeis pode ser um limitador, pois é passível de distorções.

As principais contribuições deste trabalho estão em:

- criar três índices - benefícios, carreira e desenvolvimento - e produzir conceitos mais amplos para operacionalizar as variáveis da pesquisa;

- ampliar o conhecimento sobre a relação entre a remuneração dos executivos e o desempenho financeiro das empresas;

- estudar essa relação no contexto do mercado brasileiro;

- abrir perspectivas para a realização de novos trabalhos acadêmicos;

- fornecer subsídios para as organizações aperfeiçoarem seus sistemas de remuneração.

Novos estudos podem ser realizados a partir deste. Se a proposta da Comissão de Valores Mobiliários (CVM) for aprovada, as empresas de capital aberto serão obrigadas a tornar pública a política de remuneração, informando o valor do salário fixo e do salário variável dos três principais executivos. Assim, dados adicionais sobre a remuneração dos executivos estarão disponíveis para os pesquisadores e poderão ser adotados para operacionalizar a variável.

A adoção de outras definições operacionais para desempenho financeiro, com a utilização de indicadores operacionais além dos financeiros, podem também ser consideradas. 
Outros testes estatísticos podem ser aplicados, assim como um horizonte de tempo maior. Para evitar a influência do setor de atuação das companhias nos resultados, sugere-se a realização de estudos focados em um setor específico.

Este trabalho adotou a perspectiva universal para investigar a relação entre a remuneração dos executivos e o desempenho financeiro das empresas. Segundo essa perspectiva, essa relação é linear e universal. Novos trabalhos podem ser desenvolvidos utilizando outras perspectivas. A estratégia da organização, por exemplo, pode ser incluída como variável contingencial.

Por fim, é possível que a realização de um estudo de caso contribua para entender melhor a relação entre a remuneração dos executivos e o desempenho financeiro das empresas, no contexto do mercado brasileiro. 


\section{REFERÊNCIAS}

AGGARWAL, Rajesh K.; SAMWICK, Andrew A. Executive compensation, strategic competition and relative performance evaluation: theory and evidence. The Journal of Finance, v. LIX, n. 6, p. 1999-2043, December 1999.

ALCÁZAR, Fernando Martín et al. Researching on SHRM: an analysis of the debate over the role played by human resources in firm success. Management Revue, v. 16, n. 2, p. 213-241, 2005.

ANDERSON, David R. et al. Estatística aplicada à administração e economia. São Paulo: Pioneira Thomson Learning, 2003.

ARTHUR, Jeffrey B. Effects of human resource systems on manufacturing performance and turnover. Academy of Management Journal, v. 37, n. 3, p. 670-687, Jun 1994.

ATTAWAY, Morris C. A study of the relationship between company performance and CEO compensation. American Business Review, v. 18, n. 1, p. 77-85, Jan 2000.

BÁLKIN, David B.; GÓMEZ-MEJIA, Luis R. Toward a contingency theory of compensation strategy. Strategic Management Journal, v. 8, n. 2, p. 169-182, Mar/Apr 1987.

.Matching compensation and organizational strategies. Strategic Management Journal, v. 11, n. 2, p. 153-169, Feb 1990.

BARKEMA, Harry G.; GÓMEZ-MEJIA, Luis R. Managerial compensation and firm performance: a general research framework. Academy of Management Journal, v. 41, n. 2, p. 135-145, Apr 1998.

BECKER, Brian E.; GERHART, Barry. The impact of human resource management on organizational performance: progress and prospects. Academy of Management Journal, v. 39, n. 4, p. 779-801, Aug 1996.

BECKER, Brian E.; HUSELID, Mark A. High performance work systems and firm performance: a synthesis of research and managerial implications. Research in Personnel and Human Resource Management, v. 16, p. 53-101, 1998.

BLOOM, Mattew C.; MILKOVICH, George T. Relationships among risk, incentive pay, and organizational performance. Academy of Management Journal, v. 41, n. 3, p. 283-297, 1998. 
BOSELIE, Paul et al. Human resource management and performance: lessons from the Netherlands. International of Journal of Human Resource Management, v. 12, n. 7, p. 1107-1125, November 2001.

BREWSTER, Chris. Towards a "European" model of human resource management. Journal of International Business Studies, v. 26, n. 1, p. 1-21, First Quarter 1995.

. SHRM: the value of different paradigms. Management International Review, v. 39, n. 3, p. 45-64, 1999.

BRUNI, Adriano Leal. Estatística aplicada à gestão empresarial. São Paulo: Atlas, 2007.

CARLON, Donna M. et al. Statistics as fetishes: the case of financial performance and executive compensation. Organizational Research Methods, v. 9, n. 4, p. 475-490, Oct 2006.

CARTON, Robert B.; HOFER, Charles W. Measuring organizational performance: metrics for entrepreneurship and strategic management research. Northampton: Edward Elgar, 2006.

CERVO, Amado Luiz; BERVIAN, Pedro Alcino. Metodologia científica. São Paulo: McGraw-Hill, 1973.

CHAKRAVARTHY, Balaji S. Measuring strategic performance. Strategic Management Journal, v. 7, n. 5, p. 437-458, Sep/Oct 1986.

CHIAVENATO, Idalberto. Recursos Humanos. Ed. Compacta. São Paulo: Atlas, 2000.

CONYON, Martin J. Executive compensation and incentives. Academy of Management Perspectives, p. 25-40, February 2006.

CONANT, Jeffrey S. et al. Strategic types, distinctive marketing competencies and organizational performance: a multiple measures-based study. Strategic Management Journal, v. 11, n. 5, p. 365-383, Sep 1990.

CORRAR, Luiz J. et al (Coord). Análise multivariada: para os cursos de administração, ciências contábeis e economia. São Paulo: Atlas, 2007.

DELANEY, J. T. et al. Human resource policies and practices in American firms. Washington: U. S. Government Printing Office, 1989.

DELANEY, John T.; HUSELID, Mark A. The impact of human resource management practices on perceptions of organizational performance. Academy of Management Journal, v. 39, n. 4, p. 949-969, Aug 1996. 
DELERY, John E.; DOTY, D. Harold. Modes of theorizing in strategic human resource management: tests of universalistic, contingency, and configurational performance predictions. Academy of Management Journal, v. 39, n. 4, p. 802-835, Aug 1996.

DEVERS, Cynthia E. et al. Executive compensation: a multidisciplinary review of recent developments. Journal of Management, v. 33, n. 6, p. 1016-1072, December 2007.

DUTRA, Joel Souza. A gestão de carreira. In: FLEURY, Maria Teresa L. et al. As pessoas na organização. São Paulo: Editora Gente, 2002a.

Gestão de pessoas. São Paulo: Atlas, 2002b.

EBOLI, Marisa. O desenvolvimento das pessoas e a educação corporativa. In: FLEURY, Maria Teresa L. et al. As pessoas na organização. São Paulo: Editora Gente, 2002.

FIA. Laudo técnico: pesquisa VOCÊ S/A - EXAME. 2007. Disponível em: www.fia.com.br/progep. Acesso em 04/02/2008.

FÁVERO, Luiz Paulo et al. Análise de dados: modelagem multivariada para tomada de decisões. Rio de Janeiro: Elsevier, 2009.

GERHART, Barry; MILKOVICH, George T. Organizational differences in managerial compensation and financial performance. Academy of Management Journal, v. 33, n. 4, p. 663-691, Dec 1990.

GÓMEZ-MEJIA, Luis R. Structure and process of diversification, compensation strategy, and firm performance. Strategic Management Journal, v. 13, n. 5, p. 381-397, Jun 1992.

; WELBOURNE, Theresa M. Compensation strategy: an overview and future steps. HR Human Resource Planning, v. 11, n. 3, p. 173-189, 1988.

GUJARATI, Damodar. Econometria básica. Rio de Janeiro: Elsevier, 2006.

HAIR, Jr., Joseph F. et al. Análise multivariada de dados. Porto Alegre: Bookman, 2005a.

HAIR, Jr., Joseph F. et al. Fundamentos de métodos de pesquisa em administração. Porto Alegre: Bookman, 2005b.

HANASHIRO, Darci M. et al (Org.). Gestão do fator humano: uma visão baseada em stakeholders. São Paulo: Saraiva, 2007. 
HAREL, Gedaliahu H.; TZAFRIR, Shay S. The effect of human resource management practices on the perceptions of organizational and market performance of the firm. Human Resource Management, v. 38, n. 3, p. 185-200, Fall 1999.

HUSELID, Mark A. The impact of human resource management practices on turnover, productivity, and corporate financial performance. Academy of Management Journal, v. 38, n. 3, p. 635-672, Jun 1995.

HUSELID, Mark A. et al. Technical and strategic human resource management effectiveness as determinants of firm performance. Academy of Management Journal, v. 40, n. 1, p. 171188, 1997.

JENSEN, Michael C.; MECKLING, William H. Theory of the firm: managerial behavior, agency costs, and ownership structure.Journal of Financial Economics, v. 3, n. 4, p. 305360, 1976.

KEATS, Barbara W. Diversification and business economic performance revisited: issues of measurement and causality. Journal of Management, v. 16, n. 1, p. 61-72, 1990.

KERR, Jeffrey L. Diversification strategies and managerial rewards: an empirical study. Academy of Management Journal, v. 28, n. 1, p. 155-179, Mar 1985.

LAKATOS, Eva Maria; MARCONI, Marina de Andrade. Metodologia científica. São Paulo: Atlas, 1991.

LEE, Jooh et al. A comparative study of U.S. and Korean firms: changes in diversification and performance. International Journal of Commerce \& Management, v. 13, n. 1, p. 1141, 2003

LONDON, Manuel; STUMPF, Stephen. Managing careers. Massachusetts: AddisonWesley, 1982

MAK, Simon K.; AKHTAR, Syed. Human resource management practices, strategic orientations, and company performance: a correlation study of publicly listed companies. Journal of American Academy of Business, v. 2, n. 2, p. 510-515, Mar 2003.

MANO, Cristiane et al. O que deu errado com os bônus. Exame. São Paulo: Abril, ed. 939, ano 43, n. $5,25 / 03 / 2009$.

MARCONI, Marina de Andrade; LAKATOS, Eva Maria. Fundamentos de metodologia científica. São Paulo: Atlas, 2003. 
MARÍN, Gregorio Sánchez; SÁNCHEZ, Antonio Aragón. Top managers' compensation, strategic orientations, and firm performance. Management Research, v. 1, n. 1, p. 27-44, Winter 2002-2003.

Managerial compensation and firm performance: the moderating role of firm strategy as a proxy of managerial discretion Management Research, v. 3, n. 2, p. 137-148, Spring 2005.

MILES, Raymond E.; SNOW, Charles C. Organizational strategy, structure and process. New York: McGraw Hill, 1978.

MONTEMAYOR, Edilberto F. Congruence between pay policy and competitive strategy in high-performing firms. Journal of Management, v. 22, n. 6, p. 889-908, 1996.

OZKAN, Neslihan. CEO compensation and firm performance: an empirical investigation of UK panel data. SSRN Working Paper Series. July 2007. Disponível em http://ssrn.com/abstract=1102703. Acesso em 22/10/08.

PAUL, A. K.; ANANTHARAMAN, R. N. Business strategy, HRM practices and organizational performance: a study of the Indian software industry. Journal of Transnational Management Development, v. 7, n. 3, p. 27-51, 2002.

Impact of people management practices on organizational performance: analysis of a causal model. International Journal of Human Resource Management, v. 14, n. 7, p. 1246-1266, November 2003.

PESTANA, Maria Helena; GAGEIRO, João Nunes. Análise de dados para ciências sociais - a complementaridade do SPSS. Lisboa: Silabo, 2000.

RAJAGOPALAN, Nandini. Strategic orientations, incentive plan adoptions, and firm performance: evidence from electric utility firms. Strategic Management Journal, v. 18, n. 10, p. 761-785, Nov 1997.

ROSSETTI, José Paschoal et al. Finanças corporativas. Rio de Janeiro: Elsevier, 2008.

SCHUSTER, Jay R.; ZINGHEIM, Patricia K. The new pay: linking employee and organizational performance. New York: Lexington Books, 1992.

SHIM, Eunsup; LEE, Jooh. A canonical analysis of CEO compensation and corporate performance in the service industry. Review of Accounting \& Finance, v. 2, n. 3, p. 72-90, 2003.

SIEGEL, Sidney; CASTELLAN, N. John, Jr. Estatística não paramétrica para ciências do comportamento. Porto Alegre: Artmed, 2006. 
STEVENSON, William J. Estatística aplicada à administração. São Paulo: Harbra, 2001.

STOCK, James H.; WATSON, Mark W. Econometria. São Paulo: Addison Wesley, 2004.

TERPSTRA, David E.; ROZELL, Elizabeth J. The relationship of staffing practices to organizational level measures of performance. Personnel Psychology, v. 46, n. 1, p. 27-48, Spring 1993.

TOSI, Henry L. et al. How much does performance matter? A meta-analysis of CEO pay studies. Journal of Management, v. 26, n. 2, p. 301-339, 2000.

VARMA, Arup et al. High performance work systems: exciting discovery or passing fad? Human Resource Planning, v. 22, n. 1, p. 26-37, 1999.

VENKATRAMAN, N.; RAMANUJAM, Vasudevan. Measurement of business performance in strategy research: a comparison of approaches. Academy of Management Review, v. 11, n. 4, p. 801-814, 1986.

Measurement of business economic performance: an examination of method convergence. Journal of Management, v. 13, n. 1, p. 109-122, 1987.

VERGARA, Sylvia Constant. Projetos e relatórios de pesquisa em administração. São Paulo: Atlas, 2006.

XAVIER, Paulo R. et al. Remuneração variável: quando os resultados falam mais alto. São Paulo: Makron, 1999.

YOUNDT, Mark A. et al. Human resource management, manufacturing strategy, and firm performance. Academy of Management Journal, v. 39, n. 4, p. 836-866, Aug 1996. 


\section{APÊNDICES}

APÊNDICE 1: PONTUAÇÃO DAS EMPRESAS NO ÍNDICE DE BENEFÍCIOS APÊNDICE 2: PONTUAÇÃO DAS EMPRESAS NO ÍNDICE DE CARREIRA APÊNDICE 3: PONTUAÇÃO DAS EMPRESAS NO ÍNDICE DE DESENVOLVIMENTO APÊNDICE 4: RESULTADOS DOS MODELOS DE REGRESSÃO LINEAR SIMPLES TESTADOS 
APÊNDICE 1: PONTUAÇÃO DAS EMPRESAS NO ÍNDICE DE BENEFÍCIOS

\begin{tabular}{|c|c|c|c|c|c|c|c|c|c|c|c|c|c|}
\hline \multirow{2}{*}{$\begin{array}{c}\text { Empresa } \\
\# \\
\end{array}$} & \multicolumn{12}{|c|}{ Itens } & \multirow{2}{*}{$\begin{array}{c}\text { Índice de } \\
\text { Benefícios }\end{array}$} \\
\hline & 1 & 2 & 3 & 4 & 5 & 6 & 7 & 8 & 9 & 10 & 11 & 12 & \\
\hline 1 & 2 & 2 & 2 & 2 & 2 & 2 & 2 & 2 & 2 & 2 & 2 & 2 & 24 \\
\hline 2 & 2 & 2 & 2 & 0 & 2 & 2 & 0 & 1 & 2 & 2 & 2 & 2 & 19 \\
\hline 3 & 2 & 0 & 2 & 0 & 1 & 2 & 0 & 2 & 2 & 0 & 0 & 2 & 13 \\
\hline 4 & 2 & 2 & 2 & 2 & 2 & 2 & 2 & 2 & 2 & 2 & 2 & 2 & 24 \\
\hline 5 & 2 & 0 & 2 & 0 & 2 & 0 & 2 & 2 & 2 & 2 & 0 & 0 & 14 \\
\hline 6 & 2 & 0 & 2 & 2 & 2 & 2 & 0 & 2 & 2 & 2 & 0 & 2 & 18 \\
\hline 7 & 2 & 2 & 2 & 2 & 2 & 2 & 0 & 2 & 2 & 0 & 0 & 0 & 16 \\
\hline 8 & 2 & 2 & 2 & 0 & 0 & 2 & 0 & 1 & 1 & 1 & 2 & 2 & 15 \\
\hline 9 & 2 & 2 & 0 & 0 & 2 & 2 & 0 & 1 & 0 & 0 & 0 & 0 & 9 \\
\hline 10 & 2 & 2 & 2 & 0 & 2 & 2 & 0 & 2 & 2 & 0 & 0 & 0 & 14 \\
\hline 11 & 2 & 0 & 2 & 0 & 2 & 2 & 2 & 2 & 2 & 1 & 0 & 0 & 15 \\
\hline 12 & 2 & 0 & 2 & 2 & 2 & 2 & 2 & 2 & 2 & 2 & 0 & 0 & 18 \\
\hline 13 & 2 & 1 & 2 & 0 & 0 & 2 & 2 & 2 & 2 & 0 & 0 & 2 & 15 \\
\hline 14 & 2 & 2 & 2 & 0 & 2 & 2 & 2 & 2 & 0 & 0 & 0 & 2 & 16 \\
\hline 15 & 2 & 2 & 2 & 2 & 2 & 2 & 2 & 2 & 2 & 0 & 0 & 2 & 20 \\
\hline 16 & 2 & 0 & 2 & 0 & 0 & 2 & 0 & 2 & 2 & 2 & 0 & 0 & 12 \\
\hline 17 & 2 & 1 & 0 & 0 & 2 & 2 & 2 & 2 & 0 & 2 & 0 & 2 & 15 \\
\hline 18 & 2 & 0 & 2 & 0 & 0 & 2 & 2 & 2 & 2 & 0 & 0 & 2 & 14 \\
\hline 19 & 2 & 2 & 2 & 2 & 2 & 2 & 0 & 2 & 2 & 0 & 0 & 2 & 18 \\
\hline 20 & 2 & 2 & 2 & 2 & 2 & 2 & 2 & 2 & 2 & 0 & 0 & 2 & 20 \\
\hline 21 & 2 & 2 & 2 & 2 & 2 & 2 & 2 & 2 & 2 & 0 & 0 & 2 & 20 \\
\hline 22 & 2 & 2 & 0 & 0 & 0 & 2 & 2 & 2 & 2 & 0 & 0 & 2 & 14 \\
\hline 23 & 2 & 2 & 2 & 0 & 0 & 2 & 2 & 2 & 2 & 0 & 0 & 2 & 16 \\
\hline 24 & 2 & 0 & 2 & 0 & 2 & 2 & 0 & 0 & 2 & 0 & 0 & 2 & 12 \\
\hline 25 & 2 & 2 & 0 & 0 & 0 & 2 & 0 & 2 & 2 & 0 & 0 & 2 & 12 \\
\hline 26 & 2 & 2 & 2 & 0 & 2 & 2 & 2 & 2 & 0 & 2 & 0 & 0 & 16 \\
\hline 27 & 2 & 2 & 2 & 0 & 2 & 2 & 2 & 2 & 2 & 0 & 2 & 2 & 20 \\
\hline 28 & 2 & 0 & 2 & 0 & 2 & 2 & 0 & 2 & 2 & 0 & 0 & 2 & 14 \\
\hline 29 & 2 & 1 & 2 & 0 & 0 & 2 & 2 & 2 & 2 & 1 & 0 & 2 & 16 \\
\hline 30 & 2 & 2 & 2 & 0 & 1 & 2 & 2 & 2 & 2 & 2 & 0 & 2 & 19 \\
\hline 31 & 2 & 2 & 2 & 0 & 2 & 0 & 2 & 2 & 2 & 2 & 0 & 2 & 18 \\
\hline 32 & 2 & 2 & 2 & 2 & 2 & 2 & 2 & 2 & 2 & 0 & 0 & 2 & 20 \\
\hline 33 & 2 & 2 & 2 & 0 & 2 & 0 & 0 & 2 & 2 & 2 & 0 & 2 & 16 \\
\hline 34 & 2 & 2 & 2 & 0 & 0 & 2 & 2 & 2 & 2 & 2 & 0 & 2 & 18 \\
\hline 35 & 2 & 2 & 2 & 2 & 1 & 2 & 1 & 1 & 1 & 1 & 1 & 1 & 17 \\
\hline 36 & 2 & 2 & 2 & 2 & 2 & 2 & 0 & 0 & 0 & 0 & 0 & 2 & 14 \\
\hline 37 & 2 & 2 & 2 & 0 & 0 & 2 & 2 & 2 & 0 & 0 & 0 & 2 & 14 \\
\hline 38 & 2 & 2 & 2 & 2 & 2 & 2 & 0 & 1 & 0 & 0 & 0 & 0 & 13 \\
\hline 39 & 2 & 2 & 2 & 0 & 2 & 2 & 0 & 2 & 2 & 0 & 0 & 2 & 16 \\
\hline 40 & 2 & 2 & 2 & 0 & 2 & 2 & 2 & 2 & 2 & 2 & 0 & 2 & 20 \\
\hline 41 & 2 & 0 & 0 & 0 & 0 & 2 & 2 & 2 & 2 & 0 & 0 & 2 & 12 \\
\hline 42 & 2 & 2 & 2 & 2 & 2 & 2 & 1 & 2 & 2 & 0 & 0 & 2 & 19 \\
\hline 43 & 2 & 2 & 2 & 0 & 2 & 2 & 2 & 2 & 2 & 0 & 0 & 2 & 18 \\
\hline 44 & 2 & 1 & 2 & 0 & 2 & 2 & 0 & 2 & 2 & 0 & 0 & 2 & 15 \\
\hline
\end{tabular}

FONTE: Elaborado pela autora. 
APÊNDICE 2: PONTUAÇÃO DAS EMPRESAS NO ÍNDICE DE CARREIRA

\begin{tabular}{|c|c|c|c|c|c|c|c|c|c|c|c|c|c|c|c|c|c|c|c|c|c|c|c|c|c|c|}
\hline \multirow{2}{*}{$\begin{array}{c}\text { Empresa } \\
\#\end{array}$} & \multicolumn{25}{|c|}{ Itens } & \multirow{2}{*}{$\begin{array}{l}\text { Índice de } \\
\text { Carreira }\end{array}$} \\
\hline & 1 & 2 & 3 & 4 & 5 & 6 & 7 & 8 & 9 & 10 & 11 & 12 & 13 & 14 & 15 & 16 & 17 & 18 & 19 & 20 & 21 & 22 & 23 & 24 & 25 & \\
\hline 1 & 2 & 2 & 2 & 2 & 2 & 2 & 0 & 0 & 0 & 1 & 1 & 2 & 2 & 2 & 0 & 1 & 1 & 1 & 1 & 0 & 0 & 0 & 0 & 0 & 0 & 24 \\
\hline 2 & 2 & 2 & 2 & 2 & 2 & 2 & 2 & 2 & 2 & 2 & 2 & 0 & 0 & 2 & 2 & 2 & 2 & 2 & 2 & 0 & 0 & 0 & 0 & 0 & 0 & 34 \\
\hline 3 & 2 & 2 & 2 & 2 & 0 & 0 & 2 & 0 & 0 & 0 & 0 & 0 & 0 & 0 & 0 & 1 & 0 & 1 & 0 & 0 & 0 & 0 & 0 & 0 & 0 & 12 \\
\hline 4 & 2 & 2 & 2 & 2 & 0 & 2 & 2 & 2 & 0 & 0 & 0 & 0 & 0 & 0 & 2 & 0 & 0 & 2 & 2 & 2 & 2 & 2 & 0 & 2 & 0 & 28 \\
\hline 5 & 2 & 2 & 2 & 2 & 2 & 2 & 0 & 0 & 0 & 2 & 0 & 2 & 2 & 2 & 2 & 2 & 0 & 2 & 0 & 0 & 0 & 0 & 0 & 0 & 0 & 26 \\
\hline 6 & 0 & 0 & 0 & 0 & 2 & 0 & 2 & 1 & 2 & 2 & 2 & 2 & 2 & 2 & 2 & 0 & 0 & 2 & 2 & 0 & 0 & 0 & 0 & 0 & 0 & 23 \\
\hline 7 & 2 & 2 & 2 & 2 & 2 & 0 & 0 & 0 & 2 & 2 & 2 & 1 & 0 & 0 & 2 & 0 & 0 & 0 & 0 & 1 & 2 & 0 & 2 & 2 & 2 & 28 \\
\hline 8 & 2 & 2 & 2 & 2 & 1 & 1 & 1 & 1 & 1 & 1 & 0 & 1 & 1 & 2 & 0 & 1 & 0 & 1 & 0 & 0 & 0 & 0 & 0 & 0 & 0 & 20 \\
\hline 9 & 2 & 1 & 0 & 0 & 0 & 0 & 2 & 0 & 0 & 0 & 0 & 2 & 0 & 0 & 2 & 1 & 0 & 2 & 2 & 0 & 0 & 0 & 0 & 0 & 0 & 14 \\
\hline 10 & 2 & 2 & 2 & 2 & 2 & 2 & 0 & 0 & 0 & 0 & 0 & 0 & 0 & 0 & 2 & 0 & 0 & 0 & 0 & 0 & 0 & 0 & 0 & 0 & 0 & 14 \\
\hline 11 & 2 & 2 & 2 & 2 & 2 & 0 & 1 & 1 & 0 & 1 & 0 & 2 & 2 & 2 & 2 & 2 & 2 & 2 & 2 & 0 & 0 & 0 & 0 & 0 & 0 & 29 \\
\hline 12 & 2 & 2 & 2 & 2 & 0 & 0 & 0 & 0 & 0 & 0 & 0 & 2 & 2 & 0 & 2 & 0 & 0 & 0 & 0 & 2 & 2 & 2 & 2 & 2 & 2 & 26 \\
\hline 13 & 2 & 2 & 2 & 2 & 2 & 0 & 2 & 0 & 1 & 1 & 1 & 1 & 2 & 2 & 2 & 1 & 0 & 1 & 0 & 2 & 2 & 2 & 2 & 0 & 0 & 32 \\
\hline 14 & 2 & 2 & 2 & 2 & 0 & 0 & 0 & 0 & 0 & 0 & 0 & 2 & 0 & 2 & 0 & 0 & 0 & 0 & 0 & 2 & 2 & 0 & 0 & 0 & 0 & 16 \\
\hline 15 & 0 & 0 & 0 & 0 & 0 & 2 & 0 & 0 & 0 & 0 & 0 & 0 & 0 & 0 & 2 & 0 & 2 & 2 & 2 & 2 & 2 & 0 & 0 & 2 & 2 & 18 \\
\hline 16 & 2 & 2 & 2 & 2 & 2 & 2 & 2 & 2 & 1 & 2 & 0 & 2 & 2 & 2 & 2 & 2 & 2 & 2 & 2 & 2 & 2 & 2 & 0 & 0 & 2 & 43 \\
\hline 17 & 2 & 2 & 2 & 0 & 2 & 2 & 2 & 2 & 0 & 2 & 0 & 0 & 0 & 0 & 2 & 0 & 0 & 0 & 0 & 0 & 0 & 0 & 0 & 0 & 0 & 18 \\
\hline 18 & 0 & 0 & 0 & 0 & 0 & 0 & 2 & 0 & 0 & 0 & 0 & 0 & 0 & 0 & 0 & 0 & 0 & 0 & 0 & 0 & 0 & 0 & 0 & 0 & 0 & 2 \\
\hline 19 & 2 & 2 & 2 & 2 & 0 & 2 & 1 & 1 & 0 & 1 & 0 & 0 & 0 & 0 & 0 & 1 & 2 & 2 & 0 & 0 & 0 & 0 & 0 & 0 & 0 & 18 \\
\hline 20 & 2 & 2 & 2 & 2 & 2 & 2 & 2 & 1 & 2 & 2 & 2 & 1 & 1 & 2 & 2 & 2 & 2 & 2 & 2 & 0 & 0 & 0 & 0 & 0 & 0 & 35 \\
\hline 21 & 2 & 2 & 0 & 2 & 2 & 0 & 2 & 2 & 0 & 2 & 1 & 2 & 2 & 2 & 2 & 2 & 2 & 2 & 2 & 2 & 2 & 2 & 2 & 2 & 2 & 43 \\
\hline 22 & 2 & 2 & 2 & 2 & 0 & 0 & 0 & 0 & 0 & 0 & 0 & 2 & 2 & 2 & 0 & 0 & 0 & 0 & 0 & 0 & 0 & 0 & 0 & 0 & 0 & 14 \\
\hline 23 & 2 & 2 & 2 & 2 & 0 & 0 & 0 & 0 & 0 & 0 & 0 & 0 & 0 & 2 & 0 & 0 & 0 & 2 & 2 & 0 & 0 & 0 & 0 & 0 & 0 & 14 \\
\hline 24 & 0 & 0 & 0 & 0 & 0 & 0 & 0 & 0 & 0 & 0 & 0 & 2 & 2 & 2 & 0 & 0 & 0 & 0 & 0 & 2 & 0 & 0 & 0 & 0 & 2 & 10 \\
\hline 25 & 0 & 0 & 0 & 0 & 0 & 0 & 0 & 0 & 0 & 0 & 0 & 1 & 1 & 0 & 2 & 2 & 2 & 2 & 2 & 2 & 2 & 1 & 1 & 1 & 2 & 21 \\
\hline 26 & 2 & 2 & 2 & 2 & 0 & 0 & 0 & 0 & 0 & 0 & 0 & 0 & 0 & 2 & 2 & 0 & 0 & 0 & 0 & 0 & 0 & 0 & 0 & 0 & 0 & 12 \\
\hline 27 & 2 & 2 & 2 & 2 & 2 & 2 & 2 & 2 & 0 & 2 & 2 & 2 & 2 & 2 & 2 & 2 & 2 & 2 & 2 & 2 & 2 & 2 & 2 & 2 & 2 & 48 \\
\hline 28 & 2 & 2 & 2 & 2 & 0 & 2 & 2 & 1 & 0 & 2 & 0 & 0 & 0 & 2 & 0 & 2 & 0 & 1 & 2 & 0 & 0 & 0 & 0 & 0 & 0 & 22 \\
\hline 29 & 2 & 2 & 2 & 2 & 2 & 0 & 2 & 0 & 1 & 1 & 1 & 2 & 2 & 2 & 2 & 1 & 0 & 1 & 0 & 2 & 2 & 0 & 2 & 0 & 0 & 31 \\
\hline 30 & 2 & 2 & 2 & 2 & 2 & 2 & 2 & 2 & 1 & 2 & 1 & 1 & 1 & 2 & 1 & 1 & 0 & 1 & 1 & 2 & 2 & 2 & 2 & 0 & 0 & 36 \\
\hline 31 & 2 & 2 & 2 & 0 & 2 & 2 & 2 & 2 & 0 & 0 & 0 & 2 & 0 & 0 & 2 & 2 & 2 & 0 & 0 & 0 & 0 & 0 & 0 & 0 & 0 & 22 \\
\hline 32 & 2 & 2 & 2 & 2 & 0 & 0 & 0 & 0 & 0 & 0 & 0 & 0 & 0 & 0 & 0 & 0 & 0 & 0 & 0 & 0 & 0 & 0 & 0 & 0 & 0 & 8 \\
\hline 33 & 2 & 2 & 2 & 2 & 0 & 2 & 2 & 0 & 2 & 1 & 0 & 0 & 0 & 0 & 0 & 2 & 2 & 2 & 2 & 0 & 0 & 0 & 0 & 0 & 0 & 23 \\
\hline 34 & 0 & 0 & 0 & 0 & 0 & 0 & 0 & 0 & 0 & 0 & 0 & 0 & 0 & 0 & 2 & 0 & 0 & 0 & 0 & 0 & 0 & 0 & 0 & 0 & 0 & 2 \\
\hline 35 & 2 & 2 & 2 & 2 & 1 & 0 & 1 & 1 & 0 & 2 & 1 & 1 & 1 & 2 & 1 & 2 & 0 & 2 & 2 & 0 & 0 & 0 & 0 & 0 & 0 & 25 \\
\hline 36 & 2 & 2 & 2 & 2 & 2 & 2 & 2 & 1 & 0 & 2 & 2 & 2 & 2 & 0 & 0 & 2 & 2 & 2 & 2 & 0 & 0 & 0 & 0 & 0 & 0 & 31 \\
\hline 37 & 2 & 2 & 2 & 2 & 2 & 2 & 2 & 0 & 0 & 1 & 0 & 1 & 1 & 2 & 2 & 2 & 2 & 2 & 2 & 2 & 2 & 0 & 0 & 0 & 2 & 35 \\
\hline 38 & 2 & 2 & 2 & 2 & 1 & 0 & 1 & 0 & 1 & 2 & 0 & 2 & 1 & 2 & 0 & 2 & 1 & 1 & 1 & 2 & 2 & 2 & 0 & 0 & 0 & 29 \\
\hline 39 & 2 & 2 & 2 & 2 & 0 & 0 & 0 & 2 & 2 & 2 & 0 & 2 & 2 & 2 & 1 & 2 & 2 & 2 & 2 & 2 & 2 & 2 & 2 & 2 & 0 & 39 \\
\hline 40 & 2 & 2 & 2 & 2 & 0 & 0 & 0 & 0 & 0 & 2 & 0 & 0 & 0 & 0 & 1 & 0 & 0 & 0 & 2 & 0 & 0 & 0 & 0 & 0 & 0 & 13 \\
\hline 41 & 2 & 2 & 2 & 2 & 0 & 0 & 0 & 0 & 0 & 0 & 0 & 0 & 0 & 0 & 0 & 0 & 0 & 0 & 0 & 0 & 0 & 0 & 0 & 0 & 0 & 8 \\
\hline 42 & 1 & 2 & 1 & 2 & 0 & 0 & 1 & 2 & 2 & 2 & 0 & 2 & 2 & 0 & 0 & 0 & 0 & 0 & 0 & 0 & 0 & 0 & 0 & 0 & 0 & 17 \\
\hline 43 & 0 & 0 & 0 & 0 & 0 & 0 & 0 & 0 & 0 & 1 & 0 & 0 & 0 & 2 & 2 & 0 & 0 & 0 & 0 & 2 & 0 & 0 & 2 & 2 & 2 & 13 \\
\hline 44 & 2 & 2 & 2 & 2 & 2 & 2 & 2 & 2 & 0 & 2 & 2 & 2 & 2 & 2 & 2 & 2 & 2 & 2 & 0 & 0 & 0 & 0 & 0 & 0 & 0 & 34 \\
\hline
\end{tabular}

FONTE: Elaborado pela autora. 
APÊNDICE 3: PONTUAÇÃO DAS EMPRESAS NO ÍNDICE DE DESENVOLVIMENTO

\begin{tabular}{|c|c|c|c|c|c|c|c|c|c|}
\hline \multirow{2}{*}{$\begin{array}{c}\text { Empresa } \\
\#\end{array}$} & \multicolumn{8}{|c|}{ Itens } & \multirow{2}{*}{$\begin{array}{c}\text { Índice de } \\
\text { Desenvolvimento }\end{array}$} \\
\hline & 1 & 2 & 3 & 4 & 5 & 6 & 7 & 8 & \\
\hline 1 & 2 & 2 & 2 & 2 & 2 & 2 & 2 & 2 & 16 \\
\hline 2 & 2 & 1 & 1 & 2 & 2 & 2 & 2 & 2 & 14 \\
\hline 3 & 2 & 2 & 2 & 2 & 2 & 2 & 0 & 2 & 14 \\
\hline 4 & 2 & 2 & 0 & 2 & 2 & 2 & 2 & 2 & 14 \\
\hline 5 & 2 & 1 & 2 & 2 & 2 & 1 & 0 & 2 & 12 \\
\hline 6 & 2 & 2 & 1 & 2 & 2 & 2 & 2 & 0 & 13 \\
\hline 7 & 2 & 2 & 2 & 2 & 2 & 2 & 2 & 2 & 16 \\
\hline 8 & 2 & 1 & 1 & 2 & 2 & 1 & 1 & 0 & 10 \\
\hline 9 & 0 & 0 & 0 & 2 & 2 & 2 & 2 & 0 & 8 \\
\hline 10 & 2 & 2 & 2 & 0 & 2 & 2 & 2 & 2 & 14 \\
\hline 11 & 2 & 2 & 0 & 1 & 2 & 2 & 2 & 2 & 13 \\
\hline 12 & 1 & 2 & 1 & 2 & 2 & 2 & 0 & 0 & 10 \\
\hline 13 & 2 & 2 & 0 & 1 & 2 & 2 & 2 & 0 & 11 \\
\hline 14 & 2 & 0 & 0 & 2 & 2 & 2 & 0 & 2 & 10 \\
\hline 15 & 2 & 0 & 0 & 2 & 2 & 2 & 2 & 2 & 12 \\
\hline 16 & 2 & 2 & 2 & 2 & 2 & 2 & 2 & 2 & 16 \\
\hline 17 & 2 & 2 & 2 & 2 & 2 & 2 & 2 & 2 & 16 \\
\hline 18 & 0 & 0 & 0 & 0 & 0 & 0 & 0 & 0 & 0 \\
\hline 19 & 2 & 0 & 0 & 2 & 2 & 2 & 2 & 2 & 12 \\
\hline 20 & 2 & 2 & 2 & 2 & 2 & 2 & 2 & 0 & 14 \\
\hline 21 & 2 & 2 & 1 & 2 & 2 & 2 & 2 & 2 & 15 \\
\hline 22 & 2 & 0 & 2 & 0 & 2 & 1 & 1 & 0 & 8 \\
\hline 23 & 0 & 0 & 0 & 2 & 2 & 2 & 2 & 0 & 8 \\
\hline 24 & 2 & 0 & 0 & 2 & 2 & 2 & 0 & 0 & 8 \\
\hline 25 & 2 & 1 & 0 & 2 & 2 & 1 & 2 & 1 & 11 \\
\hline 26 & 2 & 2 & 0 & 2 & 2 & 2 & 2 & 2 & 14 \\
\hline 27 & 2 & 2 & 2 & 2 & 2 & 2 & 2 & 2 & 16 \\
\hline 28 & 2 & 2 & 2 & 2 & 2 & 2 & 2 & 0 & 14 \\
\hline 29 & 2 & 2 & 0 & 1 & 2 & 2 & 2 & 0 & 11 \\
\hline 30 & 2 & 1 & 1 & 2 & 2 & 1 & 2 & 1 & 12 \\
\hline 31 & 0 & 2 & 2 & 2 & 2 & 2 & 1 & 0 & 11 \\
\hline 32 & 0 & 0 & 0 & 0 & 0 & 0 & 0 & 0 & 0 \\
\hline 33 & 2 & 2 & 2 & 2 & 2 & 2 & 2 & 2 & 16 \\
\hline 34 & 2 & 2 & 2 & 2 & 2 & 2 & 2 & 2 & 16 \\
\hline 35 & 2 & 0 & 0 & 2 & 2 & 2 & 2 & 2 & 12 \\
\hline 36 & 0 & 0 & 0 & 0 & 0 & 0 & 0 & 0 & 0 \\
\hline 37 & 2 & 2 & 2 & 2 & 2 & 2 & 2 & 2 & 16 \\
\hline 38 & 2 & 2 & 2 & 1 & 2 & 2 & 1 & 2 & 14 \\
\hline 39 & 2 & 2 & 0 & 2 & 2 & 2 & 2 & 2 & 14 \\
\hline 40 & 2 & 1 & 1 & 2 & 2 & 1 & 2 & 0 & 11 \\
\hline 41 & 2 & 2 & 1 & 2 & 2 & 2 & 1 & 1 & 13 \\
\hline 42 & 2 & 2 & 0 & 1 & 2 & 1 & 2 & 2 & 12 \\
\hline 43 & 2 & 2 & 2 & 2 & 2 & 2 & 2 & 2 & 16 \\
\hline 44 & 2 & 2 & 0 & 0 & 0 & 2 & 2 & 0 & 8 \\
\hline
\end{tabular}

FONTE: Elaborado pela autora. 


\section{APÊNDICE 4: RESULTADOS DOS MODELOS DE REGRESSÃO LINEAR SIMPLES} TESTADOS

Este apêndice exibe os resultados das regressões simples, estimados com o método dos mínimos quadrados e que não apresentaram significância estatística. Para cada um dos modelos, foi feita a análise dos pressupostos de: normalidade, autocorrelação serial, linearidade e homoscedasticidade. Os modelos atenderam a todos os pressupostos. 
Modelo 1 - Crescimento das vendas de 2006 e salário mensal médio

\begin{tabular}{|l|r|r|r|c|}
\hline \multicolumn{1}{|c|}{ Model Summary } \\
Model & $\mathrm{R}$ & R Square & $\begin{array}{c}\text { Adjusted R } \\
\text { Square }\end{array}$ & $\begin{array}{c}\text { Std. Error of the } \\
\text { Estimate }\end{array}$ \\
\hline 1 &, $077^{\mathrm{a}}$ &, 006 &,- 018 & 11,1198 \\
\hline
\end{tabular}

a. Predictors: (Constant), salmen FONTE: SPSS.

\begin{tabular}{|c|c|c|c|c|c|c|}
\hline \multicolumn{7}{|c|}{ ANOVA $^{b}$} \\
\hline & & Sum of Squares & df & Mean Square & $\mathrm{F}$ & Sig. \\
\hline \multirow[t]{3}{*}{1} & Regression & 30,908 & 1 & 30,908 & ,250 &, $620^{\mathrm{a}}$ \\
\hline & Residual & 5193,338 & 42 & 123,651 & & \\
\hline & Total & & 43 & & & \\
\hline
\end{tabular}

a. Predictors: (Constant), salmen

b. Dependent Variable: cven06 FONTE: SPSS.

\section{Coefficients $^{\mathrm{a}}$}

\begin{tabular}{|c|c|c|c|c|c|c|}
\hline \multirow{2}{*}{\multicolumn{2}{|c|}{ Model }} & \multicolumn{2}{|c|}{ Unstandardized Coefficients } & $\begin{array}{l}\text { Standardized } \\
\text { Coefficients }\end{array}$ & \multirow[b]{2}{*}{$\mathrm{t}$} & \multirow[b]{2}{*}{ Sig. } \\
\hline & & B & Std. Error & Beta & & \\
\hline 1 & (Constant) & 2,550 & 5,403 & & ,472 & ,639 \\
\hline & salmen & $9,511 \mathrm{E}-5$ &, 000 & 077 &, 500 & ,620 \\
\hline
\end{tabular}

a. Dependent Variable: cven06 FONTE: SPSS. 
Modelo 2 - Crescimento das vendas de 2006 e salário variável médio

\begin{tabular}{|l|r|r|r|c|}
\hline & & Model Summary \\
Model & $\mathrm{R}$ & R Square & $\begin{array}{c}\text { Adjusted R } \\
\text { Square }\end{array}$ & $\begin{array}{c}\text { Std. Error of the } \\
\text { Estimate }\end{array}$ \\
\hline 1 &, $120^{\mathrm{a}}$ &, 014 &,- 009 & 11,0721 \\
\hline
\end{tabular}

a. Predictors: (Constant), salvar FONTE: SPSS.

\begin{tabular}{|rr|r|r|r|r|r|}
\hline \multicolumn{2}{|l|}{ Model $^{2}$} & Sum of Squares & df & Mean Square & F & Sig. \\
\hline 1 & Regression & 75,427 & 1 & 75,427 &, 615 &, $437^{\text {a }}$ \\
& Residual & 5148,818 & 42 & 122,591 & & \\
& Total & 5224,245 & 43 & & & \\
\hline
\end{tabular}

a. Predictors: (Constant), salvar

b. Dependent Variable: cven06

FONTE: SPSS

\section{Coefficients $^{\mathrm{a}}$}

\begin{tabular}{|c|c|c|c|c|c|c|}
\hline \multirow{2}{*}{\multicolumn{2}{|c|}{ Model }} & \multicolumn{2}{|c|}{ Unstandardized Coefficients } & \multirow{2}{*}{$\begin{array}{c}\begin{array}{c}\text { Standardized } \\
\text { Coefficients }\end{array} \\
\text { Beta }\end{array}$} & \multirow[b]{2}{*}{$\mathrm{t}$} & \multirow[b]{2}{*}{ Sig. } \\
\hline & & B & Std. Error & & & \\
\hline 1 & (Constant) & 3,744 & 2,420 & & 1,547 &, 129 \\
\hline & salvar & $9,696 \mathrm{E}-6$ &, 000 &, 120 & ,784 & ,437 \\
\hline
\end{tabular}

a. Dependent Variable: cven06 FONTE: SPSS. 
Modelo 3 - Crescimento das vendas de 2006 e índice de benefícios

\begin{tabular}{|l|r|r|r|c|}
\hline \multicolumn{1}{|c|}{ Model Summary } \\
Model & \multicolumn{1}{|c|}{$\mathrm{R}$} & R Square & $\begin{array}{c}\text { Adjusted R } \\
\text { Square }\end{array}$ & $\begin{array}{c}\text { Std. Error of the } \\
\text { Estimate }\end{array}$ \\
\hline 1 &, $188^{\mathrm{a}}$ &, 035 &, 012 & 10,9544 \\
\hline
\end{tabular}

a. Predictors: (Constant), ibenef FONTE: SPSS.

\begin{tabular}{|c|c|c|c|c|c|c|}
\hline \multicolumn{7}{|c|}{ ANOVA $^{b}$} \\
\hline & & Sum of Squares & df & Mean Square & $\mathrm{F}$ & Sig. \\
\hline \multirow[t]{3}{*}{1} & Regression & 184,311 & 1 & 184,311 & 1,536 &, $222^{\mathrm{a}}$ \\
\hline & Residual & 5039,935 & 42 & 119,998 & & \\
\hline & Total & 5224,245 & 43 & & & \\
\hline
\end{tabular}

a. Predictors: (Constant), ibenef

b. Dependent Variable: cven06

FONTE: SPSS.

\section{Coefficients $^{\mathrm{a}}$}

\begin{tabular}{|c|c|c|c|c|c|c|}
\hline \multirow{2}{*}{\multicolumn{2}{|c|}{ Model }} & \multicolumn{2}{|c|}{ Unstandardized Coefficients } & \multirow{2}{*}{$\begin{array}{c}\text { Standardized } \\
\text { Coefficients }\end{array}$} & \multirow[b]{2}{*}{$\mathrm{t}$} & \multirow[b]{2}{*}{ Sig. } \\
\hline & & B & Std. Error & & & \\
\hline 1 & (Constant) & $-5,559$ & 8,772 & &,- 634 &, 530 \\
\hline & ibenef & ,658 &, 531 &, 188 & 1,239 & ,222 \\
\hline
\end{tabular}

a. Dependent Variable: cven06 FONTE: SPSS. 
Modelo 4 - Crescimento das vendas de 2006 e índice de desenvolvimento

\begin{tabular}{|l|r|r|r|c|}
\hline \multicolumn{1}{|c|}{ Model Summary } \\
Model & $\mathrm{R}$ & R Square & $\begin{array}{c}\text { Adjusted R } \\
\text { Square }\end{array}$ & $\begin{array}{c}\text { Std. Error of the } \\
\text { Estimate }\end{array}$ \\
\hline 1 &, $117^{\mathrm{a}}$ &, 014 &,- 010 & 11,0762 \\
\hline
\end{tabular}

a. Predictors: (Constant), idesen FONTE: SPSS.

\begin{tabular}{|ll|r|r|r|r|r|}
\hline \multicolumn{2}{|c|}{ ANOVA $^{\mathbf{b}}$} & \\
\hline 1 & & Sum of Squares & df & Mean Square & F & Sig. \\
\hline & Regression & 71,639 & 1 & 71,639 &, 584 &, $449^{\mathrm{a}}$ \\
& Residual & 5152,607 & 42 & 122,681 & & \\
& Total & 5224,245 & 43 & & & \\
\hline
\end{tabular}

a. Predictors: (Constant), idesen

b. Dependent Variable: cven06 FONTE: SPSS.

Coefficients $^{\mathrm{a}}$

\begin{tabular}{|c|c|c|c|c|c|c|}
\hline \multirow{2}{*}{\multicolumn{2}{|c|}{ Model }} & \multicolumn{2}{|c|}{ Unstandardized Coefficients } & \multirow{2}{*}{$\begin{array}{c}\text { Standardized } \\
\text { Coefficients }\end{array}$} & \multirow[b]{2}{*}{$\mathrm{t}$} & \multirow[b]{2}{*}{ Sig. } \\
\hline & & $\mathrm{B}$ & Std. Error & & & \\
\hline 1 & (Constant) & 8,451 & 4,670 & & 1,810 & ,078 \\
\hline & idesen &,- 290 & 379 &,- 117 &,- 764 & ,449 \\
\hline
\end{tabular}

a. Dependent Variable: cven06 FONTE: SPSS. 
Modelo 5 - Retorno sobre patrimônio líquido de 2006 e salário mensal médio

\begin{tabular}{|l|r|r|r|c|}
\hline \multicolumn{7}{|c|}{ Model Summary } \\
Model & \multicolumn{1}{|c|}{$\mathrm{R}$} & R Square & $\begin{array}{c}\text { Adjusted R } \\
\text { Square }\end{array}$ & $\begin{array}{c}\text { Std. Error of the } \\
\text { Estimate }\end{array}$ \\
\hline 1 &, $051^{\mathrm{a}}$ &, 003 &,- 021 & 17,7185 \\
\hline
\end{tabular}

a. Predictors: (Constant), salmen FONTE: SPSS.

\begin{tabular}{|c|c|c|c|c|c|c|}
\hline \multicolumn{7}{|c|}{ ANOVA $^{b}$} \\
\hline & & Sum of Squares & df & Mean Square & $\mathrm{F}$ & Sig. \\
\hline \multirow[t]{3}{*}{1} & Regression & 34,738 & 1 & 34,738 &, 111 &, $741^{\mathrm{a}}$ \\
\hline & Residual & 13185,634 & 42 & 313,944 & & \\
\hline & Total & 13220,372 & 43 & & & \\
\hline
\end{tabular}

a. Predictors: (Constant), salmen

b. Dependent Variable: roe06

FONTE: SPSS.

\section{Coefficients $^{\mathrm{a}}$}

\begin{tabular}{|c|c|c|c|c|c|c|}
\hline \multirow{2}{*}{\multicolumn{2}{|c|}{ Model }} & \multicolumn{2}{|c|}{ Unstandardized Coefficients } & \multirow{2}{*}{$\begin{array}{c}\text { Standardized } \\
\text { Coefficients }\end{array}$} & \multirow[b]{2}{*}{$\mathrm{t}$} & \multirow[b]{2}{*}{ Sig. } \\
\hline & & B & Std. Error & & & \\
\hline 1 & (Constant) & 15,791 & 8,609 & & 1,834 &, 074 \\
\hline & salmen &, 000 &, 000 &, 051 & ,333 &, 741 \\
\hline
\end{tabular}

a. Dependent Variable: roe06 FONTE: SPSS. 
Modelo 6 - Retorno sobre patrimônio líquido de 2006 e salário variável médio

\begin{tabular}{|l|r|r|r|c|}
\hline & & Model Summary \\
Model & $\mathrm{R}$ & R Square & $\begin{array}{c}\text { Adjusted R } \\
\text { Square }\end{array}$ & $\begin{array}{c}\text { Std. Error of the } \\
\text { Estimate }\end{array}$ \\
\hline 1 &, $077^{\mathrm{a}}$ &, 006 &,- 018 & 17,6890 \\
\hline
\end{tabular}

a. Predictors: (Constant), salvar FONTE: SPSS.

\begin{tabular}{|rr|r|r|r|r|r|}
\hline \multicolumn{2}{|c|}{ MNOdel $^{2}$} & Sum of Squares & df & Mean Square & \multicolumn{1}{c|}{ F } & \multicolumn{1}{c|}{ Sig. } \\
\hline 1 & Regression & 78,551 & 1 & 78,551 &, 251 &, $619^{\mathrm{a}}$ \\
& Residual & 13141,821 & 42 & 312,901 & & \\
& Total & 13220,372 & 43 & & & \\
\hline
\end{tabular}

a. Predictors: (Constant), salvar

b. Dependent Variable: roe06

FONTE: SPSS.

\section{Coefficients $^{\mathrm{a}}$}

\begin{tabular}{|c|c|c|c|c|c|c|}
\hline \multirow{2}{*}{\multicolumn{2}{|c|}{ Model }} & \multicolumn{2}{|c|}{ Unstandardized Coefficients } & \multirow{2}{*}{$\begin{array}{c}\begin{array}{c}\text { Standardized } \\
\text { Coefficients }\end{array} \\
\text { Beta }\end{array}$} & \multirow[b]{2}{*}{$\mathrm{t}$} & \multirow[b]{2}{*}{ Sig. } \\
\hline & & B & Std. Error & & & \\
\hline 1 & (Constant) & 17,111 & 3,867 & & 4,425 & 000 \\
\hline & salvar & $9,895 \mathrm{E}-6$ &, 000 &, 077 &, 501 & ,619 \\
\hline
\end{tabular}

a. Dependent Variable: roe06 FONTE: SPSS. 
Modelo 7 - Retorno sobre patrimônio líquido de 2006 e índice de benefícios

\begin{tabular}{|l|r|r|r|c|}
\hline \multicolumn{1}{|c|}{ Model Summary } \\
Model & \multicolumn{1}{|c|}{$\mathrm{R}$} & R Square & $\begin{array}{c}\text { Adjusted R } \\
\text { Square }\end{array}$ & $\begin{array}{c}\text { Std. Error of the } \\
\text { Estimate }\end{array}$ \\
\hline 1 &, $060^{\mathrm{a}}$ &, 004 &,- 020 & 17,7103 \\
\hline
\end{tabular}

a. Predictors: (Constant), ibenef FONTE: SPSS.

\begin{tabular}{|rr|r|r|r|r|r|}
\hline \multicolumn{2}{|c|}{ MNOdel $^{2}$} & Sum of Squares & df & Mean Square & \multicolumn{1}{c|}{ F } & \multicolumn{1}{c|}{ Sig. } \\
\hline 1 & Regression & 46,940 & 1 & 46,940 &, 150 &, $701^{\mathrm{a}}$ \\
& Residual & 13173,432 & 42 & 313,653 & & \\
& Total & 13220,372 & 43 & & & \\
\hline
\end{tabular}

a. Predictors: (Constant), ibenef

b. Dependent Variable: roe06

FONTE: SPSS.

\section{Coefficients $^{\mathrm{a}}$}

\begin{tabular}{|c|c|c|c|c|c|c|}
\hline \multirow{2}{*}{\multicolumn{2}{|c|}{ Model }} & \multicolumn{2}{|c|}{ Unstandardized Coefficients } & \multirow{2}{*}{$\begin{array}{c}\text { Standardized } \\
\text { Coefficients }\end{array}$} & \multirow[b]{2}{*}{$\mathrm{t}$} & \multirow[b]{2}{*}{ Sig. } \\
\hline & & B & Std. Error & & & \\
\hline 1 & (Constant) & 13,125 & 14,182 & & ,925 & ,360 \\
\hline & ibenef & ,332 &, 858 &, 060 & ,387 & ,701 \\
\hline
\end{tabular}

a. Dependent Variable: roe06 FONTE: SPSS. 
Modelo 8 - Margem líquida sobre as vendas de 2006 e salário mensal médio

\begin{tabular}{|l|r|r|r|r|}
\hline & & & \multicolumn{1}{|c|}{ Model Summary } \\
Model & $\mathrm{R}$ & R Square & \multicolumn{1}{c|}{$\begin{array}{c}\text { Square } \\
\text { Square }\end{array}$} & $\begin{array}{c}\text { Std. Error of the } \\
\text { Estimate }\end{array}$ \\
\hline 1 &, $156^{\mathrm{a}}$ &, 024 &, 001 & 9,8112 \\
\hline
\end{tabular}

a. Predictors: (Constant), salmen FONTE: SPSS.

\begin{tabular}{|rr|r|r|r|r|r|}
\hline \multicolumn{2}{|c|}{ MNOdel $^{2}$} & Sum of Squares & df & Mean Square & F & \multicolumn{1}{c|}{ Sig. } \\
\hline 1 & Regression & 100,647 & 1 & 100,647 & 1,046 &, $312^{\mathrm{a}}$ \\
& Residual & 4042,944 & 42 & 96,261 & & \\
& Total & 4143,592 & 43 & & & \\
\hline
\end{tabular}

a. Predictors: (Constant), salmen

b. Dependent Variable: mven06

FONTE: SPSS.

\section{Coefficients $^{\mathrm{a}}$}

\begin{tabular}{|c|c|c|c|c|c|c|}
\hline \multirow{2}{*}{\multicolumn{2}{|c|}{ Model }} & \multicolumn{2}{|c|}{ Unstandardized Coefficients } & \multirow{2}{*}{$\begin{array}{c}\begin{array}{c}\text { Standardized } \\
\text { Coefficients }\end{array} \\
\text { Beta }\end{array}$} & \multirow[b]{2}{*}{$\mathrm{t}$} & \multirow[b]{2}{*}{ Sig. } \\
\hline & & B & Std. Error & & & \\
\hline 1 & (Constant) & 1,886 & 4,767 & & ,396 & ,694 \\
\hline & salmen &, 000 &, 000 &, 156 & 1,023 & ,312 \\
\hline
\end{tabular}

a. Dependent Variable: mven06 FONTE: SPSS. 
Modelo 9 - Margem líquida sobre as vendas de 2006 e salário variável médio

\begin{tabular}{|l|r|r|r|r|}
\hline & & & \multicolumn{1}{|c|}{ Model Summary } \\
Model & $\mathrm{R}$ & R Square & $\begin{array}{c}\text { Adjusted R } \\
\text { Square }\end{array}$ & $\begin{array}{c}\text { Std. Error of the } \\
\text { Estimate }\end{array}$ \\
\hline 1 &, $091^{\mathrm{a}}$ &, 008 &,- 015 & 9,8912 \\
\hline
\end{tabular}

a. Predictors: (Constant), salvar FONTE: SPSS.

\begin{tabular}{|rr|r|r|r|r|r|}
\hline \multicolumn{1}{|c|}{ Model } & & Sum of Squares & df & Mean Square & \multicolumn{1}{c|}{ F } & \multicolumn{1}{c|}{ Sig. } \\
\hline 1 & Regression & 34,454 & 1 & 34,454 &, 352 &, $556^{\mathrm{a}}$ \\
& Residual & 4109,138 & 42 & 97,837 & & \\
& Total & 4143,592 & 43 & & & \\
\hline
\end{tabular}

a. Predictors: (Constant), salvar

b. Dependent Variable: mven06 FONTE: SPSS.

Coefficients $^{\mathrm{a}}$

\begin{tabular}{|c|c|c|c|c|c|c|}
\hline \multirow{2}{*}{\multicolumn{2}{|c|}{ Model }} & \multicolumn{2}{|c|}{ Unstandardized Coefficients } & \multirow{2}{*}{$\begin{array}{c}\text { Standardized } \\
\text { Coefficients }\end{array}$} & \multirow[b]{2}{*}{$\mathrm{t}$} & \multirow[b]{2}{*}{ Sig. } \\
\hline & & B & Std. Error & & & \\
\hline 1 & (Constant) & 5,591 & 2,162 & & 2,586 & 013 \\
\hline & salvar & $6,553 \mathrm{E}-6$ &, 000 &, 091 &, 593 &, 556 \\
\hline
\end{tabular}

a. Dependent Variable: mven06 FONTE: SPSS. 
Modelo 10 - Margem líquida sobre as vendas de 2006 e índice de benefícios

\begin{tabular}{|l|r|r|r|c|}
\hline \multicolumn{7}{|c|}{ Model Summary } \\
Model & $\mathrm{R}$ & R Square & $\begin{array}{c}\text { Adjusted R } \\
\text { Square }\end{array}$ & $\begin{array}{c}\text { Std. Error of the } \\
\text { Estimate }\end{array}$ \\
\hline 1 &, $144^{\mathrm{a}}$ &, 021 &,- 003 & 9,8287 \\
\hline
\end{tabular}

a. Predictors: (Constant), ibenef FONTE: SPSS.

\begin{tabular}{|rr|r|r|r|r|r|}
\hline \multicolumn{2}{|c|}{ MNOdel $^{2}$} & Sum of Squares & df & Mean Square & F & \multicolumn{1}{c|}{ Sig. } \\
\hline 1 & Regression & 86,226 & 1 & 86,226 &, 893 &, $350^{\mathrm{a}}$ \\
& Residual & 4057,365 & 42 & 96,604 & & \\
& Total & 4143,592 & 43 & & & \\
\hline
\end{tabular}

a. Predictors: (Constant), ibenef

b. Dependent Variable: mven06

FONTE: SPSS.

\section{Coefficients $^{\mathrm{a}}$}

\begin{tabular}{|c|c|c|c|c|c|c|}
\hline \multirow{2}{*}{\multicolumn{2}{|c|}{ Model }} & \multicolumn{2}{|c|}{ Unstandardized Coefficients } & \multirow{2}{*}{$\begin{array}{c}\begin{array}{c}\text { Standardized } \\
\text { Coefficients }\end{array} \\
\text { Beta }\end{array}$} & \multirow[b]{2}{*}{$\mathrm{t}$} & \multirow[b]{2}{*}{ Sig. } \\
\hline & & $\mathrm{B}$ & Std. Error & & & \\
\hline 1 & (Constant) &,- 783 & 7,871 & &,- 099 & ,921 \\
\hline & ibenef & 450 & ,476 &, 144 & ,945 &, 350 \\
\hline
\end{tabular}

a. Dependent Variable: mven06 FONTE: SPSS. 
Modelo 11 - Margem líquida sobre as vendas de 2006 e índice de carreira

\begin{tabular}{|c|r|r|r|c|}
\hline & & & \multicolumn{1}{|c|}{ Model Summary } \\
Model & $\mathrm{R}$ & R Square & \multicolumn{1}{c|}{$\begin{array}{c}\text { Squared R } \\
\text { Square }\end{array}$} & $\begin{array}{c}\text { Std. Error of the } \\
\text { Estimate }\end{array}$ \\
\hline 1 &, $063^{\mathrm{a}}$ &, 004 &,- 020 & 9,9126 \\
\hline
\end{tabular}

a. Predictors: (Constant), icarr FONTE: SPSS.

\begin{tabular}{|rr|r|r|r|r|r|}
\hline \multicolumn{2}{|c|}{ MNOdel $^{2}$} & Sum of Squares & df & Mean Square & F & \multicolumn{1}{c|}{ Sig. } \\
\hline 1 & Regression & 16,674 & 1 & 16,674 &, 170 &, $682^{\mathrm{a}}$ \\
& Residual & 4126,918 & 42 & 98,260 & & \\
& Total & 4143,592 & 43 & & & \\
\hline
\end{tabular}

a. Predictors: (Constant), icarr

b. Dependent Variable: mven06

FONTE: SPSS.

\section{Coefficients $^{\mathrm{a}}$}

\begin{tabular}{|c|c|c|c|c|c|c|}
\hline \multirow{2}{*}{\multicolumn{2}{|c|}{ Model }} & \multicolumn{2}{|c|}{ Unstandardized Coefficients } & \multirow{2}{*}{$\begin{array}{c}\text { Standardized } \\
\text { Coefficients } \\
\text { Beta }\end{array}$} & \multirow[b]{2}{*}{$\mathrm{t}$} & \multirow[b]{2}{*}{ Sig. } \\
\hline & & B & Std. Error & & & \\
\hline 1 & (Constant) & 7,827 & 3,505 & & 2,233 & 031 \\
\hline & icarr &,- 057 & ,139 &,- 063 &,- 412 & ,682 \\
\hline
\end{tabular}

a. Dependent Variable: mven06 FONTE: SPSS. 
Modelo 12 - Margem líquida sobre as vendas de 2006 e índice de desenvolvimento

Model Summary

\begin{tabular}{|l|r|r|r|c|}
\hline Model & $\mathrm{R}$ & R Square & \multicolumn{1}{|c|}{$\begin{array}{c}\text { Adjusted R } \\
\text { Square }\end{array}$} & $\begin{array}{l}\text { Std. Error of the } \\
\text { Estimate }\end{array}$ \\
\hline 1 &, $027^{\mathrm{a}}$ &, 001 &,- 023 & 9,9291 \\
\hline
\end{tabular}

a. Predictors: (Constant), idesen

FONTE: SPSS.

\begin{tabular}{|rr|r|r|r|r|r|}
\hline \multicolumn{2}{|c|}{ MNOdel $^{2}$} & Sum of Squares & df & Mean Square & F & Sig. \\
\hline 1 & Regression & 2,925 & 1 & 2,925 &, 030 &, $864^{\mathrm{a}}$ \\
& Residual & 4140,667 & 42 & 98,587 & & \\
& Total & 4143,592 & 43 & & & \\
\hline
\end{tabular}

a. Predictors: (Constant), idesen

b. Dependent Variable: mven06

FONTE: SPSS.

Coefficients $^{\mathbf{a}}$

\begin{tabular}{|c|c|c|c|c|c|c|}
\hline \multirow{2}{*}{\multicolumn{2}{|c|}{ Model }} & \multicolumn{2}{|c|}{ Unstandardized Coefficients } & \multirow{2}{*}{$\begin{array}{c}\text { Standardized } \\
\text { Coefficients }\end{array}$} & \multirow[b]{2}{*}{$\mathrm{t}$} & \multirow[b]{2}{*}{ Sig. } \\
\hline & & B & Std. Error & & & \\
\hline 1 & (Constant) & 5,847 & 4,186 & & 1,397 &, 170 \\
\hline & idesen & ,059 &, 340 &, 027 &, 172 & ,864 \\
\hline
\end{tabular}

a. Dependent Variable: mven06 FONTE: SPSS. 
Modelo 13 - Crescimento das vendas de 2007 e salário mensal médio

\begin{tabular}{|l|r|r|r|c|}
\hline \multicolumn{1}{|c|}{ Model Summary } \\
\hline Model & \multicolumn{1}{|c|}{$\mathrm{R}$} & R Square & $\begin{array}{c}\text { Adjusted R } \\
\text { Square }\end{array}$ & $\begin{array}{c}\text { Std. Error of the } \\
\text { Estimate }\end{array}$ \\
\hline 1 &, $112^{\mathrm{a}}$ &, 012 &,- 011 & 17,7279 \\
\hline
\end{tabular}

a. Predictors: (Constant), salmen FONTE: SPSS.

\begin{tabular}{|ll|r|r|r|r|r|}
\hline \multicolumn{2}{|c|}{ ANOVA $^{\mathbf{b}}$} \\
\hline 1 & Sum of Squares & df & Mean Square & F & \multicolumn{1}{c|}{ Sig. } \\
\hline & Regression & 166,190 & 1 & 166,190 &, 529 &, $471^{\mathrm{a}}$ \\
& Residual & 13199,716 & 42 & 314,279 & & \\
& Total & 13365,906 & 43 & & & \\
\hline
\end{tabular}

a. Predictors: (Constant), salmen

b. Dependent Variable: cven07

FONTE: SPSS.

\section{Coefficients $^{\mathrm{a}}$}

\begin{tabular}{|c|c|c|c|c|c|c|}
\hline \multirow{2}{*}{\multicolumn{2}{|c|}{ Model }} & \multicolumn{2}{|c|}{ Unstandardized Coefficients } & \multirow{2}{*}{$\begin{array}{c}\text { Standardized } \\
\text { Coefficients } \\
\text { Beta }\end{array}$} & \multirow[b]{2}{*}{$\mathrm{t}$} & \multirow[b]{2}{*}{ Sig. } \\
\hline & & B & Std. Error & & & \\
\hline 1 & (Constant) &,- 996 & 8,614 & &,- 116 & ,909 \\
\hline & salmen &, 000 &, 000 & ,112 &, 727 & ,471 \\
\hline
\end{tabular}

a. Dependent Variable: cven07

FONTE: SPSS. 
Modelo 14 - Crescimento das vendas de 2007 e salário variável médio

\begin{tabular}{|l|r|r|r|c|}
\hline \multicolumn{1}{|c|}{ Model Summary } \\
Model & $\mathrm{R}$ & R Square & $\begin{array}{c}\text { Adjusted R } \\
\text { Square }\end{array}$ & $\begin{array}{c}\text { Std. Error of the } \\
\text { Estimate }\end{array}$ \\
\hline 1 &, $084^{\mathrm{a}}$ &, 007 &,- 017 & 17,7759 \\
\hline
\end{tabular}

a. Predictors: (Constant), salvar FONTE: SPSS.

\begin{tabular}{|ll|r|r|r|r|r|}
\hline \multicolumn{2}{|c|}{ ANOVA $^{\mathbf{b}}$} & \\
\hline 1 & & Sum of Squares & df & Mean Square & \multicolumn{1}{c|}{ F } & \multicolumn{1}{c|}{ Sig. } \\
\hline & Regression & 94,677 & 1 & 94,677 &, 300 &, $587^{\mathrm{a}}$ \\
& Residual & 13271,229 & 42 & 315,982 & & \\
& Total & 13365,906 & 43 & & & \\
\hline
\end{tabular}

a. Predictors: (Constant), salvar

b. Dependent Variable: cven07

FONTE: SPSS.

\section{Coefficients $^{\mathrm{a}}$}

\begin{tabular}{|c|c|c|c|c|c|c|}
\hline \multirow{2}{*}{\multicolumn{2}{|c|}{ Model }} & \multicolumn{2}{|c|}{ Unstandardized Coefficients } & \multirow{2}{*}{$\begin{array}{c}\begin{array}{c}\text { Standardized } \\
\text { Coefficients }\end{array} \\
\text { Beta }\end{array}$} & \multirow[b]{2}{*}{$\mathrm{t}$} & \multirow[b]{2}{*}{ Sig. } \\
\hline & & B & Std. Error & & & \\
\hline 1 & (Constant) & 3,419 & 3,886 & &, 880 & ,384 \\
\hline & salvar & $1,086 \mathrm{E}-5$ &, 000 &, 084 &, 547 &, 587 \\
\hline
\end{tabular}

a. Dependent Variable: cven07

FONTE: SPSS. 
Modelo 15 - Crescimento das vendas de 2007 e índice de benefícios

\begin{tabular}{|l|r|r|r|c|}
\hline \multicolumn{1}{|c|}{ Model Summary } \\
Model & \multicolumn{1}{|c|}{$\mathrm{R}$} & R Square & $\begin{array}{c}\text { Adjusted R } \\
\text { Square }\end{array}$ & $\begin{array}{c}\text { Std. Error of the } \\
\text { Estimate }\end{array}$ \\
\hline 1 &, $087^{\mathrm{a}}$ &, 008 &,- 016 & 17,7710 \\
\hline
\end{tabular}

a. Predictors: (Constant), ibenef FONTE: SPSS.

\begin{tabular}{|rl|r|r|r|r|r|}
\hline \multicolumn{2}{|c|}{ MNOdel $^{2}$} & Sum of Squares & df & Mean Square & F & \multicolumn{1}{c|}{ Sig. } \\
\hline 1 & Regression & 101,908 & 1 & 101,908 &, 323 &, $573^{\mathrm{a}}$ \\
& Residual & 13263,998 & 42 & 315,809 & & \\
& Total & 13365,906 & 43 & & & \\
\hline
\end{tabular}

a. Predictors: (Constant), ibenef

b. Dependent Variable: cven07

FONTE: SPSS.

\section{Coefficients $^{\mathrm{a}}$}

\begin{tabular}{|c|c|c|c|c|c|c|}
\hline \multirow{2}{*}{\multicolumn{2}{|c|}{ Model }} & \multicolumn{2}{|c|}{ Unstandardized Coefficients } & \multirow{2}{*}{$\begin{array}{c}\text { Standardized } \\
\text { Coefficients }\end{array}$} & \multirow[b]{2}{*}{$\mathrm{t}$} & \multirow[b]{2}{*}{ Sig. } \\
\hline & & B & Std. Error & & & \\
\hline 1 & (Constant) & 12,898 & 14,231 & & ,906 & ,370 \\
\hline & ibenef &,- 489 &, 861 &,- 087 &,- 568 &, 573 \\
\hline
\end{tabular}

a. Dependent Variable: cven07

FONTE: SPSS. 
Modelo 16 - Crescimento das vendas de 2007 e índice de carreira

\begin{tabular}{|l|r|r|r|c|}
\hline & & Model Summary \\
Model & $\mathrm{R}$ & R Square & $\begin{array}{c}\text { Adjusted R } \\
\text { Square }\end{array}$ & $\begin{array}{c}\text { Std. Error of the } \\
\text { Estimate }\end{array}$ \\
\hline 1 &, $001^{\mathrm{a}}$ &, 000 &,- 024 & 17,8392 \\
\hline
\end{tabular}

a. Predictors: (Constant), icarr FONTE: SPSS.

\begin{tabular}{|ll|r|r|r|r|r|}
\hline \multicolumn{2}{|c|}{ MNOdel $^{2}$} & Sum of Squares & df & Mean Square & F & \multicolumn{1}{c|}{ Sig. } \\
\hline 1 & Regression &, 019 & 1 &, 019 &, 000 &, $994^{\mathrm{a}}$ \\
& Residual & 13365,888 & 42 & 318,235 & & \\
& Total & 13365,906 & 43 & & & \\
\hline
\end{tabular}

a. Predictors: (Constant), icarr

b. Dependent Variable: cven07

FONTE: SPSS.

\section{Coefficients $^{\mathrm{a}}$}

\begin{tabular}{|c|c|c|c|c|c|c|}
\hline \multirow{2}{*}{\multicolumn{2}{|c|}{ Model }} & \multicolumn{2}{|c|}{ Unstandardized Coefficients } & \multirow{2}{*}{$\begin{array}{c}\text { Standardized } \\
\text { Coefficients }\end{array}$} & \multirow[b]{2}{*}{$\mathrm{t}$} & \multirow[b]{2}{*}{ Sig. } \\
\hline & & B & Std. Error & & & \\
\hline 1 & (Constant) & 5,003 & 6,308 & & ,793 & ,432 \\
\hline & icarr &,- 002 &, 250 &,- 001 &,- 008 & ,994 \\
\hline
\end{tabular}

a. Dependent Variable: cven07

FONTE: SPSS. 
Modelo 17 - Crescimento das vendas de 2007 e índice de desenvolvimento

\begin{tabular}{|l|r|r|r|c|}
\hline & & & \multicolumn{1}{|c|}{ Model Summary } \\
Model & $\mathrm{R}$ & R Square & \multicolumn{1}{c|}{$\begin{array}{c}\text { Squared R } \\
\text { Square }\end{array}$} & $\begin{array}{c}\text { Std. Error of the } \\
\text { Estimate }\end{array}$ \\
\hline 1 &, $088^{\mathrm{a}}$ &, 008 &,- 016 & 17,7699 \\
\hline
\end{tabular}

a. Predictors: (Constant), idesen FONTE: SPSS.

\begin{tabular}{|rl|r|r|r|r|r|}
\hline \multicolumn{2}{|c|}{ MNOdel $^{2}$} & Sum of Squares & df & Mean Square & \multicolumn{1}{c|}{ F } & \multicolumn{1}{c|}{ Sig. } \\
\hline 1 & Regression & 103,619 & 1 & 103,619 &, 328 &, $570^{\mathrm{a}}$ \\
& Residual & 13262,287 & 42 & 315,769 & & \\
& Total & 13365,906 & 43 & & & \\
\hline
\end{tabular}

a. Predictors: (Constant), idesen

b. Dependent Variable: cven07

FONTE: SPSS.

\section{Coefficients $^{\mathrm{a}}$}

\begin{tabular}{|c|c|c|c|c|c|c|}
\hline \multirow{2}{*}{\multicolumn{2}{|c|}{ Model }} & \multicolumn{2}{|c|}{ Unstandardized Coefficients } & \multirow{2}{*}{$\begin{array}{c}\text { Standardized } \\
\text { Coefficients }\end{array}$} & \multirow[b]{2}{*}{$\mathrm{t}$} & \multirow[b]{2}{*}{ Sig. } \\
\hline & & B & Std. Error & & & \\
\hline 1 & (Constant) & 8,967 & 7,492 & & 1,197 & ,238 \\
\hline & idesen &,- 349 & 608 &,- 088 &,- 573 &, 570 \\
\hline
\end{tabular}

a. Dependent Variable: cven07 FONTE: SPSS. 
Modelo 18 - Retorno sobre patrimônio líquido de 2007 e salário mensal médio

\begin{tabular}{|l|r|r|r|c|}
\hline \multicolumn{1}{|c|}{ Model Summary } \\
Model & \multicolumn{1}{|c|}{$\mathrm{R}$} & R Square & $\begin{array}{c}\text { Adjusted R } \\
\text { Square }\end{array}$ & $\begin{array}{c}\text { Std. Error of the } \\
\text { Estimate }\end{array}$ \\
\hline 1 &, $097^{\mathrm{a}}$ &, 009 &,- 014 & 14,0737 \\
\hline
\end{tabular}

a. Predictors: (Constant), salmen FONTE: SPSS.

\begin{tabular}{|rl|r|r|r|r|r|}
\hline \multicolumn{2}{|c|}{ MNOdel $^{2}$} & Sum of Squares & df & Mean Square & \multicolumn{1}{c|}{ F } & \multicolumn{1}{c|}{ Sig. } \\
\hline 1 & Regression & 79,369 & 1 & 79,369 &, 401 &, $530^{\mathrm{a}}$ \\
& Residual & 8318,913 & 42 & 198,069 & & \\
& Total & 8398,282 & 43 & & & \\
\hline
\end{tabular}

a. Predictors: (Constant), salmen

b. Dependent Variable: roe07

FONTE: SPSS.

\section{Coefficients $^{\mathrm{a}}$}

\begin{tabular}{|c|c|c|c|c|c|c|}
\hline \multirow{2}{*}{\multicolumn{2}{|c|}{ Model }} & \multicolumn{2}{|c|}{ Unstandardized Coefficients } & \multirow{2}{*}{$\begin{array}{c}\text { Standardized } \\
\text { Coefficients } \\
\text { Beta }\end{array}$} & \multirow[b]{2}{*}{$\mathrm{t}$} & \multirow[b]{2}{*}{ Sig. } \\
\hline & & B & Std. Error & & & \\
\hline 1 & (Constant) & 12,548 & 6,838 & & 1,835 & 074 \\
\hline & salmen &, 000 & 000 & ,097 & ,633 &, 530 \\
\hline
\end{tabular}

a. Dependent Variable: roe07

FONTE: SPSS. 
Modelo 19 - Retorno sobre parimônio líquido de 2007 e salário variável médio

\begin{tabular}{|l|r|r|r|c|}
\hline \multicolumn{1}{|c|}{ Model Summary } \\
Model & \multicolumn{1}{|c|}{$\mathrm{R}$} & R Square & $\begin{array}{c}\text { Adjusted R } \\
\text { Square }\end{array}$ & $\begin{array}{c}\text { Std. Error of the } \\
\text { Estimate }\end{array}$ \\
\hline 1 &, $068^{\mathrm{a}}$ &, 005 &,- 019 & 14,1077 \\
\hline
\end{tabular}

a. Predictors: (Constant), salvar FONTE: SPSS.

\begin{tabular}{|rl|r|r|r|r|r|}
\hline \multicolumn{2}{|c|}{ MNOdel $^{2}$} & Sum of Squares & df & Mean Square & \multicolumn{1}{c|}{ F } & \multicolumn{1}{c|}{ Sig. } \\
\hline 1 & Regression & 39,106 & 1 & 39,106 &, 196 &, $660^{\mathrm{a}}$ \\
& Residual & 8359,175 & 42 & 199,028 & & \\
& Total & 8398,282 & 43 & & & \\
\hline
\end{tabular}

a. Predictors: (Constant), salvar

b. Dependent Variable: roe07

FONTE: SPSS.

Coefficients $^{\mathbf{a}}$

\begin{tabular}{|c|c|c|c|c|c|c|}
\hline \multirow{2}{*}{\multicolumn{2}{|c|}{ Model }} & \multicolumn{2}{|c|}{ Unstandardized Coefficients } & \multirow{2}{*}{$\begin{array}{c}\text { Standardized } \\
\text { Coefficients }\end{array}$} & \multirow[b]{2}{*}{$\mathrm{t}$} & \multirow[b]{2}{*}{ Sig. } \\
\hline & & B & Std. Error & & & \\
\hline 1 & (Constant) & 15,674 & 3,084 & & 5,083 & ,000 \\
\hline & salvar & $6,982 \mathrm{E}-6$ & ,000 & ,068 & ,443 & 660 \\
\hline
\end{tabular}

a. Dependent Variable: roe07

FONTE: SPSS. 
Modelo 20 - Retorno sobre patrimônio líquido de 2007 e índice de benefícios

\begin{tabular}{|l|r|r|r|c|}
\hline \multicolumn{7}{|c|}{ Model Summary } \\
Model & \multicolumn{1}{|c|}{$\mathrm{R}$} & R Square & $\begin{array}{c}\text { Adjusted R } \\
\text { Square }\end{array}$ & $\begin{array}{c}\text { Std. Error of the } \\
\text { Estimate }\end{array}$ \\
\hline 1 &, $063^{\mathrm{a}}$ &, 004 &,- 020 & 14,1127 \\
\hline
\end{tabular}

a. Predictors: (Constant), ibenef FONTE: SPSS.

\begin{tabular}{|rl|r|r|r|r|r|}
\hline \multicolumn{2}{|c|}{ MNOdel $^{2}$} & Sum of Squares & df & Mean Square & \multicolumn{1}{c|}{ F } & \multicolumn{1}{c|}{ Sig. } \\
\hline 1 & Regression & 33,187 & 1 & 33,187 &, 167 &, $685^{\mathrm{a}}$ \\
& Residual & 8365,095 & 42 & 199,169 & & \\
& Total & 8398,282 & 43 & & & \\
\hline
\end{tabular}

a. Predictors: (Constant), ibenef

b. Dependent Variable: roe07

FONTE: SPSS.

\section{Coefficients $^{\mathrm{a}}$}

\begin{tabular}{|c|c|c|c|c|c|c|}
\hline \multirow{2}{*}{\multicolumn{2}{|c|}{ Model }} & \multicolumn{2}{|c|}{ Unstandardized Coefficients } & \multirow{2}{*}{$\begin{array}{c}\begin{array}{c}\text { Standardized } \\
\text { Coefficients }\end{array} \\
\text { Beta }\end{array}$} & \multirow[b]{2}{*}{$\mathrm{t}$} & \multirow[b]{2}{*}{ Sig. } \\
\hline & & B & Std. Error & & & \\
\hline 1 & (Constant) & 12,133 & 11,301 & & 1,074 & ,289 \\
\hline & ibenef & ,279 & 684 &, 063 & ,408 & 685 \\
\hline
\end{tabular}

a. Dependent Variable: roe07

FONTE: SPSS. 
Modelo 21 - Retorno sobre patrimônio líquido de 2007 e índice de carreira

\begin{tabular}{|l|r|r|r|c|}
\hline \multicolumn{1}{|c|}{ Model Summary } \\
Model & \multicolumn{1}{|c|}{$\mathrm{R}$} & R Square & $\begin{array}{c}\text { Adjusted R } \\
\text { Square }\end{array}$ & $\begin{array}{c}\text { Std. Error of the } \\
\text { Estimate }\end{array}$ \\
\hline 1 &, $190^{\mathrm{a}}$ &, 036 &, 013 & 13,8823 \\
\hline
\end{tabular}

a. Predictors: (Constant), icarr FONTE: SPSS.

\begin{tabular}{|rl|r|r|r|r|r|}
\hline \multicolumn{2}{|c|}{ MNOdel $^{2}$} & Sum of Squares & df & Mean Square & \multicolumn{1}{c|}{ F } & \multicolumn{1}{c|}{ Sig. } \\
\hline 1 & Regression & 304,158 & 1 & 304,158 & 1,578 &, $216^{\mathrm{a}}$ \\
& Residual & 8094,124 & 42 & 192,717 & & \\
& Total & 8398,282 & 43 & & & \\
\hline
\end{tabular}

a. Predictors: (Constant), icarr

b. Dependent Variable: roe07

FONTE: SPSS.

\section{Coefficients $^{\mathrm{a}}$}

\begin{tabular}{|c|c|c|c|c|c|c|}
\hline \multirow{2}{*}{\multicolumn{2}{|c|}{ Model }} & \multicolumn{2}{|c|}{ Unstandardized Coefficients } & \multirow{2}{*}{$\begin{array}{c}\text { Standardized } \\
\text { Coefficients }\end{array}$} & \multirow[b]{2}{*}{$\mathrm{t}$} & \multirow[b]{2}{*}{ Sig. } \\
\hline & & B & Std. Error & & & \\
\hline 1 & (Constant) & 22,242 & 4,909 & & 4,531 &, 000 \\
\hline & icarr &,- 245 &, 195 &,- 190 & $-1,256$ & ,216 \\
\hline
\end{tabular}

a. Dependent Variable: roe07

FONTE: SPSS. 
Modelo 22 - Retorno sobre patrimônio líquido de 2007 e índice de desenvolvimento

\begin{tabular}{|l|r|r|r|c|}
\hline & & Model Summary \\
Model & $\mathrm{R}$ & R Square & $\begin{array}{c}\text { Adjusted R } \\
\text { Square }\end{array}$ & $\begin{array}{c}\text { Std. Error of the } \\
\text { Estimate }\end{array}$ \\
\hline 1 &, $191^{\mathrm{a}}$ &, 036 &, 014 & 13,8804 \\
\hline
\end{tabular}

a. Predictors: (Constant), idesen FONTE: SPSS.

\begin{tabular}{|c|c|c|c|c|c|c|}
\hline \multicolumn{7}{|c|}{ ANOVA $^{b}$} \\
\hline & & Sum of Squares & $\mathrm{df}$ & Mean Square & $\mathrm{F}$ & Sig. \\
\hline \multirow[t]{3}{*}{1} & Regression & 306,360 & 1 & 306,360 & 1,590 &, $214^{\mathrm{a}}$ \\
\hline & Residual & 8091,921 & 42 & 192,665 & & \\
\hline & Total & 8398,282 & 43 & & & \\
\hline
\end{tabular}

a. Predictors: (Constant), idesen

b. Dependent Variable: roe07

FONTE: SPSS.

Coefficients $^{\mathrm{a}}$

\begin{tabular}{|c|c|c|c|c|c|c|}
\hline \multirow{2}{*}{\multicolumn{2}{|c|}{ Model }} & \multicolumn{2}{|c|}{ Unstandardized Coefficients } & \multirow{2}{*}{$\begin{array}{c}\text { Standardized } \\
\text { Coefficients }\end{array}$} & \multirow[b]{2}{*}{$\mathrm{t}$} & \multirow[b]{2}{*}{ Sig. } \\
\hline & & B & Std. Error & & & \\
\hline \multirow[t]{2}{*}{1} & (Constant) & 23,556 & 5,852 & & 4,025 &, 000 \\
\hline & idesen &,- 599 & ,475 &,- 191 & $-1,261$ & ,214 \\
\hline
\end{tabular}

a. Dependent Variable: roe07

FONTE: SPSS. 
Modelo 23 - Margem líquida sobre as vendas de 2007 e salário mensal médio

\begin{tabular}{|l|r|r|r|c|}
\hline \multicolumn{1}{|c|}{ Model Summary } \\
Model & $\mathrm{R}$ & R Square & $\begin{array}{c}\text { Adjusted R } \\
\text { Square }\end{array}$ & $\begin{array}{c}\text { Std. Error of the } \\
\text { Estimate }\end{array}$ \\
\hline 1 &, $122^{\mathrm{a}}$ &, 015 &,- 009 & 8,3417 \\
\hline
\end{tabular}

a. Predictors: (Constant), salmen FONTE: SPSS.

\begin{tabular}{|rr|r|r|r|r|r|}
\hline \multicolumn{2}{|c|}{ MNOdel $^{2}$} & Sum of Squares & df & Mean Square & F & \multicolumn{1}{c|}{ Sig. } \\
\hline 1 & Regression & 44,008 & 1 & 44,008 &, 632 &, $431^{\mathrm{a}}$ \\
& Residual & 2922,544 & 42 & 69,584 & & \\
& Total & 2966,552 & 43 & & & \\
\hline
\end{tabular}

a. Predictors: (Constant), salmen

b. Dependent Variable: mven07

FONTE: SPSS.

\section{Coefficients $^{\mathrm{a}}$}

\begin{tabular}{|c|c|c|c|c|c|c|}
\hline \multirow{2}{*}{\multicolumn{2}{|c|}{ Model }} & \multicolumn{2}{|c|}{ Unstandardized Coefficients } & $\begin{array}{l}\text { Standardized } \\
\text { Coefficients }\end{array}$ & \multirow[b]{2}{*}{$\mathrm{t}$} & \multirow[b]{2}{*}{ Sig. } \\
\hline & & B & Std. Error & Beta & & \\
\hline 1 & (Constant) & 3,449 & 4,053 & &, 851 & ,400 \\
\hline & salmen &, 000 &, 000 &, 122 & ,795 & ,431 \\
\hline
\end{tabular}

a. Dependent Variable: mven07

FONTE: SPSS. 
Modelo 24 - Margem líquida sobre as vendas de 2007 e salário variável médio

\begin{tabular}{|l|r|r|r|c|}
\hline \multicolumn{7}{|c|}{ Model Summary } \\
Model & \multicolumn{1}{|c|}{$\mathrm{R}$} & R Square & $\begin{array}{c}\text { Adjusted R } \\
\text { Square }\end{array}$ & $\begin{array}{c}\text { Std. Error of the } \\
\text { Estimate }\end{array}$ \\
\hline 1 &, $038^{\mathrm{a}}$ &, 001 &,- 022 & 8,3983 \\
\hline
\end{tabular}

a. Predictors: (Constant), salvar FONTE: SPSS.

\begin{tabular}{|rr|r|r|r|r|r|}
\hline \multicolumn{1}{|c|}{ Model } & & Sum of Squares & df & Mean Square & \multicolumn{1}{c|}{ F } & \multicolumn{1}{c|}{ Sig. } \\
\hline 1 & Regression & 4,224 & 1 & 4,224 &, 060 &, $808^{\mathrm{a}}$ \\
& Residual & 2962,328 & 42 & 70,532 & & \\
& Total & 2966,552 & 43 & & & \\
\hline
\end{tabular}

a. Predictors: (Constant), salvar

b. Dependent Variable: mven07

FONTE: SPSS.

Coefficients $^{\mathrm{a}}$

\begin{tabular}{|c|c|c|c|c|c|c|}
\hline \multirow{2}{*}{\multicolumn{2}{|c|}{ Model }} & \multicolumn{2}{|c|}{ Unstandardized Coefficients } & \multirow{2}{*}{$\begin{array}{c}\text { Standardized } \\
\text { Coefficients }\end{array}$} & \multirow[b]{2}{*}{$\mathrm{t}$} & \multirow[b]{2}{*}{ Sig. } \\
\hline & & $\mathrm{B}$ & Std. Error & & & \\
\hline 1 & (Constant) & 6,188 & 1,836 & & 3,371 & ,002 \\
\hline & salvar & $2,295 \mathrm{E}-6$ & 000 & ,038 &, 245 & ,808 \\
\hline
\end{tabular}

a. Dependent Variable: mven07

FONTE: SPSS. 
Modelo 25 - Margem líquida sobre as vendas de 2007 e índice de benefícios

\begin{tabular}{|l|r|r|r|c|}
\hline \multicolumn{7}{|c|}{ Model Summary } \\
Model & \multicolumn{1}{|c|}{$\mathrm{R}$} & R Square & $\begin{array}{c}\text { Adjusted R } \\
\text { Square }\end{array}$ & $\begin{array}{c}\text { Std. Error of the } \\
\text { Estimate }\end{array}$ \\
\hline 1 &, $036^{\mathrm{a}}$ &, 001 &,- 023 & 8,3990 \\
\hline
\end{tabular}

a. Predictors: (Constant), ibenef FONTE: SPSS.

\begin{tabular}{|rr|r|r|r|r|r|}
\hline \multicolumn{2}{|c|}{ MNOdel $^{2}$} & Sum of Squares & df & Mean Square & F & \multicolumn{1}{c|}{ Sig. } \\
\hline 1 & Regression & 3,751 & 1 & 3,751 &, 053 &, $819^{\mathrm{a}}$ \\
& Residual & 2962,800 & 42 & 70,543 & & \\
& Total & 2966,552 & 43 & & & \\
\hline
\end{tabular}

a. Predictors: (Constant), ibenef

b. Dependent Variable: mven07

FONTE: SPSS.

Coefficients $^{\mathrm{a}}$

\begin{tabular}{|c|c|c|c|c|c|c|}
\hline \multirow{2}{*}{\multicolumn{2}{|c|}{ Model }} & \multicolumn{2}{|c|}{ Unstandardized Coefficients } & \multirow{2}{*}{$\begin{array}{c}\begin{array}{c}\text { Standardized } \\
\text { Coefficients }\end{array} \\
\text { Beta }\end{array}$} & \multirow[b]{2}{*}{$\mathrm{t}$} & \multirow[b]{2}{*}{ Sig. } \\
\hline & & B & Std. Error & & & \\
\hline 1 & (Constant) & 4,990 & 6,726 & & ,742 & ,462 \\
\hline & ibenef & ,094 & ,407 & 036 &, 231 & ,819 \\
\hline
\end{tabular}

a. Dependent Variable: mven07

FONTE: SPSS. 
Modelo 26 - Margem líquida sobre as vendas de 2007 e índice de carreira

\begin{tabular}{|c|r|r|r|c|}
\hline & & & \multicolumn{1}{|c|}{ Model Summary } \\
Model & $\mathrm{R}$ & R Square & \multicolumn{1}{c|}{$\begin{array}{c}\text { Square } \\
\text { Square }\end{array}$} & $\begin{array}{c}\text { Std. Error of the } \\
\text { Estimate }\end{array}$ \\
\hline 1 &, $123^{\mathrm{a}}$ &, 015 &,- 008 & 8,3403 \\
\hline
\end{tabular}

a. Predictors: (Constant), icarr FONTE: SPSS.

\begin{tabular}{|rr|r|r|r|r|r|}
\hline \multicolumn{2}{|c|}{ MNOdel $^{2}$} & Sum of Squares & df & Mean Square & F & \multicolumn{1}{c|}{ Sig. } \\
\hline 1 & Regression & 44,980 & 1 & 44,980 &, 647 &, $426^{\mathrm{a}}$ \\
& Residual & 2921,571 & 42 & 69,561 & & \\
& Total & 2966,552 & 43 & & & \\
\hline
\end{tabular}

a. Predictors: (Constant), icarr

b. Dependent Variable: mven07

FONTE: SPSS.

\section{Coefficients $^{\mathrm{a}}$}

\begin{tabular}{|c|c|c|c|c|c|c|}
\hline \multirow{2}{*}{\multicolumn{2}{|c|}{ Model }} & \multicolumn{2}{|c|}{ Unstandardized Coefficients } & $\begin{array}{l}\text { Standardized } \\
\text { Coefficients }\end{array}$ & \multirow[b]{2}{*}{$\mathrm{t}$} & \multirow[b]{2}{*}{ Sig. } \\
\hline & & B & Std. Error & Beta & & \\
\hline 1 & (Constant) & 8,659 & 2,949 & & 2,936 &, 005 \\
\hline & icarr &,- 094 &, 117 &,- 123 &,- 804 & ,426 \\
\hline
\end{tabular}

a. Dependent Variable: mven07 FONTE: SPSS. 
Modelo 27 - Margem líquida sobre as vendas de 2007 e índice de desenvolvimento

\begin{tabular}{|l|r|r|r|r|}
\hline & & Model Summary \\
Model & $\mathrm{R}$ & R Square & $\begin{array}{c}\text { Adjusted R } \\
\text { Square }\end{array}$ & $\begin{array}{c}\text { Std. Error of the } \\
\text { Estimate }\end{array}$ \\
\hline 1 &, $202^{\mathrm{a}}$ &, 041 &, 018 & 8,2308 \\
\hline
\end{tabular}

a. Predictors: (Constant), idesen FONTE: SPSS.

\begin{tabular}{|rr|r|r|r|r|r|}
\hline \multicolumn{1}{|c|}{ Model } & & Sum of Squares & df & Mean Square & \multicolumn{1}{c|}{ F } & \multicolumn{1}{c|}{ Sig. } \\
\hline 1 & Regression & 121,250 & 1 & 121,250 & 1,790 &, $188^{\mathrm{a}}$ \\
& Residual & 2845,301 & 42 & 67,745 & & \\
& Total & 2966,552 & 43 & & & \\
\hline
\end{tabular}

a. Predictors: (Constant), idesen

b. Dependent Variable: mven07

FONTE: SPSS.

Coefficients $^{\mathbf{a}}$

\begin{tabular}{|c|c|c|c|c|c|c|}
\hline \multirow{2}{*}{\multicolumn{2}{|c|}{ Model }} & \multicolumn{2}{|c|}{ Unstandardized Coefficients } & \multirow{2}{*}{$\begin{array}{c}\begin{array}{c}\text { Standardized } \\
\text { Coefficients }\end{array} \\
\text { Beta }\end{array}$} & \multirow[b]{2}{*}{$\mathrm{t}$} & \multirow[b]{2}{*}{ Sig. } \\
\hline & & B & Std. Error & & & \\
\hline 1 & (Constant) & 2,178 & 3,470 & & ,628 &, 534 \\
\hline & idesen &, 377 & ,282 & ,202 & 1,338 &, 188 \\
\hline
\end{tabular}

a. Dependent Variable: mven07

FONTE: SPSS. 